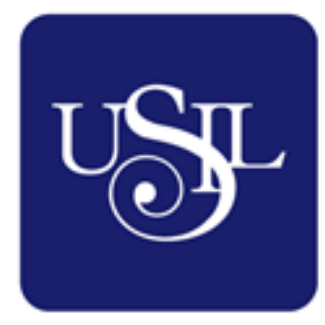

UNIVERSIDAD

SAN IGNACIO

DE LOYOLA

\author{
ESCUELA DE POSTGRADO
}

Maestría en Gestión de Negocios de Nutrición

\title{
EFECTO DE LAS HOJAS DE MORINGA OLEIFERA SOBRE EL CONTROL DE LA GLUCEMIA EN RATAS DIABÉTICAS INDUCIDAS: REVISIÓN SISTEMÁTICA
}

Tesis para optar el Grado de Maestro en Gestión de Negocios de Nutrición

\section{ROCIO ISABEL PALOMINO VALLEJO}

\author{
Asesor: \\ Dr. Felipe León Ignacio Cconchoy \\ Lima - Perú \\ 2020
}




\section{DEDICATORIA}

A Dios por darme la fortaleza y sabiduría para perseguir mis sueños.

A mis padres que me enseñaron el valor del trabajo arduo para cumplir mis metas.

A mi familia por motivarme cada día a ser mejor profesional.

A mi compañero Dennis Mauricio Torres Wong, por apoyarme en todo momento y confiar en mis sueños. 


\section{AGRADECIMIENTOS}

A la Universidad San Ignacio de Loyola por darme la oportunidad de realizar mis estudios de Postgrado y, también, por contar con una excelente plana docente para el programa, donde no solo se evidencia la calidad de los profesionales con los que cuenta la institución, sino también la calidez.

Agradezco al Dr. Felipe Ignacio Concchoy, mi asesor y docente en la maestría, por compartir sus conocimientos, brindarme su apoyo y enseñarme el valor de la humildad en la vida profesional.

A los Doctores Carlos Alvarado-Ortiz y Teresa Blanco de Alvarado-Ortiz, por su apoyo y tiempo dedicado a las correcciones del presente trabajo.

A mi amiga Natali Huzco Rutti por brindarme su apoyo y animarme a culminar la investigación.

A mis compañeros de la maestría por hacer de este programa una grata experiencia que perdurará en mi memoria. 


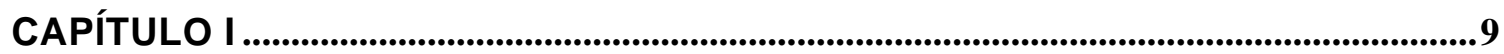

PLANTEAMIENTO DEL PROBLEMA

1.1. Descripción de la realidad problemática ..........................................................................9

1.2. Formulación del problema general y específicos.....................................................11

1.3. Delimitación de objetivos general y específicos ...................................................12

1.4. Justificación de la investigación ......................................................................12

1.5. Limitaciones de la investigación ...................................................................13

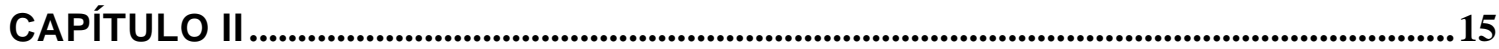

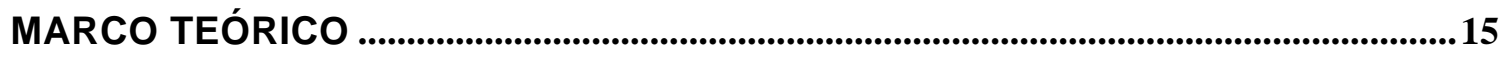

2.1. Antecedentes de la investigación, análisis e interpretación ..................................15

2.2. Fundamentos teóricos de la investigación, análisis e interpretación .................16

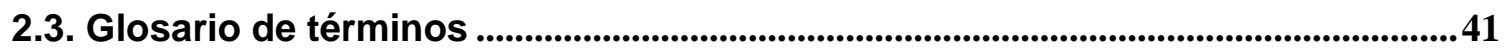

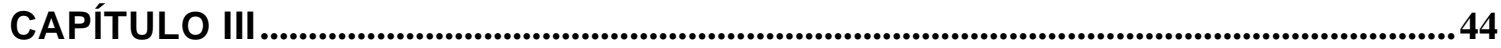

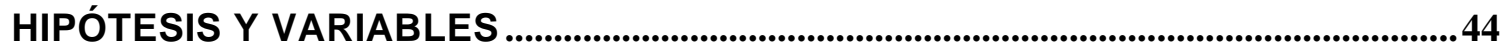

3.1. Hipótesis general............................................................................................................................. 44

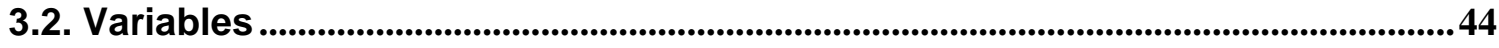

3.3 Conceptualización y operacionalización de variables ................................................45

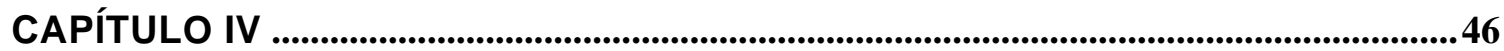

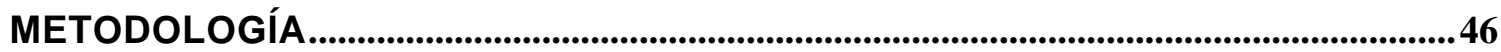

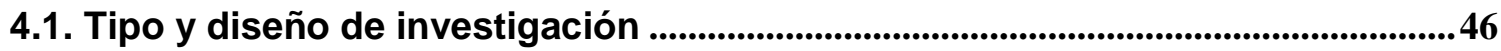

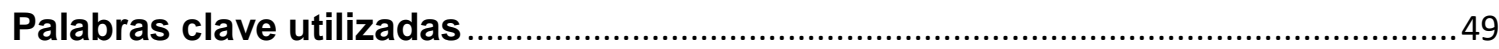

4.2. Selección de la población y la muestra.......................................................................50

4.3. Recolección de datos .................................................................................................................51

4.4. Métodos, técnicas e instrumentos para el análisis de datos...............................52

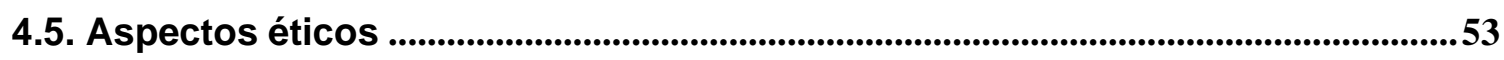

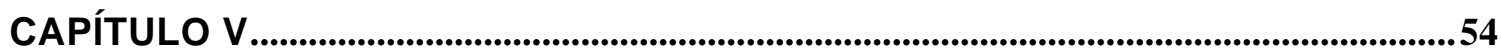

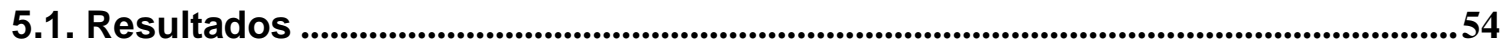

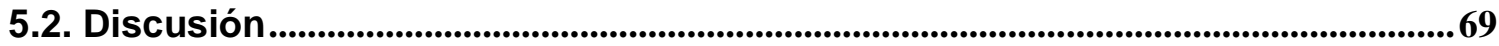

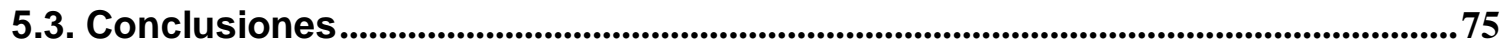

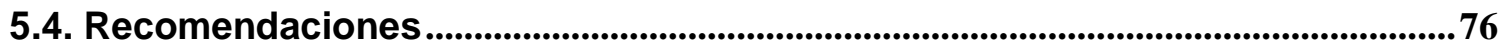

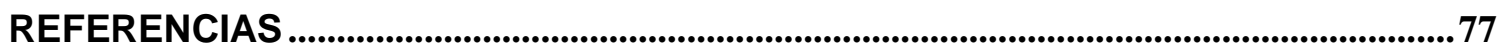

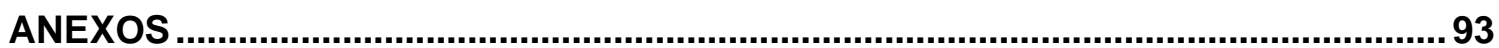




\section{ÍNDICE DE TABLAS}

Tabla 1. Criterios diagnósticos para diabetes, 2018.

Tabla 2. Criterios diagnósticos para prediabetes, 2018.

Tabla 3. Contenido de macronutrientes en hojas frescas y secas de Moringa oleífera en $\mathrm{g} / 100 \mathrm{~g}$

Tabla 4. Contenido de vitaminas en hojas frescas y secas de Moringa oleífera en mg $1100 \mathrm{~g}$. . .33

Tabla 5. Contenido de minerales en hojas frescas y secas de Moringa oleífera en $\mathrm{mg} / 100 \mathrm{~g}$.....

Tabla 6. Contenido de antioxidantes y fitoquímicos de las hojas de Moringa oleífera en $\mathrm{mg} / 100 \mathrm{~g}$.

Tabla 7. Cribado cualitativo de los constituyentes fitoquímicos en las hojas de Moringa oleífera utilizando extracto etéreo, etanolico y acuoso.

Tabla 8. Compuestos bioactivos presentes en las hojas de Moringa oleifera......................36

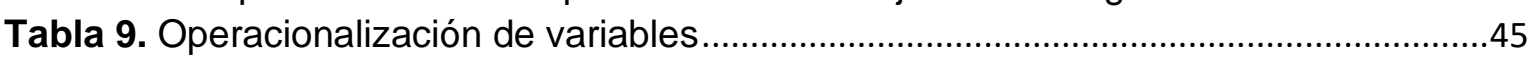

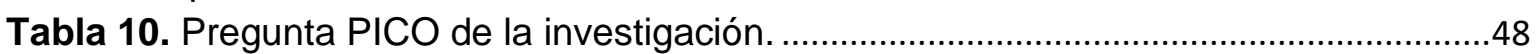




\section{ÍNDICE DE FIGURAS}

Figura 1. Partes de la Moringa oleífera.

Figura 2. Diagrama de flujo de la información del modelo prisma, a través de las diferentes fases de la revisión sistemática. 


\section{RESUMEN}

Objetivos: Evaluar el efecto de las hojas de Moringa oleífera sobre el control de la glucemia en ratas diabéticas inducidas. Materiales y métodos: Revisión sistemática, basadas en la declaración PRISMA y las directrices establecidas por Cochrane. Se realizarón búsquedas en las bases de datos: EBSCO host, ProQuest, Scopus, PubMed, Hindawi, DOAJ, AJOL (African Journals online), BioMed Central, Web of Science, SciELO, Google Scholar. Se identificaron 251 artículos que respondieron la pregunta de investigación. De ellos, se excluyeron 233 artículos que no cumplían con los criterios de inclusión y exclusión establecidos. La muestra final fue de 18 estudios. La estrategia de búsqueda fue Moringa oleífera AND "Glucose" "Hypoglycemic agents", "Antihyperglycemic Agents", "Antidiabetic agents", "Diabetes Mellitus", "Diabetes Mellitus type 2", "Glycated Hemoglobin A", "Insulin Sensitivity" "Insulin Resistance", "Blood Glucose". Resultados: Se analizaron 18 estudios de carácter experimental. La administración (100 - $1500 \mathrm{mg} / \mathrm{kg}$ ) subcronica (5 - 60 dias) con las hojas de Moringa oleífera reduce en forma significativa $(p<0,05)$ los niveles de glucemia en ratas diabéticas inducidas. Conclusiones: Las hojas de Moringa oleífera reducen los niveles de glucemia en las ratas diabéticas inducidas.

Palabras clave: Moringa oleífera; diabetes; glucosa; insulina. 


\section{SUMMARY}

Objectives: To assess the effect of the Moringa oleifera leaves on glycemic control in induced diabetic rats. Materials and methods: Systematic review, based on the PRISMA statement and the guidelines established by Cochrane. The databases were searched: EBSCO host, ProQuest, Scopus, PubMed, Hindawi, DOAJ, AJOL (African Journals online), BioMed Central, Web of Science, SciELO, Google Scholar. 251 articles were identified that answered the research question. Of these, 233 articles that did not meet the established inclusion and exclusion criteria were excluded. The final sample was 18 studies. The search strategy was Moringa oleifera AND "Glucose" "Hypoglycemic agents", "Antihyperglycemic Agents", "Antidiabetic agents", "Diabetes Mellitus", "Diabetes Mellitus type 2", "Glycated Hemoglobin A", "Insulin Sensitivity" "Insulin Resistance", "Blood Glucose". Results: 18 experimental studies were analyzed. Subchronic administration (100 - $1500 \mathrm{mg} / \mathrm{kg}$ ) (5 - 60 days) with Moringa oleifera leaves significantly reduces $(p<0,05)$ blood glucose levels in induced diabetic rats. Conclusions: Moringa oleifera leaves reduce blood glucose levels in induced diabetic rats.

Keywords: Moringa oleífera; diabetes; glucose; insulin. 


\section{CAPÍTULO I}

\section{PLANTEAMIENTO DEL PROBLEMA}

\subsection{Descripción de la realidad problemática}

En los últimos años, las fuentes herbarias y dietéticas han sido ampliamente estudiadas. Se han encontrado que muchas de estas plantas presentan componentes bioactivos que exhiben propiedades farmacológicas y, además, tienen significación terapéutica en el sistema de la medicina tradicional ${ }^{(1)}$. Las hojas de Moringa oleífera contienen muchos ingredientes activos con valores nutricionales y medicinales ${ }^{(2)(3)}$. Las especies de moringa pertenecientes a la familia monogénica Moringaceae, en particular Moringa oleífera, han atraído en los últimos años mucha atención por sus propiedades antidiabéticas en los modelos preclínicos ${ }^{(4)(5)}$. Muchas partes de la planta de moringa, incluyendo hojas, vainas inmaduras, flores y frutas son comestibles y se usan como hortalizas en varios países ${ }^{(6)(7)}$.

Se ha descrito que el extracto acuoso de hojas de Moringa oleífera posee potentes efectos antihiperglucémicos y antihiperlipidémicos, tanto en modelos de ratas insulinorresistentes como en modelos de ratas insulino-deficientes ${ }^{(8)}$. Se observaron beneficios similares en pacientes diabéticos con extracto acuoso que demostraron efecto hipoglucémico efectivo en humanos ${ }^{(9)(10)(11)(12) . ~}$

Según la OMS, la diabetes es una enfermedad crónica que aparece cuando el páncreas no produce suficiente insulina o cuando el organismo no utiliza eficazmente la insulina que produce. El número de diabéticos en todo el mundo fue de 422 millones, en el año 2014; mientras que en el año 1980, eran 108 millones $^{(13)}$. La prevalencia mundial de la diabetes casi se ha duplicado desde ese año, pues ha pasado del $4,7 \%$ al $8,5 \%$ en la población adulta ${ }^{(14)}$.

Según la Federación Internacional de Diabetes, el 8,3\% de la población mundial presenta diabetes mellitus, y se estima que el número de individuos aquejados por esta enfermedad se incremente a más de 592 millones ${ }^{(15)}$. Si la tendencia actual continua, se estima para Sudamérica y Centroamérica el aumento en el número de personas con diabetes mellitus de 59,8\% (pasando de 24 a 38,5 millones) en el periodo de tiempo desde el año 2013 al año $2035^{(15)}$. Según la Organización Mundial de la Salud, en el año 2014, y para la región 
de las Américas, los países con mayor prevalencia de diabetes mellitus en adultos $\geq 18$ años fueron: Guyana, Surinam, Chile y Argentina ${ }^{(15)}$. Según los Perfiles de los Países para la Diabetes 2016, de la Organización Mundial de la Salud, en el Perú, el 2\% del total de muertes en todas las edades es causado por la diabetes ${ }^{(14)}$. Además, según la Encuesta Demográfica y de Salud Familiar - ENDES 2015 - el 2,9\% de la población de 15 y más años de edad fue diagnosticado con diabetes mellitus ${ }^{(16)}$.

Las terapias convencionales utilizadas, actualmente para la diabetes, incluyen la estimulación de la secreción de insulina endógena, la mejora de la acción de la insulina en los tejidos diana, los agentes hipoglucemiantes orales tales como biguanidas y sulfonilureas y la inhibición de la degradación del almidón dietético dirigiéndose a glicosidasas intestinales tales como $\alpha$-amilasa y alpha - glucosidasa ${ }^{(17)}$.

El régimen de tratamiento de la diabetes mellitus tipo 2, en todo el mundo, ha prescrito el uso de metformina y sulfonilurea en combinación como tratamiento antidiabético de primera línea estándar durante años ${ }^{(18)}$. Sin embargo, el uso a largo plazo de estos fármacos resulta en una disminución progresiva de la función de las células $\beta$, y en 3 años hasta el $50 \%$ de los pacientes diabéticos necesitan un agente farmacológico adicional para mantener la hemoglobina glicosilada $(\mathrm{HbA} 1 \mathrm{c})$ por debajo de $7.0 \%{ }^{(18)}$. Las plantas medicinales son un recurso de bajo costo y presentan menos efectos secundarios que los medicamentos convencionales ${ }^{(19)}$. Existe un interés creciente en su uso potencial como tratamiento alternativo para la diabetes ${ }^{(20)}$.

La hiperglucemia aumenta la formación de especies reactivas de oxígeno (ROS) (21). Además, el estrés oxidativo juega un papel importante en el desarrollo de la diabetes ${ }^{(21)}$, lo que provoca daño oxidativo a las biomoléculas, alterando la función celular normal y que no puede ser contrarrestado por los sistemas antioxidantes de defensa(22)(23)(24). Afortunadamente, dicho daño se puede evitar o disminuir con la administración de dosis adecuadas de antioxidantes exógenos, para mejorar la calidad de vida de los pacientes diabéticos ${ }^{(25)}$. Por lo tanto, los fármacos con propiedades antioxidantes y antidiabéticas serían útiles en el tratamiento de pacientes con diabetes ${ }^{(26)}$.

La Moringa oleífera Lam, moringaceae es una planta altamente nutritiva con propiedades medicinales excepcionales ${ }^{(27)}$. La Moringa oleífera se cultiva en muchos países tropicales y subtropicales de Asia y África ${ }^{(28)}$ y es una buena fuente de proteínas, $\beta$-caroteno, vitaminas $A, B, C$ y $E$, riboflavina, ácido nicotínico, ácido fólico, piridoxina, aminoácidos, minerales y diversos compuestos fenólicos ${ }^{(27)(29)}$. La Moringa oleífera es ampliamente utilizado y reconocido en la medicina ayurvédica para el tratamiento de problemas 
cardíacos y de circulación. Además, ejercen un efecto antimicrobiano, antiulceroso, hepatoprotector, reduce el colesterol, efecto cardioprotector y antidiabético ${ }^{(30)(31)}$; también, se ha informado sobre su eficacia contra la desnutrición y el desequilibrio de la hormona tiroidea ${ }^{(32)}$.

La incidencia de la diabetes está aumentando considerablemente a nivel mundial. Además, la mortalidad por la diabetes podría multiplicarse por dos, entre los años 2005 y $2030{ }^{(33)}$. Su impacto afecta no solo la salud física sino también la financiera de quienes la padecen, por los elevados costos para su tratamiento. Por esta razón, es importante controlar la diabetes mellitus, en el mundo, buscando tratamientos terapéuticos que sean efectivos con mínimos efectos segundarios en la experiencia clínica y a un costo relativamente bajo.

Por lo tanto, las hojas de Moringa oleífera podrían ser una terapia alternativa para el control

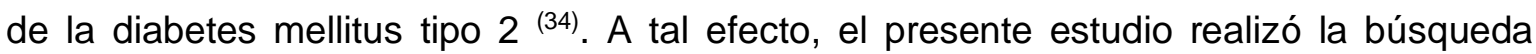
exhaustiva y el análisis crítico de artículos primarios que respondieron la pregunta de investigación, mediante la metodología PRISMA de REVISIONES SISTEMÁTICAS.

\subsection{Formulación del problema general y específicos}

\section{Problema general:}

¿Cuál es el efecto de las hojas de Moringa oleífera sobre el control de la glucemia en las ratas diabéticas inducidas?

\section{Problemas específicos:}

¿Cuál es el mecanismo de acción del extracto de las hojas de Moringa oleífera en el control de la diabetes mellitus en ratas inducidas?

¿Cuál sería la dosis efectiva del extracto de las hojas de Moringa oleífera en el control de la diabetes mellitus en ratas inducidas? 


\subsection{Delimitación de objetivos general y específicos}

\section{Objetivo general:}

Evaluar el efecto de las hojas de Moringa oleífera sobre el control de la glucemia en las ratas diabéticas inducidas.

\section{Objetivos específicos:}

Identificar el mecanismo de acción del extracto de las hojas de Moringa oleífera en el control de la diabetes mellitus en ratas inducidas.

Determinar la dosis efectiva del extracto de hojas de Moringa oleífera en el control de la diabetes mellitus en ratas inducidas.

\subsection{Justificación de la investigación}

En relación a todo lo mencionado, se considera relevante conocer el efecto de las hojas de Moringa oleífera en el control de la diabetes mellitus tipo 2 para valorarse en la terapia alternativa de la enfermedad y proponer de manera eficiente conceptos claros que informen a la población, como a los profesionales de la salud ${ }^{(35)}$.

El estudio se justifica por su:

- Utilidad, porque permitirá conocer las propiedades farmacológicas y la significación terapéutica de las hojas de Moringa oleífera en el control de la diabetes mellitus, mediante la lectura crítica, la búsqueda exhaustiva y específica en fuentes bibliográficas con alto nivel de evidencia científica.

- Relevancia social, porque realizar una revisión sistemática sobre el efecto de la Moringa oleífera en el control de la diabetes mellitus tipo 2, permitirá obtener conceptos claros en la utilidad de las hojas de moringa oleífera para el manejo de la enfermedad. Además, la moringa cuenta a su favor con otra corriente que lo sitúa como un alimento idóneo para combatir la malnutrición en países en desarrollo. Instituciones como la FAO han promovido su uso y algunas ONGs han puesto en marcha programas de desarrollo de su cultivo y consumo; así mismo, dar a conocer con sensatez los "beneficios" de las hojas de moringa oleífera para la salud en la población les permitirá consumirla como terapia alternativa de la enfermedad mejorando su calidad de vida. 
- Implicancias prácticas, porque el uso de las hojas de la Moringa oleífera, como alimento funcional en la medicina tradicional ayudará en el control de la diabetes, con base científica coadyuvante en el tratamiento de la enfermedad (36)(37). Asimismo, la población, en general, contará con información relevante de sus beneficios en la salud, con lo cual se logrará incentivar su producción y consumo.

- Valor teórico, porque mediante la revisión sistemática sobre el efecto de las hojas de Moringa oleífera en el control de la diabetes mellitus, se entiende los mecanismos de acción de la moringa sobre el efecto hipoglucémico y otros beneficios en el tratamiento alternativo de la diabetes, basado en la evidencia científica.

\subsection{Limitaciones de la investigación}

La investigación no logró realizar la combinación de los resultados mediante los métodos estadísticos debido a la heterogeneidad en los resultados de los estudios primarios (diferencias en el tipo de diseño empleado, métodos empleados para la recogida de la información, diferentes sistemas disolventes de la planta) para poder obtener una estima global del efecto. Sin embargo, se pudo responder a la pregunta de investigación mediante un análisis crítico y el procedimiento sistemático para recopilar la información de los estudios.

\subsection{Novedad científica, teórica y práctica de la investigación}

- La presente investigación es la primera revisión sistemática que evalúa el efecto de las hojas de Moringa oleífera sobre el control de la glucemia en ratas diabéticas inducidas.

- La diabetes mellitus es una enfermedad crónica que se caracteriza por presentar elevadas concentraciones de glucosa en sangre de manera persistente o crónica generando daño macro y microvascular, y como consecuencia afectando la calidad de vida de las personas que la padecen. Por esta razón, es importante llevar un buen control de la diabetes mellitus: mejorando el estilo de vida, cumpliendo a cabalidad el tratamiento farmacéutico, generando hábitos de alimentación saludable e incorporar el ejercicio como parte de su estilo de vida. La Moringa oliefera es una planta que, en los últimos años, ha sido ampliamente estudiada y muchos estudios han revelado su gran potencial antidiabético y antioxidante. Las hojas de Moringa oleífera parecen mejorar los niveles de glucosa en la sangre de ratas diabéticas inducidas por aloxano o Streptozotocina. Además, identificar el 
mecanismo de acción de las hojas de Moringa oleífera sobre el control de la glucemia puede respaldar tal efecto. Asimismo, determinar la dosis efectiva permite conocer la eficacia del tratamiento subcrónico y contribuye a establecer el valor referencial para futuros estudios de investigación. 


\section{CAPÍTULO II}

\section{MARCO TEÓRICO}

\subsection{Antecedentes de la investigación, análisis e interpretación}

- Abd El Latif A., et al. (2014), en su artículo titulado "El extracto de hoja de Moringa oleífera mejora la diabetes inducida por aloxano en ratas por regeneración y reducción de la expresión de piruvato carboxilasa (38)", concluyeron que el extracto de las hojas de Moringa oleífera posee potentes efectos hipoglucémicos a través de la normalización de la enzima piruvato carboxilasa hepática y la regeneración de los hepatocitos y las células pancreáticas dañadas. El antecedente contribuye con la investigación para demostrar las propiedades hipoglucemiantes de la Moringa Oleífera en ratas inducidas por aloxano.

- Olayaki L., et al. (2015), en su artículo titulado "El extracto metanólico de hojas de Moringa oleífera mejora la tolerancia a la glucosa, la síntesis de glucógeno y el metabolismo lipídico en ratas diabéticas inducidas por aloxano (39)", demostraron que la administración oral de extracto metanólico de hojas de Moringa oleífera redujo significativamente la concentración de glucosa en la sangre en ratas diabéticas inducidas por aloxano al estimular la síntesis de glucógeno hepático y muscular, aumentando la secreción de insulina y la captación de glucosa en el hígado y Tejidos musculares. Además, el tratamiento con extracto también dio como resultado un perfil lipídico mejorado en ratas diabéticas.

En el antecedente, se muestra información que contribuye con la tesis, pues demuestra los potenciales efectos beneficiosos del consumo de la Moringa oleífera en población diabética.

Anthanont P., et al. (2016), en su artículo titulado "las hojas de Moringa oleífera aumentan la secreción de insulina después de la administración de una única dosis: un estudio preliminar en sujetos sanos ${ }^{(10) ", ~ d e m o s t r a r o n ~ q u e ~}$ las cápsulas de polvo de hoja de Moringa oleífera en dosis alta (4 g) aumentaba significativamente la secreción de insulina en personas sanas.

El antecedente contribuye con la tesis para sustentar y demostrar la importancia de conocer la dosis efectiva de la Moringa oleífera para el tratamiento alternativo de la enfermedad. 
Paula P.C., et al. (2017), en su artículo titulado "Un aislado de proteína de hojas de Moringa oleífera tiene efectos hipoglucemiantes y antioxidantes en ratones diabéticos inducidos por aloxano (40)", obtuvieron la siguiente conclusión: el estudio se demostró que la administración de dosis única intraperitoneal (i.p.) de Mo-LPI (aislado de proteína de las hojas de Moringa oleífera) (500 mg / kg.bw) redujo el nivel de glucosa en sangre (reducciones de 34,3\%, 60,9\% y $66,4 \%$ después de 1,3 y 5 h, respectivamente). El efecto de Mo-LPI también se evidenció en la repetición prueba de dosis con una reducción del $56,2 \%$ en el nivel de glucosa en sangre en el séptimo día después de i.p. administración. Mo-LPI es un prometedor agente alternativo o complementario para tratar la diabetes.

Este antecedente, contribuye con la investigación para demostrar las propiedades de la proteína de las hojas de Moringa oleífera relacionado al descenso de la glucemia, para el control eficaz de la enfermedad.

\footnotetext{
Jaiswal D., et al. (2013), en su artículo titulado "El Papel de la Moringa oleífera en la regulación de la diabetes - estrés oxidativo inducido (41)", concluyen que las actividades antioxidantes de las hojas de Moringa oleífera eran significativas, tanto en los estudios in vivo como in vitro; sugieren que la ingesta regular de las hojas de Moringa oleífera, a través de la dieta, puede proteger tanto a los pacientes normales como a los diabéticos contra el daño oxidativo.

Este antecedente contribuye con la investigación, pues demuestra los efectos antioxidantes del consumo de las hojas de Moringa oleífera en los pacientes con diabetes mellitus, cobrando gran importancia para evitar futuras complicaciones debido al estrés oxidativo que genera la enfermedad.
}

\subsection{Fundamentos teóricos de la investigación, análisis e interpretación}

\section{Diabetes mellitus}

\section{Definición}

El término diabetes mellitus (DM) describe un desorden metabólico de múltiples etiologías, caracterizado por hiperglucemia crónica con disturbios en el metabolismo de los carbohidratos, grasas y proteínas y que resulta de defectos en la secreción y/o en la acción de la insulina ${ }^{(42)}$. 
La diabetes mellitus es una enfermedad metabólica caracterizada por hiperglucemia ${ }^{(43)}$. La hiperglucemia en todos los casos se debe a una deficiencia funcional de acción de la insulina ${ }^{(44)}$. La acción deficiente de la insulina puede deberse a una disminución de su secreción por las células beta del páncreas, una reducción en la respuesta de tejidos blanco a la insulina (resistencia a la insulina), o un aumento en las hormonas contrarreguladoras que se oponen a los efectos de la insulina ${ }^{(45)}$.

\section{Epidemiología}

La diabetes mellitus es una pandemia universal de tendencia ascendente según la Organización Mundial de la Salud. 422 millones de adultos, en todo el mundo, tenían diabetes en 2014, frente a los 108 millones de 1980. La prevalencia mundial de la diabetes casi se ha duplicado desde ese año, pues ha pasado del $4,7 \%$ al $8,5 \%$ en la población adulta ${ }^{(33)}$.

A medida que la prevalencia de obesidad aumenta en la población infantil, los casos de DM2 en niños y adolescentes se están incrementando. La prevalencia varía de 0,1 a 5\%, señalándose que se ha producido un aumento de 10 veces en las últimas décadas ${ }^{(46)}$.

\section{Clasificación de diabetes}

La clasificación, clásica, de la diabetes incluye dos grandes tipos: diabetes mellitus insulinodependientes y diabetes mellitus no insulinodependientes. Recientemente, el Comité de Expertos de la Asociación Americana de Diabetes (ADA) y la Organización Mundial de la Salud (OMS) han propuesto una nueva clasificación que contempla 4 grupos $^{(47)}$

La diabetes se clasifica en las siguientes categorías:

1. Diabetes tipo 1 (destrucción de células $\beta$ del páncreas con déficit absoluto de insulina).

2. Diabetes tipo 2 (resistencia a la insulina, deterioro gradual de la función de las células beta y disminución de la segregación de la insulina por el páncreas).

3. Diabetes mellitus gestacional (DMG) diabetes que se diagnostica en el segundo o tercer trimestre del embarazo.

4. Diabetes específicas por otras causas (por ejemplo: MODY, fibrosis quística, diabetes inducida por medicamentos). 
Algunos pacientes no pueden clasificarse claramente como tipo 1 o tipo 2 porque la presentación clínica es muy variable, pero el diagnóstico se hace más claro con el paso del tiempo ${ }^{(47)}$.

Para efecto del presente estudio, solo se definirá la diabetes mellitus tipo 2 (insulino no dependientes)

\section{Diabetes mellitus tipo 2}

La diabetes mellitus tipo 2 (DM2) se presenta en personas con grados variables de resistencia a la insulina, además se requiere también que exista una deficiencia en la producción de insulina que puede o no ser predominante. Ambos fenómenos, deben estar presentes en algún momento para que se eleve la glucemia ${ }^{(44)(48)}$. Aunque no existen marcadores clínicos que indiquen con precisión cuál de los dos defectos primarios predomina en cada paciente, el sobrepeso y obesidad se ha relacionado con el aumento de la resistencia a la insulina mientras que la pérdida de peso sugiere una reducción progresiva en la producción de la hormona ${ }^{(44)(48)}$. Aunque este tipo de diabetes se presenta principalmente en el adulto, su frecuencia está aumentada en niños y adolescentes obesos $^{(48)(49)}$.

En este tipo de diabetes puede ocurrir sobreproducción de otras hormonas como el Glucagón y la hormona de crecimiento que se opone a la acción de la insulina (50)(51). Hay también una deficiencia en la secreción de somatostatina en respuesta a la glucosa, lo cual puede contribuir a la hiperglucemia. La somatostatina prolonga el tránsito intestinal y retarda la absorción de la glucosa ${ }^{(50)(51)}$.

Con frecuencia ( $85 \%$ de los casos), se vincula con obesidad, lo cual es otro factor que incrementa la resistencia a la insulina ${ }^{(50)(51)}$.

\section{Patogenia de la diabetes mellitus tipo 2}

La historia natural de la diabetes tipo 2, comienza con la tolerancia normal a la glucosa, resistencia a la insulina y la hiperinsulinemia compensatoria, con la progresión de intolerancia a la glucosa (IGT) y la diabetes mellitus ${ }^{(52)}$. En las poblaciones de alto riesgo que padecen de síndrome metabólico, la progresión normal a IGT se asocia con aumentos marcados de glucosa y los niveles de insulina en plasma en ayunas. Además, se observa la disminución de la sensibilidad a la insulina de los tejidos periféricos. La progresión de 
IGT a diabetes tipo 2 con hiperglucemia en ayunas leve (120-140mg / dl, 6.7-7.8mmol / L) es anunciado por la incapacidad de la célula beta de mantener su alta tasa de secreción de insulina en respuesta de la alta tasa de producción glucosa en plasma con deterioro de la sensibilidad a la insulina de los tejidos. Con el tiempo, la alta tasa de secreción de insulina no se puede mantener, las células beta comienzan en pendiente descendente de la curva de Starling, provocando la hiperglucemia en ayunas e intolerancia a la glucosa. Cabe destacar, que la hiperinsulinemia es un fuerte predictor del desarrollo de la intolerancia a la glucosa y diabetes tipo 2. Las fases evolutivas de la secreción de insulina se detallarán en las secciones subsiguientes:

\section{DM 2: Fases evolutivas}

Fase I: secreción de insulina adecuada para las necesidades metabólicas: glucosa normal

- Resistencia a la insulina: presente.

- Hiperinsulinismo compensador: presente.

- Masa de células beta: normal.

Fase II: Secreción de insulina insuficiente para las necesidades metabólicas: prediabetes 2

- Resistencia a la insulina: presente.

- Hiperinsulinismo compensador: presente o no.

- Masa de células beta: disminuida.

Fase III: Secreción de insulina insuficiente para las necesidades metabólicas: prediabetes 2

- Resistencia a la insulina: presente.

- Hiperinsulinismo compensador: ausente.

- Masa de células beta: disminuida.

La diabetes mellitus tipo 2 pasa por tres fases que finalmente terminan desencadenado en resistencia a la insulina, células b atrofiadas y la disminución de la segregación de insulina por el páncreas ${ }^{(47)}$.

Según la versión actualizada de la patogenia de la Diabetes Mellitus tipo 2 De Fronzo ha identificado hasta ocho mecanismos a los que denomina "el octeto del mal agüero"(52). Todos ellos condicionan hiperglicemia: 
1. Disminución del efecto de incretinas.

2. Incremento de la lipolisis.

3. Incremento en la reabsorción tubular de glucosa en el riñón.

4. Disminución de la captación de glucosa por el músculo.

5. Disfunción en los neurotransmisores cerebrales.

6. Incremento de la gluconeogénesis por el hígado.

7. Incremento en la secreción de glucagón por las células alfa del páncreas.

8. Disminución paulatina en la secreción de insulina por el páncreas.

\section{Diagnóstico}

La diabetes mellitus es una enfermedad compleja y generalmente es silenciosa en su etapa inicial, puede ser diagnosticada ya sea a través de una prueba rápida de glucosa en plasma o de una prueba de glucosa en plasma 2 horas después de haber recibido 75 gramos de glucosa vía oral o con una prueba de hemoglobina glicosilada $(A 1 C){ }^{(47)(53)}$. Los criterios se muestran en la siguiente tabla:

Tabla 1. Criterios diagnósticos para diabetes, 2018.

\begin{tabular}{lc}
\hline Criterio diagnóstico & Diabetes mellitus \\
\hline Glucemia en ayunas & $\geq 126 \mathrm{mg} / \mathrm{dL}^{*}$ \\
Glucemia a las 2 horas tras una & $\geq 200 \mathrm{mg} / \mathrm{dL}^{* *}$ \\
sobrecarga oral de glucosa & \\
Hemoglobina glicosilada (A1C) & $\geq 6,5 \%$ \\
Glucemia en plasma venoso al azar $\geq 200 \mathrm{mg} / \mathrm{dL}$ con síntomas típicos
\end{tabular}

*Se define ayunas como la ausencia de la ingesta calórica al menos 8 horas.

** La prueba debe ser realizada con una carga de $75 \mathrm{~g}$ de glucosa anhidra disuelta en agua. De acuerdo a los criterios establecidos por la OMS.

Fuente: Adaptado de Criterios diagnósticos para diabetes ADA (American Diabetes Association) ${ }^{(47)(53)}$.

El National Health and Nutrition Examination Survey (NHANES) indica que un punto de corte de $\mathrm{A} 1 \mathrm{C} \geq 6,5 \%$ detecta un tercio más de pacientes con diabetes sin diagnosticar que una prueba de glucosa en ayuno $\geq 126 \mathrm{mg} / \mathrm{dL}{ }^{(47)(54)}$. Es importante tomar en cuenta la edad, raza/etnia y la presencia de anemia o de alguna hemoglobinopatía cuando se usa la A1C para diagnosticar diabetes. Los estudios epidemiológicos muestran, hasta el 
momento, que la $\mathrm{A} 1 \mathrm{C}$ es solo útil para adultos, sin embargo, sigue en discusión si debe seguir siendo el mismo punto de corte tanto para adultos como adolescentes y niños ${ }^{(47)(53)}$.

\section{Diagnóstico para pacientes con Prediabetes}

La prediabetes es un estado que precede al diagnóstico de diabetes tipo 2. Esta condición es común, está en aumento epidemiológico y se caracteriza por elevación en la concentración de glucosa superando los niveles normales sin alcanzar los valores diagnósticos de diabetes. Se determina con la concentración de glucosa plasmática ${ }^{(55)}$.

Tabla 2. Criterios diagnósticos para prediabetes, 2018.

\begin{tabular}{lc}
\hline Criterio diagnóstico & Prediabetes \\
\hline $\begin{array}{l}\text { Glucemia en ayunas } \\
\text { Glucemia a las } 2 \text { horas tras una }\end{array}$ & 140 a $199 \mathrm{mg} / \mathrm{dL}$ \\
$\begin{array}{l}\text { sobrecarga oral de glucosa } \\
\text { Hemoglobina glicosilada (A1C) }\end{array}$ & 5,7 a $6,4 \%$ \\
\hline $\begin{array}{l}\text { Fuente: Criterios diagnósticos para Prediabetes ADA (American Diabetes Association) }{ }^{(53)} . \\
\text { Complicaciones de la diabetes mellitus }\end{array}$
\end{tabular}

La diabetes mellitus presenta un alto riesgo de morbilidad y mortalidad, como consecuencia de las complicaciones agudas y crónicas propias de la enfermedad (56).

La cetoacidosis y el coma hiperosmolar son las dos complicaciones metabólicas agudas más importantes. Básicamente están ocasionados por una hiperglicemia derivada de la reducción de la insulina circulante asociada a una elevación del glucagón, las catecolaminas, el cortisol, y la hormona de crecimiento ${ }^{(56)}$.

Las complicaciones crónicas más prevalentes de la diabetes (retinopatía, nefropatía y neuropatía) pueden incluir alteraciones microangiopáticas secundarias al daño tisular que ocasiona la hiperglicemia crónica ${ }^{(57)}$. La glucosilación de las proteínas tisulares y de otras macromoléculas, y un exceso de producción de compuestos poliolicos de glucosa están entre los mecanismos implicados. Los pacientes con diabetes también pueden presentar complicaciones macroangiopáticas (cardiopatía isquémica, enfermedad vascular periférica y enfermedad vascular cerebral) como consecuencia del incremento de la aterogeneidad que produce la enfermedad (56)(57).

La presencia y progresión de las complicaciones crónicas se han asociado a diferentes factores de riesgo como son la edad, el sexo, el sedentarismo, la obesidad, el tabaquismo, los antecedentes familiares de la diabetes, el tiempo de evolución de la enfermedad, la 
hipertensión arterial, la dislipidemia, y especialmente a un deficiente control metabólico ${ }^{(56)(57)}$.

El control de la glicemia es fundamental para el control de la diabetes. Una disminución de glucosa en sangre retarda o previene la presencia de complicaciones. Su monitorización de forma periódica permite evaluar el grado de control metabólico (56)(57).

\section{Complicaciones crónicas}

\section{Retinopatía diabética}

La retinopatía diabética $(\mathrm{RD})$ es una complicación que provoca la diabetes debido a una serie de cambios en los pequeños vasos de la retina. Hay que considerar que a veces pueden ser afectados también los vasos de mayor tamaño ${ }^{(58)}$. Forma parte de la enfermedad ocular del diabético, la oftalmopatía diabética, que incluye también la afectación de otras estructuras del ojo: cristalino (cataratas) y cámara anterior (glaucoma). Se clasifica en dos fases, proliferativa y no proliferativa. La proliferativa progresa a una enfermedad más amplia. El edema macular diabético (EMD) es la causa más frecuente de disminución de la agudeza visual en los diabéticos ${ }^{(59)}$.

En todas las fases de la RD es esencial el control metabólico y en concreto de la glucemia, hemoglobina glucosilada ( $\mathrm{HbA1c}$ ), la dislipidemia, la anemia, la hipertensión arterial (HTA), el sobrepeso y el estado renal (microalbuminuria en orina); ayuda de forma significativa a reducir el riesgo de pérdida de visión en los pacientes con $\mathrm{RD}^{(58)}$.

Actualmente, la prevalencia de RD oscila alrededor del $25 \%$ de la población diabética. La edad cronológica en el momento de aparición de la DM y la duración de la misma tienen un marcado efecto sobre el momento de aparición de la retinopatía; después de 20 años de evolución de DM 2, más del 60\% muestra algún tipo de retinopatía. También influye el correcto tratamiento médico, de esta manera, pacientes con mejor control glucémico tienen menor riesgo de retinopatía ${ }^{(59)}$.

Es relevante destacar que en la DM 2 hasta un $20 \%$ de pacientes, que no saben que tienen $\mathrm{DM}$, presentan $\mathrm{RD}$ en el momento del diagnóstico, lo que indica que el inicio de la DM se ha producido varios años antes y que las lesiones microvasculares pueden preceder a la clínica de la propia DM ${ }^{(59)}$.

En la actualidad, existen avances en imagen y diagnóstico de la RD y EMD y el uso de terapia intravítrea ${ }^{(58)}$. Además, el tratamiento con Láser-terapia puede evitar la progresión 
a ceguera hasta en un $60 \%$ de casos. Esto supone un desafío, y a la vez, la oportunidad de poner en marcha estrategias de detección y tratamiento precoces en pacientes de riesgo ${ }^{(59)}$.

\section{Nefropatía diabética}

La nefropatía diabética (NFD) es la segunda causa de insuficiencia renal terminal. Es una complicación frecuente en la diabetes mellitus y genera daño a nivel de la microvasculatura renal. Las complicaciones microvasculares que suele acompañar más a la diabetes tipo 1, pero la alta prevalencia de diabetes tipo 2 y su progresivo aumento, hace que el número de casos con NFD crezca en las últimas décadas ${ }^{(59)(60)}$.

La incidencia de nefropatía es baja en los primeros 10 años de diabetes, aumentando después y alcanzando un pico de incidencia a los 15-20 años del diagnóstico de la enfermedad, y posteriormente disminuye con una incidencia acumulada de daño renal que varía según los estudios entre 25 a 40\% tras 25 años de diagnóstico. Es un problema de salud pública de gran magnitud en el mundo occidental, ya que aproximadamente un tercio de los pacientes diabéticos llegan a presentar esta enfermedad renal ${ }^{(59)(60)}$

Su patogenia es multifactorial y el análisis de los factores causantes de su aparición y progresión ha sido objeto de múltiples estudios prospectivos en las últimas décadas ${ }^{(59)}$. Entre los factores asociados a un aumento de riesgo para la NFD destacan, principalmente, el mal control glucémico, la hipertensión arterial, la hiperfiltración glomerular, la dislipidemia y la propia excreción urinaria de albúmina ${ }^{(59)(61)}$.

La combinación de estos factores define al subgrupo de pacientes diabéticos con un mayor riesgo para la aparición de microalbuminuria y enfermedad cardiovascular. El tratamiento multifactorial e intensivo de estos factores de riesgo, que permite un mejor control de la glucemia, de los lípidos séricos y de la presión arterial disminuye el riesgo de NFD, RD y ND ${ }^{(62)}$.

Al inicio de la diabetes, se producen cambios en la función renal: Las lesiones consisten en engrosamiento de la membrana glomerular basal, expansión mesangial y acumulación hialina en las arteriolas. La nefropatía ya establecida se caracteriza por la expansión mesangial nodular, acumulación hialina en arteriolas aferente y eferente, y una membrana basal del glomérulo marcadamente engrosada. Además, la perdida de los podocitos es crucial en la esclerosis del glomérulo ${ }^{(63)}$.

La modificación de diversas moléculas por la persistente hiperglucemia, con la formación final de los productos avanzados de la glicosilación (AGEs), juega un papel fundamental. 
Asimismo, los niveles elevados de glucosa ejercen sus efectos tóxicos en el interior de las células a través de su incorporación por transportadores de glucosa, activándose una cadena enzimática de distintas reacciones que incluyen: formación de sorbitol, aumento de stress oxidativo, activación de la proteín kinsa $C(P K C)$ y activación de la ruta de la hexosaminasa. Todas estas vías enzimáticas y metabólicas van a contribuir a la activación de citoquinas y de factores de crecimiento que participan de manera activa en la aparición y desarrollo de la ND ${ }^{(64)(65)}$.

En la ND ha sido demostrada la relación directa entre la severidad de la lesión renal y el grado de estrés oxidativo. Así, pacientes diabéticos con nefropatía establecida exhiben un mayor grado de daño oxidativo. Además, los pacientes con un aumento en la excreción urinaria de albúmina (EUA) muestran mayores niveles de peroxidación lipídica que sujetos con normoalbuminuria ${ }^{(64)}$.

En todos los diabéticos, se determinará la microalbuminuria en el momento del diagnóstico, cualquiera que sea la edad, y anualmente hasta los 70 años ${ }^{(59)}$. Debe insistirse en la necesidad de abandonar el hábito de fumar, que se asocia con peor pronóstico de la nefropatía. Cuando existe macroalbuminuria se debe limitar la ingestión de proteínas a 0,8 g/Kg de peso/día ${ }^{(59)}$.

\section{Neuropatía diabética}

La neuropatía diabética es la complicación microvascular más frecuente de la Diabetes Mellitus, se incluyen distintos cuadros que afectan al sistema nervioso, con distribución anatómica y características clínicas diferentes: neuropatías de pares craneales, por atrapamiento, proximales, polineuritis distal ${ }^{(59)(66)}$.

La etiopatogenia probablemente es mixta. La hipótesis más clásica presume a la hiperglucemia como responsable directa de la lesión de la fibra nerviosa a través de la acumulación de sorbitol. Pero en los últimos años, la microangiopatía ha cobrado mayor importancia, considerando a la isquemia y la consiguiente hipoxia como responsable de la lesión ${ }^{(59)}$.

La polineuritis distal simétrica diabética (PND) es la forma clínica más frecuente de neuropatía diabética y su transcendencia radica en el riesgo que implica la aparición de lesiones en el pie ${ }^{(59)}$. 
La clasificación de la neuropatía diabética, según su fisiopatología. Se divide en metabólica microvascular e hipóxica, autoinmune e inflamatoria, compresiva, secundario a complicaciones de la diabetes y relacionado con el tratamiento ${ }^{(67)}$.

Las neuropatías metabólico-microvasculares son las más frecuentes; La polineuropatía distal (DPN, por sus siglas en inglés) se caracteriza por disminución de la sensibilidad térmica-dolorosa, más severa en las regiones más distales de las extremidades. Su severidad aumenta con el empeoramiento del control glucémico. Entre las neuropatías inflamatorio-autoinmunes, la radículo-plexopatía lumbosacra (DLRPN por sus siglas en inglés) ocurre en $1 \%$ de los pacientes con dolor de extremidades inferiores, pérdida de fuerza y atrofia del cuádriceps. Tiene tendencia a la mejoría con tratamiento sintomático del dolor, rehabilitación y control glucémico óptimo con insulinoterapia intensificada. Las neuropatías compresivas tienen en común un aumento de volumen de axones y fascículos, lo que causa daño isquémico cuando nervio atraviesa canales osteofibrosos inextensibles, como el canal del carpo (síndrome de canal carpiano), la epitróclea (neuropatía ulnar) y la cabeza del peroné (neuropatía peronea). Con respecto a las neuropatías relacionadas con el tratamiento de la diabetes, destaca la "neuritis insulínica", descrita en 1933, que consiste en una neuropatía extremadamente dolorosa, precedida por una brusca mejoría del control glucémico mediante insulina al reanudar tratamiento insulínico que había sido suspendido con el fin de perder peso, lo que sugiere déficit de tiamina más que la isquemia sugerida en modelos animales ${ }^{(67)}$.

Son factores de riesgo para el desarrollo de PND: el mal control glucémico, el tiempo de evolución de la diabetes, la edad avanzada, el tabaco, el alcohol y la isquemia EEII (59). 


\section{Diabetes inducida}

La inducción de la diabetes se ha logrado por medio de diversas técnicas experimentales (68)(69). Históricamente, Frederick Banting de Grant (1891-1941) y Charles Herbert Best (1899-1978), dos científicos canadienses, fueron los primeros en desarrollar la diabetes

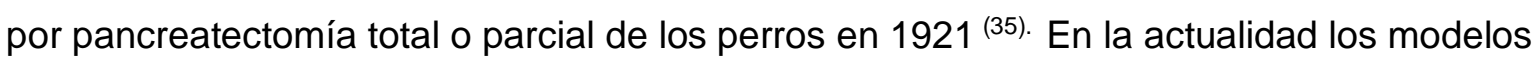
de roedores resultan ser la mejor opción para la investigación de la diabetes mellitus debido a su pequeño tamaño, además, son fáciles de manejar, omnívoros en la naturaleza, y el comportamiento tranquilo que tienen. Normalmente los modelos de roedores se clasifican en dos grandes clases: modelos genéticos o inducidos espontáneamente y modelos no genéticos o experimentación de conteo inducida. Los modelos no genéticos o modelos inducidos experimentalmente suelen preferirse a los modelos inducidos genéticamente debido a su menor costo, mayor disponibilidad, facilidad de inducción de la diabetes y además, son más fácil de mantener en comparación con los modelos genéticos ${ }^{(70)}$.

Algunos de los primeros modelos de diabetes en roedores experimentales descritos eran los modelos inducidos químicamente. El primero de ellos fue aloxano usado en 1943 por Goldner y Gomori (71). Tiempo después, un segundo compuesto químico llamado streptozotocina (STZ), fue reconocido como un inductor de la diabetes ${ }^{(72)}$. Ambos compuestos funcionan mediante la destrucción selectiva de células beta del páncreas a través de un mecanismo de estrés oxidativo ${ }^{(73)}$. Ambos compuestos químicos se utilizan para desarrollar modelos de animales que se asemejan a diabetes mellitus tipo 1 y tipo 2 en función de la dosis administrada ${ }^{(72)}$.

\section{Aloxano: mecanismo de acción}

Aloxano es un derivado de ácido úrico y tiene dos efectos patológicos distintos: de manera selectiva inhibe la secreción de insulina inducida por glucosa a través de la inhibición específica de la glucoquinasa, el sensor de glucosa de la célula beta, y que causa un estado de diabetes dependientes de la insulina a través de su capacidad para inducir la formación de ROS, lo que resulta en la necrosis selectiva de las células beta. Estos dos efectos se pueden asignar a las propiedades químicas específicas de aloxano, el denominador común es la captación celular selectiva y la acumulación de aloxano por la célula beta ${ }^{(74)}$.

\section{Strepptozotocina: mecanismo de acción}

La streptozotocina es un antibiótico natural producido por las especies bacterianas Streptomyces achromogenes que inhibe la secreción de insulina y causa un estado de diabetes mellitus dependiente de insulina. Ambos efectos pueden atribuirse a sus 
propiedades químicas específicas, a saber, su potencial de alquilación de ADN, mediante la acción toxica de la STZ. Al igual que con el aloxano, su especificidad de las células beta es principalmente el resultado de captación celular selectiva y la acumulación. La streptozotocina se acumula selectivamente en células beta pancreáticas a través de la absorción vía GLUT2 y la muerte de las células beta a través de la necrosis mediante la alquilación de ADN por la acción toxica de la STZ ${ }^{(74)}$.

\section{Modelo adulto aloxano - streptozotocin (STZ)}

Según se mencionó anteriormente el aloxano y la STZ son sustancias que actúan destruyendo selectivamente las células $\beta$ pancreáticas mediante la inducción de estrés oxidativo, dando como resultado la deficiencia de insulina, hiperglucemia y cetosis. En las últimas décadas, varias combinaciones se han utilizado para desarrollar modelos animales mediante el uso de STZ o aloxano; incluyendo una sola dosis alta de inyección de STZ (> $65 \mathrm{mg} / \mathrm{kg} \mathrm{BW}$ ), baja dosis múltiples inyecciones STZ ( $60 \mathrm{mg} / \mathrm{kg} \mathrm{BW}$ ) da como resultado una destrucción masiva de células beta pancreáticas, más característico de la diabetes mellitus tipo 1, mientras que dosis intermedias de las inyecciones de STZ (entre 40 y 55 $\mathrm{mg} / \mathrm{kg} \mathrm{BW}$ ) causa solamente deterioro parcial de los mecanismos de secreción de insulina observados en la diabetes mellitus tipo $2^{(70)(75)}$. La STZ se inyecta generalmente vía intraperitoneal en dosis variables a ratas $(35-65 \mathrm{mg} / \mathrm{kg}$ de peso corporal) y ratones (100$200 \mathrm{mg} / \mathrm{kg} \mathrm{BW}$ ) y en el caso de aloxano, 40-200 mg / kg BW a ratas y 50-200 mg / kg BW a ratones ${ }^{(72)(70) \text {. }}$

Después de un periodo de ventana de 72 horas se procede a realizar pruebas químicas en los roedores para determinar si se consideran diabéticos. Estos modelos se caracterizan por hiperglucemia en ayunas o sin ayuno, niveles bajos de insulina sérica e hiperlipidemia, pero la resistencia a la insulina a menudo está ausente. A pesar de esto, estos modelos son extremadamente populares para la detección farmacológica de rutina de los agentes antihipeglucémicos e insulinotrópicos ${ }^{(72)}$. 


\section{Tratamiento farmacológico de la Diabetes mellitus tipo 2}

En algunos casos el control de la glucemia puede conseguirse adoptando un estilo de vida saludable. No obstante, este planteamiento no siempre es eficaz, ya que depende de las características del paciente y de su grado de adherencia a las recomendaciones. Por este motivo, varias sociedades científicas aconsejan asociar metformina de forma concomitante desde el inicio en la mayoría de pacientes ${ }^{(76)(77) .}$

En todo caso, no es recomendable demorar más de 3 meses la introducción de metformina si no se ha conseguido el objetivo de control individualizado (77).

\section{Metformina}

La metformina es un fármaco efectivo para el tratamiento de la Diabetes mellitus tipo 2. Según las investigaciones científicas el mecanismo de acción de este fármaco se da mediante su unión a receptores específicos activa la AMP-cinasa, disminuye la producción hepática de glucosa y aumenta la captación intestinal de glucosa, que actúa como un mecanismo de aclarado de la hiperglucemia en la diabetes. Su efecto en el peso corporal es neutro o, en algún caso, induce una modesta reducción. Los inconvenientes que podrían darse al utilizar este fármaco serian efectos adversos gastrointestinales, acidosis láctica y deficiencia de la vitamina B12, entre otras ${ }^{(76)(77)(78)}$.

El tratamiento con metformina debe empezar con un comprimido al día (850 mg) con la comida principal para mitigar los efectos adversos gastrointestinales. Las dosis deberían incrementarse cada una o 2 semanas hasta un máximo de 2 o 3 comprimidos según la evaluación del paciente, ya que la respuesta es dependiente de la dosis. Un 85\% de los pacientes consiguen la máxima reducción de $\mathrm{HbA} 1 \mathrm{c}(2 \%)$ con dosis de $2.000 \mathrm{mg}$, sin obtener reducciones adicionales cuando se llega a los $2.500 \mathrm{mg}$. Además, la metformina es un fármaco de bajo coste y baja complejidad ${ }^{(76)}$.

\section{Glibenclamida}

La glibenclamida es una sulfonilurea que actúan en los receptores específicos de la célula beta pancreática. Aumentan la liberación de la insulina preformada (primera fase de secreción insulínica), no estimulan su biosíntesis y el cociente plasmático proinsulina/insulina es normal. Las sulfonilureas como la glibenclamida actúan mediante su unión a un receptor específico, situado en la membrana de la célula beta (SUR-1), que junto con una unidad interna «rectificadora» (Kir 6.2), forman parte de los denominados canales de K+ ATP dependientes. Esta unión provocará un cierre de los citados canales, con despolarización de la membrana celular y la ulterior apertura de canales de Ca++ 
dependientes de voltaje, favoreciendo el tránsito intracelular de este ión hacia el citoplasma y la posterior exocitosis insulínica. Se ha comprobado que la glibenclamida, mediante su penetración en el interior de la célula beta, podría a su vez interactuar con los propios gránulos insulínicos, ejerciendo una acción directa en la exocitosis insulínica. Acciones complementarias, si bien menos trascendentes, descritas para las sulfonilureas en el páncreas son la disminución de secreción de glucagón y el aumento en la liberación de somatostatina. La dosis diaria recomendada 2,5 a $15 \mathrm{mg}$ por día con una vida media oscila entre 10-15 h. La glibenclamida no es un fármaco oral de primera línea para el tratamiento de la diabetes mellitus tipo 2 debido a su riesgo de hipoglucemia, aumento de peso y un posible incremento de mortalidad cardiovascular. Sin embargo, por su escasa complejidad de uso y por razones de coste-efectividad se siguen considerando fármacos adecuados en pacientes con bajo riesgo de hipoglucemia ${ }^{(79)(78)}$. 


\section{Moringa oleífera}

\section{Definición}

La Moringa oleífera Lam es una de las especies más conocidas y más ampliamente distribuidas de la familia monogénica Moringaceae. Muchas partes de la planta de moringa, incluyendo hojas, vainas inmaduras, flores y frutas son comestibles y se usan como hortalizas en varios países ${ }^{(80)}$.

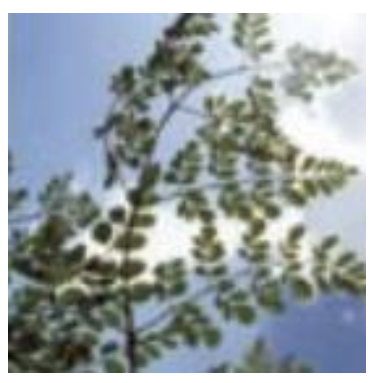

Hojas de Moringa

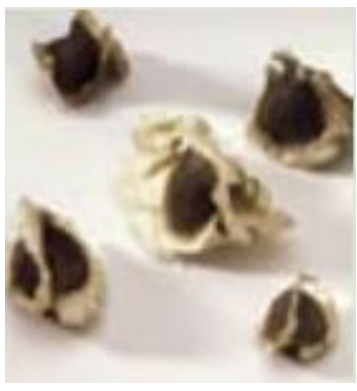

Semillas de Moringa
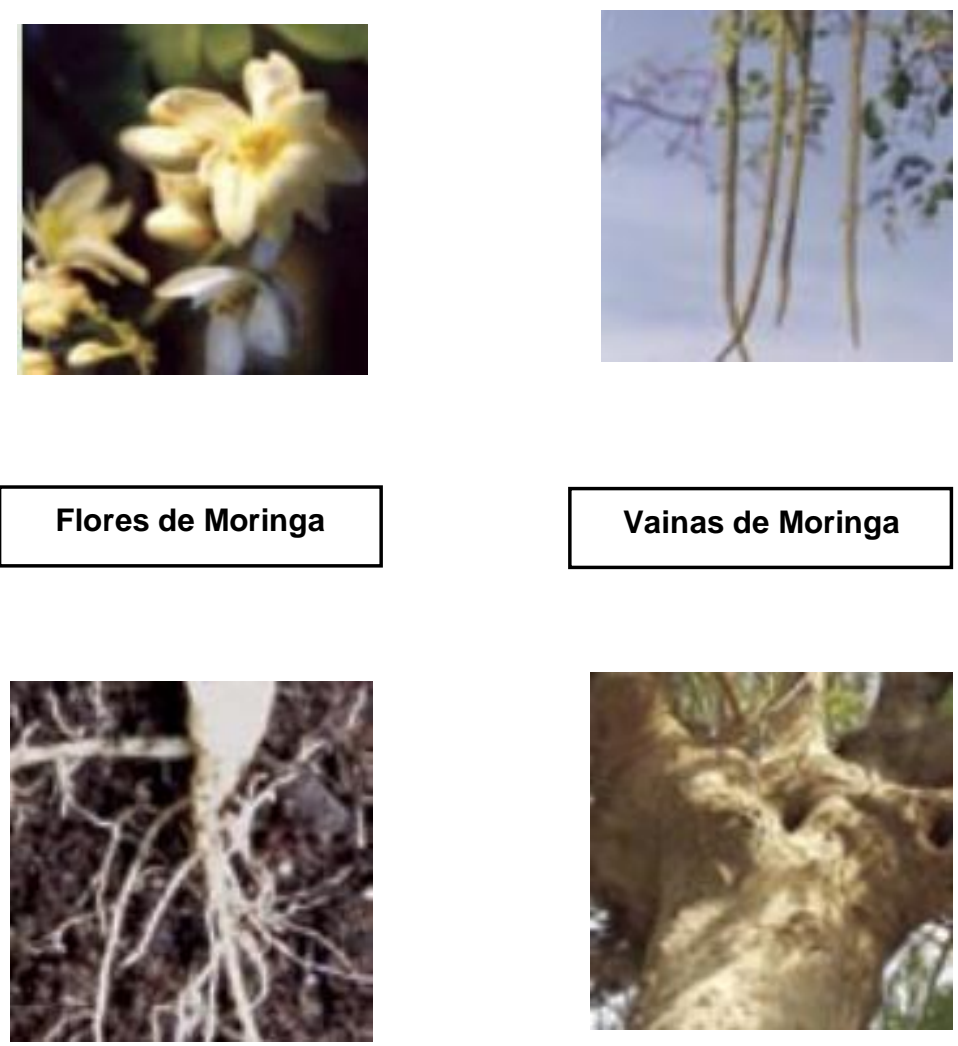

Raices de Moringa

Vainas de Moringa

Flores de Moringa

Corteza de Moringa

Figura 1. Partes de la Moringa oleífera

Fuente: Imagen extraída del libro "El árbol milagroso": La Moringa oleífera - Trees for life international $^{(81)}$. 


\section{Plantaciones y condiciones del suelo}

La Moringa oleífera es un árbol originario del sur del Himalaya, el nordeste de la India, Bangladesh, Afganistán, y Pakistán ${ }^{(82)}$; se ha adaptado, en Perú y en varias zonas del pacífico y el caribe. La Moringa oleífera se puede cultivar en cualquier región tropical y subtropical del mundo con una temperatura alrededor de 25 - $35^{\circ} \mathrm{C}$. Requiere suelo arenoso o franco con un $\mathrm{pH}$ ligeramente alcalino y una precipitación neta de 250 - 3000 $\mathrm{mm}{ }^{(32)}$. Se sigue el método de siembra directa, ya que tiene granos de germinación. Las semillas de moringa están diseñadas para germinar dentro de 5 a 12 días después de la siembra y pueden implantarse a una profundidad de $2 \mathrm{~cm}$ en el suelo. Después de crecer a unos $30 \mathrm{~cm}$, puede ser trasplantado ${ }^{(83)}$.

El árbol también se puede cultivar a partir de esquejes con $1 \mathrm{~m}$ de longitud y $4-5 \mathrm{~cm}$ de diámetro, pero estas plantas pueden no tener un buen sistema de raíces profundas. Estas plantas tienden a ser sensibles a la sequía y los vientos. Para fines comerciales, se puede seguir una plantación intensiva y semi - intensiva a gran escala de moringa. En el cultivo comercial, el espaciamiento es importante ya que ayuda en el manejo de la planta y la cosecha. La Moringa oleífera difiere en la composición de nutrientes en diferentes lugares (84). El árbol cultivado en la India tiene ligeramente diferentes componentes nutricionales que un árbol cultivado en Nigeria. Se atribuye que a temperaturas altas, las proteínas y las enzimas se desnaturalizan, esto podría ser la causa de la diferencia en el contenido de nutrientes ${ }^{(83)}$.

\section{Preparaciones tradicionales}

Desde hace milenios, prácticamente todas las partes de Moringa oleífera han sido utilizadas por el hombre. Las hojas, las flores, los frutos y las raíces son reconocidos por su valor nutritivo y pueden ser usados tanto en la alimentación humana como en el animal. Prácticamente todas las partes de la planta tienen uso alimenticio y se utilizan para la elaboración de diferentes platos en la India, Indonesia, Filipinas, Malasia, el Caribe y en varios países africanos ${ }^{(82)}$.

Las hojas tiernas cocinadas se emplean en la preparación de ensaladas, sopas y salsas; también pueden ser consumidas crudas, como otras verduras. Las flores cocinadas tienen un sabor que recuerda al de algunas setas comestibles. Las vainas tiernas son muy apreciadas en la India; se preparan del mismo modo que las habichuelas y su sabor es parecido al de los espárragos. Al madurar, las vainas se tornan algo leñosas y pierden cualidades como alimentos. No obstante, las semillas pueden ser separadas de la vaina madura y utilizadas como alimento. Las semillas maduras se pueden preparar de manera 
similar a los guisantes; y también consumirse fritas, tostadas (como el maní), en infusiones y en salsas. En Malasia, las vainas verdes se utilizan como ingredientes de variedades locales de curry. A partir de las raíces se preparan salsas que, por su sabor, recuerdan al rábano picante; por ello la moringa en algunos sitios se conoce como el árbol del rábano(36).

\section{Propiedades nutricionales}

A través, de la investigación se encuentra que la Moringa oleífera contiene muchos nutrientes esenciales como las vitaminas, minerales, aminoácidos, beta carotenos, antioxidantes, nutrientes antiinflamatorios y ácidos grasos como el omega 3 y $6{ }^{(85)}$.

Las hojas de moringa actúan como una buena fuente de antioxidantes naturales debido a la presencia de diversos tipos de compuestos antioxidantes como el ácido ascórbico, los flavonoides, los compuestos fenólicos y los carotenoides ${ }^{(86)}$. Las altas concentraciones de ácido ascórbico, sustancias estrogénicas y $\beta$-sitosterol, hierro, calcio, fósforo, cobre, vitaminas $A, B$ y $C, \alpha$-tocoferol, riboflavina, ácido nicotínico, ácido fólico, piridoxina, $\beta$ caroteno, proteínas y, en particular, aminoácidos esenciales tales como metionina, cistina, triptófano y lisina presentes en las hojas y vainas de moringa, lo convierten en un suplemento dietético prácticamente ideal ${ }^{(87)}$.

Tabla 3. Contenido de macronutrientes en hojas frescas y secas de Moringa oleífera en $\mathrm{g} / 100 \mathrm{~g}$.

\begin{tabular}{lll} 
Componentes & Hojas frescas & Hojas secas \\
\hline Energía (Kcal) & 86,6 & $304 \pm 87$ \\
Humedad $(\mathrm{mg})$ & $76,4 \pm 3,01$ & $7,4 \pm 2,89$ \\
Proteína $(\mathrm{g})$ & $8,8 \pm 3,72$ & $24 \pm 5,8$ \\
Carbohidratos $(\mathrm{g})$ & $7,6 \pm 12,5$ & $36 \pm 9,2$ \\
Lípidos $(\mathrm{g})$ & $1,5 \pm 0,37$ & $6 \pm 2,5$ \\
Fibra cruda $(\mathrm{g})$ & $2,2 \pm 1,01$ & $9 \pm 7,45$ \\
Fibra dietética total $(\mathrm{g})$ & $5,3 \pm 7,3$ & $20,6 \pm 28,6$
\end{tabular}

Fuente: Adaptado de ECHO Research Notes. The Nutrient Content of Moringa oleifera Leaves - 2013 (88).

Como se observa en la tabla 3, existe una considerable variabilidad en el contenido calórico y de macronutrientes entre las hojas frescas y secas siendo esta última versión la de mayor contenido de nutrientes y de fibra, por ello resulta una buena alternativa para introducirla en la alimentación de la población. 
Tabla 4. Contenido de vitaminas en hojas frescas y secas de Moringa oleífera en mg $/ 100 \mathrm{~g}$.

\begin{tabular}{lll}
\hline Componentes & Hojas frescas & Hojas secas \\
\hline Tiamina $(\mathrm{mg})$ & 0,26 & 2,6 \\
Riboflavina $(\mathrm{mg})$ & 0,66 & $1,29-20,5$ \\
Niacina $(\mathrm{mg})$ & 2,22 & 8,2 \\
Vitamina B6 $(\mathrm{mg})$ & 1,2 & 2,4 \\
Folato $(\mu \mathrm{g})$ & 40 & 540 \\
Vitamina A $(\mathrm{mg})$ & $1286 \pm 689$ & $3639 \pm 1979,8$ \\
Vitamina C $(\mathrm{mg})$ & $162 \pm 63,0$ & $172 \pm 37,7$ \\
Vitamina E $(\mathrm{mg})$ & 25 & $56-113$
\end{tabular}

Fuente: Adaptado de ECHO Research Notes. The Nutrient Content of Moringa oleifera Leaves - 2013 (88).

Como se observa en la tabla 4, el contenido de vitaminas en las diferentes presentaciones de las hojas de Moringa oleífera dista mucho en cantidad, existiendo una diferencia significativa entre ambas; siendo las hojas secas las que contienen mayor concentración de vitaminas liposolubles e hidrosolubles.

Tabla 5. Contenido de minerales en hojas frescas y secas de Moringa oleífera en mg/100 g.

\begin{tabular}{lll} 
Componentes & Hojas frescas & Hojas secas \\
\hline Calcio $(\mathrm{mg})$ & $532 \pm 378,8$ & $1897 \pm 748,4$ \\
Magnesio $(\mathrm{mg})$ & $26-151$ & $473 \pm 429,4$ \\
Potasio $(\mathrm{mg})$ & $414 \pm 302,7$ & $1467 \pm 636,7$ \\
Sodio $(\mathrm{mg})$ & 16 & $220 \pm 180,0$ \\
Hierro $(\mathrm{mg})$ & $10,8 \pm 6,04$ & $32,5 \pm 10,78$ \\
Zinc $(\mathrm{mg})$ & $0,3 \pm 1,3$ & $2,4 \pm 1,12$ \\
Fósforo $(\mathrm{mg})$ & $90-112$ & $297 \pm 149,0$ \\
Cu $(\mathrm{mg})$ & $0,23 \pm 0,125$ & $0.9 \pm 0,48$
\end{tabular}

Fuente: Adaptado de ECHO Research Notes. The Nutrient Content of Moringa oleifera Leaves - 2013 (88).

Como se observa en la tabla 5, la Moringa oleífera contiene altas concentraciones de minerales en su composición. De acuerdo a los valores que se expresan en la tabla 5 , las hojas secas de moringa tienen mayor concentración de minerales que las hojas frescas de la planta. 


\section{Propiedades medicinales}

\section{Propiedades antidiabéticas}

Las especies de moringa, pertenecientes a la familia monogénica Moringaceae, en particular Moringa oleífera, han atraído en los últimos años mucha atención por sus propiedades antidiabéticas en modelos preclínicos ${ }^{(36)}$.

La diabetes mellitus es un trastorno metabólico crónico, el paciente diabético presenta una etapa de hiperglucemia crónica y deterioro de la tolerancia a la glucosa. La Moringa oleífera es bien conocida por sus acciones farmacológicas y se utiliza para el tratamiento tradicional de diabetes mellitus ${ }^{(89)}$.

Los efectos antidiabéticos de algunas plantas medicinales fueron fortalecidos por los datos científicos, ya que los remedios herbales para la diabetes se reconocen en diferentes sociedades ${ }^{(90)}$.

Ajit et al., 2003, informaron que se ha confirmado la actividad hipoglucémica de Moringa oleífera, con actividades significativas de disminución de glucosa en la sangre. El metanol extraído de su polvo de frutos secos ha producido tiocarbamatos de $\mathrm{N}$-Bezilo, carbamatos de $\mathrm{N}$-bencilo, nitrilos de bencilo y bencilo; que demuestran activar la liberación de insulina de forma significativa de las células beta pancreáticas de roedores, y tienen actividades inhibidoras de la enzima ciclooxigenasa y la inhibición de la peroxidación lipídica ${ }^{\left({ }^{91)}\right.}$.

La actividad hipoglucémica y anti hiperglucemiante de las hojas de Moringa oleífera puede deberse probablemente a la presencia de terpenoides, que parece estar implicado en la estimulación de las células b y la subsiguiente secreción de la insulina ${ }^{(92)}$.

\section{Propiedades antioxidantes}

Los compuestos antioxidantes tales como flavonoides, carotenoides y antocianina del extracto de Moringa oleífera podría eliminar radicales libres tales como superóxido (O2), peróxido de hidrógeno (H2O2), radicales de nitrógeno (NO-) procedentes de vías metabólicas de humanos. El extracto hidroalcohólico de Moringa oleífera tiene un potencial efecto antioxidante. Esto podría atribuirse a la presencia de fitoconstituyentes como los compuestos polifenólicos (flavonoides) ${ }^{(93)}$. 
Tabla 6. Contenido de antioxidantes y fitoquímicos de las hojas de Moringa oleífera en $\mathrm{mg} / 100 \mathrm{~g}$.

\begin{tabular}{llll}
\hline Componentes & Mínimo & Máximo & Media \pm SD \\
\hline Alcaloides $(\mathrm{mg})$ & 430,00 & 460,00 & $446,67 \pm 12,11$ \\
Fitatos $(\mathrm{mg})$ & 730,00 & 865,00 & $794,17 \pm 65,22$ \\
Taninos $(\mathrm{mg})$ & 480,00 & 525,00 & $501,67 \pm 19,15$ \\
Saponinas $(\mathrm{mg})$ & 815,00 & 880,00 & $844,17 \pm 27,82$ \\
Oxalatos $(\mathrm{mg})$ & 23,00 & 24,30 & $23,65 \pm 0,58$ \\
Flavonoides totales $(\mathrm{mg})$ & 835 & 865 & $846,67 \pm 16,07$
\end{tabular}

Fuente: Adaptado de Advances in Biological Research. Evaluation of Proximate, Minerals, Vitamins and Phytochemical Composition of Moringa oleifera Lam. Cultivated in Ado Ekiti, Nigeria $-2015^{(94)}$.

Según se observa en la tabla 6 , el analisis fitoquímico a las hojas de Moringa oleifera revelo altas concentraciones de flavonoides, alcaloides y saponinas. La dosis recomendada de consumo de flavonoides para que se produzca "una contribución importante al potencial antioxidante a la dieta humana" es de 20 a 26 mg/día ${ }^{(95)}$. Resultando las hojas de moringa oleífera una fuente sustancial de antioxidantes naturales.

Tabla 7. Cribado cualitativo de los constituyentes fitoquímicos en las hojas de Moringa oleífera utilizando extracto etéreo, etanolico y acuoso.

\begin{tabular}{|c|c|c|c|}
\hline Fitoquímicos & $\begin{array}{l}\text { Extracto } \\
\text { etéreo }\end{array}$ & $\begin{array}{l}\text { Extracto } \\
\text { etanolico }\end{array}$ & $\begin{array}{l}\text { Extracto } \\
\text { acuoso }\end{array}$ \\
\hline Taninos gálicos & + & + & ++ \\
\hline Taninos catecol & + & -- & ++ \\
\hline Cumarinas & -- & -- & -- \\
\hline Esteroides y triterpenoides & +++ & ++ & ++ \\
\hline Flavonoides & ++ & ++ & ++ \\
\hline Saponinas & + & + & ++ \\
\hline Antraquinonas & + & ++ & +++ \\
\hline Alcaloides & + & -- & ++ \\
\hline Azúcares reductores & -- & ++ & ++ \\
\hline \multicolumn{4}{|c|}{$\begin{array}{l}+++=\text { Alta concentración; ++ = Moderada concentración; + = Baja concentración; -- = No } \\
\text { detectado. }\end{array}$} \\
\hline \multicolumn{4}{|c|}{$\begin{array}{l}\text { Fuente: Adaptado de Journal of Medicinal Plants Research. Phytochemicals and uses of } \\
\text { Moringa oleifera leaves in Ugandan rural communities }-2010^{(96)} \text {. }\end{array}$} \\
\hline \multicolumn{4}{|c|}{$\begin{array}{l}\text { Como se observa en la tabla } 7 \text { todos los solventes extrajeron esteroides y triterpenoides, } \\
\text { flavonoides, antraquinonas y saponinas. El éter y el etanol no extrajeron alcaloides, }\end{array}$} \\
\hline
\end{tabular}


Tabla 8. Compuestos bioactivos presentes en las hojas de Moringa oleífera.

\begin{tabular}{|c|c|c|c|}
\hline $\begin{array}{l}\text { Compuesto } \\
\text { identificado }\end{array}$ & Clase & Actividad & Referencia \\
\hline quercetin-3-rutinósido & Flavonoide & Antioxidante, antiinflamatoria & $(97)(98)$ \\
\hline Quercetina & Flavonoide & $\begin{array}{l}\text { Propiedades antioxidantes, } \\
\text { hipolipidémicas y antidiabéticas. } \\
\text { Inhibición de colesterol esterasa } \\
\text { y a-glucosidasa }\end{array}$ & $(99)(100)(97)$ \\
\hline Quercetina-3- & Flavonoide & Antioxidante, antitumoral & \\
\hline Glicosídeo & & & $(97)(101)(102)$ \\
\hline $\begin{array}{l}\text { kaempferol-3-O- } \beta \text { - } \\
\text { glucopiranosídeo }\end{array}$ & Flavonoide & $\begin{array}{l}\text { Antioxidante, antitumoral, } \\
\text { Actividad antidiabética, } \\
\text { cardioprotector }\end{array}$ & $(97)(102)(103)$ \\
\hline isorhamnetina & Flavonoide & Antioxidante, antiinflamatoria & $(97)(104)(98)$ \\
\hline Kaempferol & Flavonoide & $\begin{array}{l}\text { Antioxidante, antiinflamatoria, } \\
\text { antitumoral y cardioprotector }\end{array}$ & $(97)(105)(104)(106)$ \\
\hline Apigenina & Flavonoide & $\begin{array}{l}\text { Antioxidante, } \\
\text { Antitinflamatoria, } \\
\text { Cardioprotector y propiedades } \\
\text { antididabeticas }\end{array}$ & $(97)(105)(107)(108)$ \\
\hline Luteolina & Flavonoide & $\begin{array}{l}\text { Antioxidante, antiinflamatoria y } \\
\text { antimicrobiano }\end{array}$ & $(97)(98)(109)(110)$ \\
\hline Genisteína & Flavonoide & $\begin{array}{l}\text { Antioxidante, } \\
\text { antiinflamatoria }\end{array}$ & $(97)(98)(111)$ \\
\hline Daidzeina & Flavonoide & $\begin{array}{l}\text { Antioxidante, } \\
\text { Antitinflamatoria, } \\
\text { Cardioprotector y propiedades } \\
\text { antididabeticas }\end{array}$ & $(97)(98)(112)$ \\
\hline Epicatequina & Flavonoide & $\begin{array}{l}\text { Antioxidante, antiinflamatoria y } \\
\text { propiedades antidiabeticas }\end{array}$ & $(98)(97)(113)$ \\
\hline $\begin{array}{l}\text { Quercetin-3-O-(6"- } \\
\text { malonyl) glucoside }\end{array}$ & Flavonoide & $\begin{array}{l}\text { Antioxidante, } \\
\text { antitumoral }\end{array}$ & $(97)(98)$ \\
\hline $\begin{array}{l}\text { Kaempferol-3-O- } \\
\text { glucoside }\end{array}$ & Flavonoide & $\begin{array}{l}\text { Antioxidante, } \\
\text { antiinflamatoria }\end{array}$ & $(97)(98)$ \\
\hline $\begin{array}{l}\text { Kaempherol-3-O- } \alpha- \\
\text { rhamnoside }\end{array}$ & Flavonoide & Antioxidante, antiinflamatoria & $(97)(98)(114)$ \\
\hline $\begin{array}{l}\text { 4-( } \alpha-L- \\
\text { rhamnopyranosyloxy) } \\
\text { benzyl glucosinolate } \\
\text { (glucomoringin) }\end{array}$ & Glucosinolato & $\begin{array}{l}\text { Antitumoral, } \\
\text { antioxidante }\end{array}$ & $(97)(98)(115)(116)$ \\
\hline
\end{tabular}




\begin{tabular}{|c|c|c|c|}
\hline $\begin{array}{l}\text { Compuesto } \\
\text { identificado }\end{array}$ & Clase & Actividad & Referencia \\
\hline $\begin{array}{l}\text { 4-[( } \alpha-L-r h a m n o s y l o x y) \\
\text { benzyl] } \\
\text { Isothiocyanate }\end{array}$ & Isotiocianato & $\begin{array}{l}\text { Antioxidante, } \\
\text { Antitumoral, } \\
\text { Antibacterial, } \\
\text { Cardioprotector y propiedades } \\
\text { antididabeticas }\end{array}$ & $(97)(116)(117)(118)$ \\
\hline $\begin{array}{l}\text { 4-[(4'-O-acetyl- } \alpha-L- \\
\text { rhamnosyloxy) } \\
\text { benzyl] } \\
\text { Isothiocyanate }\end{array}$ & Isotiocianato & $\begin{array}{l}\text { Antioxidante, } \\
\text { Antitumoral, } \\
\text { Antibacterial, } \\
\text { Cardioprotector y propiedades } \\
\text { antididabeticas }\end{array}$ & $(97)(116)(119)(120)$ \\
\hline Ácido gálico & Ácido fenólico & $\begin{array}{l}\text { Neuroprotector, } \\
\text { Antioxidante, } \\
\text { Cardioprotector, } \\
\text { Antitumoral }\end{array}$ & $(97)(121)(122)(123)$ \\
\hline Ácido salicílico & Ácido fenólico & $\begin{array}{l}\text { Propiedades desmolíticas y } \\
\text { comedolíticas }\end{array}$ & $(97)(98)(124)(125)$ \\
\hline Ácido gentisico & Ácido fenólico & $\begin{array}{l}\text { Propiedades antiinflamatorias, } \\
\text { antirreumáticas y antioxidantes. }\end{array}$ & $(98)(97)(126)$ \\
\hline Ácido siringico & Ácido fenólico & $\begin{array}{l}\text { Antioxidante, antiproliferativo, } \\
\text { antitumoral, actividad } \\
\text { hepatoprotectora y } \\
\text { propiedades antididabeticas }\end{array}$ & $(97)(98)(127)(106)$ \\
\hline Ácido elágico & Ácido fenólico & $\begin{array}{l}\text { Antioxidante, } \\
\text { Propiedades antidiabeticas }\end{array}$ & $(97)(98)(128)(129)(123)$ \\
\hline Ácido ferúlico & Ácido fenólico & $\begin{array}{l}\text { Antioxidante, antiinflamatoria y } \\
\text { propiedades antidiabeticas }\end{array}$ & $(97)(98)(123)(130)$ \\
\hline Ácido cafeico & Ácido fenólico & $\begin{array}{l}\text { Antioxidante, } \\
\text { Antiinflamatoria, } \\
\text { Antimicrobiana, } \\
\text { Antitumoral, } \\
\text { Propiedades } \\
\text { Antidiabéticas }\end{array}$ & $(97)(98)(131)(132)$ \\
\hline Ácido p-cumárico & Ácido fenólico & $\begin{array}{l}\text { Antioxidante, } \\
\text { Antiinflamatoria }\end{array}$ & $(97)(98)(133)(134)$ \\
\hline Ácido clorogénico & Ácido fenólico & $\begin{array}{l}\text { Antioxidante, } \\
\text { Antiinflamatoria, } \\
\text { Antihipertensivas } \\
\text { Hipolipemiante, } \\
\text { Propiedades } \\
\text { Antidiabéticas }\end{array}$ & $(97)(98)(123)(135)(136)$ \\
\hline
\end{tabular}




\begin{tabular}{|c|c|c|c|}
\hline $\begin{array}{l}\text { Compuesto } \\
\text { identificado }\end{array}$ & Clase & Actividad & Referencia \\
\hline $\begin{array}{l}\text { Ácido } \\
\text { criptoclorogénico }\end{array}$ & Ácido fenólico & $\begin{array}{l}\text { Antioxidante, } \\
\text { propiedades antididabeticas }\end{array}$ & $(97)(102)(137)$ \\
\hline $\begin{array}{l}\text { 4'- } \\
\text { hidroxifeniletanamida- } \\
\text { a-L-ramnopiranosido }\end{array}$ & Alcaloide & $\begin{array}{l}\text { Antioxidante, } \\
\text { Efecto cardioprotector }\end{array}$ & $(97)(100)(138)$ \\
\hline $\begin{array}{l}\mathrm{N}, \quad \alpha-\mathrm{L}- \\
\text { Rhamnopyranosyl } \\
\text { vincosamide }\end{array}$ & Alcaloide & $\begin{array}{l}\text { Antioxidante, } \\
\text { Efecto cardioprotector }\end{array}$ & $(97)(139)(100)$ \\
\hline $\begin{array}{l}\text { Pyrrolemarumine-4"- } \\
\text { O- } \alpha-\text {-L- } \\
\text { rhamnopyranoside }\end{array}$ & Alcaloide & $\begin{array}{l}\text { Antioxidante, } \\
\text { Efecto cardioprotector }\end{array}$ & $(97)(100)(138)$ \\
\hline Niacimicina & Glucosinolato & $\begin{array}{l}\text { Antioxidante, } \\
\text { Antitumoral, } \\
\text { Efecto cardioprotector }\end{array}$ & $(97)(140)(141)(142)$ \\
\hline Niaziminina & Glucosinolato & $\begin{array}{l}\text { Antioxidante, } \\
\text { Antitumoral, } \\
\text { Efecto cardioprotector }\end{array}$ & $(97)(143)$ \\
\hline$\beta$-sitosterol & Esterol & $\begin{array}{l}\text { Antioxidante, } \\
\text { Propiedades antidiabéticas, } \\
\text { hipolipidémico, antitumoral, } \\
\text { antiartrítico y hepatoprotector }\end{array}$ & $(97)(144)(145)(100)$ \\
\hline
\end{tabular}

Fuente: Adaptado de Frontiers in Pharmacology. Moringa Genus: A Review of Phytochemistry and Pharmacology $-2018^{\left({ }^{(97)} \text {. }\right.}$

En la table 8 se muestra algunos compuestos bioactivos presentes en las hojas de Moringa oleifera como alcaloides, saponinas, taninos, esteroides, ácidos fenólicos, glucosinolatos, flavonoides y terpenos. La diversidad de estos fitoquímicos en el género contribuye a sus numerosos usos farmacológicos. Ademas, algunos compuestos mostraron resultados favorables utilizadas en el modelo animal y se listaron las referencias correspondientes.

\section{Otras propiedades}

Moringa Oleífera, varias partes de esta planta, como las hojas, raíces, semillas, corteza, frutas, flores y vainas inmaduras han sido reivindicadas en la literatura tradicional como valiosas contra una amplia variedad de enfermedades. Indian Materia Médica describe los usos de las raíces. La Moringa oleífera es usada en el tratamiento de una serie de dolencias como asma, gota, lumbago, reumatismo, bazo hepatomegalia, inflamaciones internas 
profundas, infecciones dérmicas, infecciones gastrointestinales y afecciones calculadoras. En las últimas décadas, los extractos de hojas, semillas y raíces de la Moringa oleífera han sido ampliamente estudiadas para muchos usos potenciales incluyendo cicatrización de heridas, propiedad antitumoral, antifertilidad, actividad hipotensora y efecto hipocolesterolemiante, antibacterianos, antifúngicos, afrodisíacos, colagogos, antioxidantes, hepatoprotectores, inmunomoduladores, cardiotónicos y como estimulantes cardíacos y circulatorios. Se ha demostrado que tiene potenciales valores terapéuticos contra el cáncer, la diabetes, la artritis reumatoide y otras enfermedades y se está empleando para el tratamiento de diferentes dolencias en el sistema indígena de la medicina en particular en el sur de Asia ${ }^{(146)}$. Los beneficios de las hojas de Moringa oleífera podrían atribuirse a través de la ejecución su potente actividad antiinflamatoria, que inhibe la activación de las vías NF-KB y PI3K / Akt, mitigando el estrés oxidativo eliminando los radicales libres y mejorando los roles neuroprotectores ${ }^{(147)}$. Debido a estas variedades anchas, la planta ganó el nombre del "árbol del milagro" y del "árbol de la maravilla" en Tailandia.

\section{Efecto del consumo de las hojas de moringa en el control de la diabetes}

En los últimos años, las fuentes herbarias y dietéticas de componentes bioactivos que tienen propiedades farmacológicas y significación terapéutica en el sistema tradicional de medicina han atraído mucha atención en terapias complementarias y adyuvantes ${ }^{(1)}$.

Algunos estudios preclínicos sobre modelos animales han mostrado beneficios de especies de moringa como Moringa oleífera en la diabetes inducida experimentalmente. La mayoría de estos estudios han tomado el efecto anti-hiperglucémico como el indicador final de las propiedades antidiabéticas ${ }^{(1)}$.

La Moringa oleífera contiene muchos ingredientes activos con valores nutricionales y medicinales. Se utiliza comúnmente en la medicina folicular como un agente antidiabético.

Prácticamente, todas las partes de la planta tienen uso alimenticio ${ }^{(148)}$. Las frutas, las hojas, las flores, las raíces y el aceite son altamente apreciados por su valor nutritivo y se utilizan para la elaboración de diferentes platos en la India, Indonesia, Filipinas, Malasia, el Caribe y en varios países africanos ${ }^{(148)}$.

En la medicina tradicional india, la Moringa oleífera es usada para el tratamiento de la diabetes y la hipertensión arterial. El anecdotario popular en naciones africanas también reporta varios casos de cura milagrosa de diabetes e hipertensión usando remedios 
preparados a partir de esta planta. La incipiente investigación científica al respecto ya ha obtenido evidencias convincentes de muchos de esos casos, aunque la confirmación de otros requiere mayores pesquisajes. En años recientes, en diferentes países se han realizado investigaciones encaminadas a evaluar el potencial hipoglucemiante, antidiabético e hipotensivo de la moringa usando ensayos bioclínicos, farmacológicos y bioquímicos. En la India, se investigaron 30 plantas medicinales, a las que los sistemas de medicina Ayurveda, Unani y Siddha les atribuían actividad hipoglucemiante; el estudio confirmó que 24 de ellas provocaban una disminución en la concentración de glucosa en la sangre de ratas albinas, y una de las especies con mayor efecto hipoglucemiante resultó ser Moringa oleífera ${ }^{(149)(150)}$.

Recientemente se ha demostrado la presencia, en Moringa oleífera, de importantes fitoquímicos responsables de sus propiedades curativas. En uno de los primeros estudios exhaustivos sobre la composición química de esta especie se reveló que es rica en varias sustancias muy peculiares, como glucosinolatos, isotiocianatos, flavonoides, antocianinas, proantocianidinas y cinamatos; también se incluyó la distribución de fitoquímicos en las distintas partes del árbol ${ }^{(6)}$.

Muchos compuestos encontrados en las hojas de Moringa oleífera podrían estar involucrados en la homeostasis de la glucosa. Estudios de investigación revelaron que los isotiocianatos reducen la resistencia a la insulina y la resistencia hepática (118)(151)(100). Además los compuestos fenólicos, los flavonoides y los taninos presentes en la planta también inhiben la sacarasa intestinal $y$, en cierta medida, la $\alpha$-amilasa pancreática regulando la homeostasis de la glucosa postprandial ${ }^{(100)}$.

Según el estudio realizado por Omodanisi El, et al. (2017), se evaluó las actividades antihiperglicémicas, antiinflamatorias y antioxidantes del extracto de metanol de la moringa oleífera en ratas Wistar nefrotóxicas inducidas por la diabetes; donde la Moringa oleífera tiene la capacidad de protección contra el daño oxidativo debido a su alto contenido de polifenoles, flavonoides y flavonoles. También se encontró que la Moringa oleífera puede ser utilizado como un agente antidiabético en el tratamiento de la diabetes ${ }^{(152)}$.

Según el estudio realizado por Edoga, et al. (2013), mostraron los posibles efectos hipoglucémicos de Moringa oleífera sobre en ratones normoglucémicos e hiperglucémicos. Sugiriendo que tales efectos hipoglucémicos e hipolipidémicos del extracto de hojas de Moringa oleífera podrían deberse a su alto contenido de fitoquímicos antioxidantes, incluyendo cumarina, flavonoides, esteroles, terpenoides, triterpenoides, alcaloides, 
saponinas y fenólicos, que presentan efectos antidiabéticos y antihiperlipidémicos en ratas diabéticas tipo 1 y $2^{(153)}$.

Otro estudio realizado por Tang, et al. (2017), demostró que el extracto de hojas de Moringa oleífera de Camboya posee potentes actividades antioxidantes y disminuye los niveles de glucosa en sangre. Además, el extracto de hoja protege el riñón contra el daño mediado por especies reactivas de oxígeno (ROS), mejorando las defensas antioxidantes celulares y minimizando la hiperglucemia en el grupo de extracto de Moringa oleífera. Por lo tanto, el extracto de hoja de Moringa oleífera de Camboya podría ser utilizado como una fuente de antioxidantes naturales y agentes antidiabéticos y, puede tener una aplicación potencial como reactivo terapéutico ${ }^{(20)}$.

El efecto hipoglucémico y antihiperglucémico de las hojas de Moringa oleífera podría deberse a la presencia de terpenoides, que están involucrados en la estimulación de las células $\beta$ y la subsecuente secreción de insulina. Además, se han demostrado el rol de los flavonoides en la acción hipoglucémica ${ }^{(100)(154)}$.

Es importante recalcar, la relación directa entre el alto contenido de fitoquímicos presentes en las hojas de Moringa oleífera y la efectividad en el descenso de la glucosa en pacientes con Diabetes mellitus tipo 2.

\subsection{Glosario de términos}

Moringa oleífera: árbol nativo de múltiples propósitos del Himalaya en el norte de la India y cultivado a través de los trópicos. Posee grandes propiedades nutricionales y clínicas ${ }^{(34)}$. Antioxidante: es una molécula capaz de retardar o prevenir la oxidación de otras moléculas ${ }^{(21)}$.

Antidiabético: es un medicamento usado para reducir los niveles de glucosa en sangre, por lo que se indica en el tratamiento de la diabetes mellitus ${ }^{(155)}$.

Hipoglucemiante: es una sustancia con propiedades adecuadas para reducir los niveles de azúcar en sangre.

Plantas medicinales: contienen principios que pueden utilizarse en la curación de enfermedades.

Hipertensión arterial: también conocida como tensión arterial alta o elevada, es un trastorno en el que los vasos sanguíneos tienen una tensión persistentemente alta, lo que puede dañarlos. 
Radicales libres: son sustancias químicas muy reactivas que introducen oxígeno en las células, produciendo la oxidación de sus partes, alteraciones en el ADN, y que provocan cambios que aceleran el envejecimiento del cuerpo ${ }^{(156)}$.

Monohidrato de aloxano: es un compuesto químico, estructuralmente similar a la urea y posee acción necrosante específica y selectiva sobre las células $\beta$ de los islotes de Langerhans ${ }^{(69)(157)}$.

Streptozotocina: es un agente antimicrobiano. Posee una acción citotóxica sobre las células $\beta$ pancreáticas, y este agente es la primera opción para la inducción de diabetes en animales ${ }^{(74)(158)(159) \text {. }}$

Extracto etanólico: extracto con olor característico, obtenido a partir de materia prima desecada de origen vegetal, por maceración o percolación en contacto con etanol, seguida de la eliminación de dicho solvente por un procedimiento físico ${ }^{(160)}$.

Extracto metanólico: sustancia obtenida por extracción de una parte de una materia prima, usando un solvente como metanol ${ }^{(133)}$.

a-glucosidasa: la alfa glucosidasa o maltasa ácida es una enzima lisosomal con acción catalítica del glucógeno, su deficiencia impide la degradación y aprovechamiento del glucógeno. Los inhibidores de la alfa-glucosidasa (como la acarbosa) disminuyen la absorción de carbohidratos desde el tracto digestivo, reduciendo así los niveles de glucosa después de las comidas ${ }^{(161) .}$

a-amilasa: la $\alpha$-amilasa representa la enzima amilolítica más conocida. Cataliza la hidrólisis de enlaces $\alpha$-1,4-glucosídicos en almidón y a-glucanos ${ }^{(162)}$.

Colesterol esterasa pancreática: enzima que hidroliza los esteres del colesterol, rompe en enlace éster de los ésteres de colesterol para producir un ácido graso y colesterol libre. Se encuentra presente en el jugo pancreático y en el intestino ${ }^{(163)}$.

Malondialdehído: es uno de los productos finales de la peroxidación de ácidos grasos poliinsaturados en las células. Un aumento en los radicales libres causa la sobreproducción de MDA. El nivel de malondialdehído se conoce comúnmente como un marcador de estrés oxidativo ${ }^{(164)}$.

Superóxido dismutasa (SOD): es una enzima que se encuentra en nuestro organismo y es el más potente de los antioxidantes naturales. Está presente en las membranas celulares internas y externas. Encargada de regular el estrés oxidativo ${ }^{(165)}$. 
Glucógeno sintasa: enzima responsable de la degradación y síntesis del glucógeno, que es un polímero de unidades de glucosa que proporciona una fuente de energía fácilmente disponible en los mamíferos ${ }^{(166)}$.

Catalasa: es una enzima que se encuentra en casi todos los organismos de los seres vivos. La CAT como parte del sistema antioxidante está involucrada en la destrucción del H2O2 generado durante el metabolismo celular. Por lo tanto, actúa como antioxidante y protege la célula contra el estrés oxidativo ${ }^{(167)}$.

Glutatión peroxidasa (GPx): es una enzima dependiente del micronutriente selenio (Se), juega un papel crítico en la reducción de lípidos y peróxidos de hidrógeno ${ }^{(168)}$. 


\section{CAPÍTULO III}

\section{HIPÓTESIS Y VARIABLES}

\subsection{Hipótesis general}

Las hojas de Moringa oleífera reducen los niveles de glucemia en las ratas diabéticas inducidas

\section{Hipótesis general nula}

Las hojas de Moringa oleífera no reducen los niveles de glucemia en las ratas diabéticas inducidas

\subsection{Variables}

Variable independiente:

- Moringa oleífera

Variable dependiente:

- Glucemia 


\subsection{Conceptualización y operacionalización de variables}

Tabla 9. Operacionalización de variables

\begin{tabular}{|c|c|c|c|c|}
\hline Variables & Definición Conceptual & $\begin{array}{l}\text { Definición } \\
\text { operacional }\end{array}$ & $\begin{array}{l}\text { Escala de } \\
\text { medición }\end{array}$ & Indicadores \\
\hline $\begin{array}{l}\text { Moringa } \\
\text { oleifera }\end{array}$ & $\begin{array}{l}\text { Moringa oleífera Lam, es una de las } \\
\text { especies más conocidas y más } \\
\text { ampliamente distribuidas de la } \\
\text { familia monogénica Moringaceae. } \\
\text { Muchas partes de la planta de } \\
\text { moringa, incluyendo hojas, vainas } \\
\text { inmaduras, flores y frutas son } \\
\text { comestibles y se usan como } \\
\text { hortalizas en varios países (39). En el } \\
\text { Perú se iniciaron las pruebas de } \\
\text { siembra en el departamento de Ica, } \\
\text { en la Pampa de Villacurí en el año } \\
2009 \text { (169). Actualmente el clima de } \\
\text { Tumbes ofrece el mejor ambiente } \\
\text { para el crecimiento de este árbol } \\
\text { capaz de tolerar las sequías y las } \\
\text { zonas áridas, pues requiere poca } \\
\text { agua. }\end{array}$ & & Nominal & $\begin{array}{l}\text { Grupo con } \\
\text { tratamiento } \\
\text { de extracto } \\
\text { de hojas de } \\
\text { Moringa } \\
\text { oleífera } \\
\text { Grupo sin } \\
\text { tratamiento } \\
\text { de extracto } \\
\text { de hojas de } \\
\text { Moringa } \\
\text { oleífera }\end{array}$ \\
\hline Glucemia & $\begin{array}{l}\text { Es la cantidad de glucosa contenida } \\
\text { en la sangre; generalmente se } \\
\text { expresa en gramos por litro de } \\
\text { sangre. El término proviene del } \\
\text { francés glycémie y fue propuesto por } \\
\text { el fisiólogo Claude Bernard, por lo } \\
\text { que es traducido en ocasiones como } \\
\text { glicemia, aunque este término no se } \\
\text { encuentra registrado por la Real } \\
\text { Academia Española (RAE) }{ }^{(170)} \text {. }\end{array}$ & $\begin{array}{l}\text { Hemoglobina } \\
\text { Glicosilada } \\
\text { A1C: }<6.5 \% \\
\text { Glucemia en ayunas: } \\
70-100 \mathrm{mg} / \mathrm{dl}\end{array}$ & Razón & $\begin{array}{l}\text { Número } \\
\text { decimal }\end{array}$ \\
\hline \multirow[t]{2}{*}{$\begin{array}{l}\text { Glucosa en ayunas } \\
\text { (FBS) }\end{array}$} & $\begin{array}{l}\text { La prueba de glucosa en ayunas, es } \\
\text { una buena herrramienta para el }\end{array}$ & $\begin{array}{l}\text { Normal: } 70-100 \\
\mathrm{mg} / \mathrm{dl}\end{array}$ & Razón & $\begin{array}{l}\text { Número } \\
\text { decimal }\end{array}$ \\
\hline & diagnóstico de la diabetes ${ }^{(171)}$ & $\begin{array}{l}\text { Prediabetes: } 100- \\
125 \mathrm{mg} / \mathrm{dl} \\
\text { Diabetes: } \\
\mathrm{mg} / \mathrm{dL}\end{array}$ & & \\
\hline $\begin{array}{l}\text { Glucosa } \\
\text { Postprandial } \\
\text { (PPG) }\end{array}$ & $\begin{array}{l}\text { La prueba mide la cantidad de } \\
\text { glucosa en sangre después de } \\
\text { ingerir alimentos. }\end{array}$ & & Razón & $\begin{array}{l}\text { Número } \\
\text { entero }\end{array}$ \\
\hline $\begin{array}{l}\text { Hemoglobina } \\
\text { Glucosilada } \\
(\mathrm{HbA} 1 \mathrm{c})\end{array}$ & $\begin{array}{l}\text { Es un marcador de glucemias } \\
\text { crónicas ampliamente utilizado (2-3 } \\
\text { meses) }{ }^{(172)} \text {. }\end{array}$ & $\begin{array}{l}\text { Normal: } \leq 5.4 \\
\text { Prediabetes: } 5.5-6.4 \\
\text { Diabetes: } \geq 6.5\end{array}$ & Razón & $\begin{array}{l}\text { Número } \\
\text { decimal }\end{array}$ \\
\hline $\begin{array}{llr}\text { HOMA - IR } & & \\
\text { (índice } & & \text { de } \\
\text { resistencia a } & \text { la } \\
\text { insulina) } & & \end{array}$ & $\begin{array}{l}\text { Permite realizar estimaciones de } \\
\text { resistencia insulínica y función de las } \\
\text { células beta mediante las } \\
\text { concentraciones de la glucosa y la } \\
\text { insulina plasmáticas en ayunas }{ }^{(173)} \text {. }\end{array}$ & $\begin{array}{l}\text { Test de tolerancia } \\
\text { insulinica }\end{array}$ & Razón & $\begin{array}{l}\text { Número } \\
\text { decimal }\end{array}$ \\
\hline $\begin{array}{l}\text { Insulina } \\
\text { (In) }\end{array}$ & $\begin{array}{l}\text { Es el incremento de insulina en la } \\
\text { sangre después de la ingesta de } \\
\text { glucosa. }\end{array}$ & & Razón & $\begin{array}{l}\text { Número } \\
\text { decimal }\end{array}$ \\
\hline $\begin{array}{llr}\text { OGTT } & & \\
\text { (Prueba } & & \text { de } \\
\text { tolerancia a } \\
\text { glucosa) }\end{array}$ & $\begin{array}{l}\text { Esta prueba mide la respuesta del } \\
\text { cuerpo al azúcar (glucosa). Se } \\
\text { puede usar como prueba de } \\
\text { detección para la diabetes de tipo } 2 \\
\text { (174). }\end{array}$ & 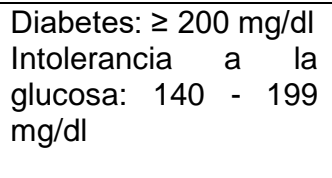 & Razón & $\begin{array}{l}\text { Número } \\
\text { decimal }\end{array}$ \\
\hline
\end{tabular}




\section{CAPÍTULO IV}

\section{METODOLOGÍA}

\subsection{Tipo y diseño de investigación}

La presente investigación es una revisión sistemática de la literatura científica, que consiste en la síntesis de la mejor evidencia disponible para responder a una pregunta concreta mediante la aplicación de una metodología explícita y rigurosa ${ }^{(35)}$. Para ello, utiliza el mismo procedimiento que cualquier estudio de investigación: se formula un objetivo, se busca, se identifican y se valoran las pruebas disponibles siguiendo un protocolo con criterios explícitos, y se obtienen conclusiones a partir del análisis de los datos recogidos y la interpretación de los resultados ${ }^{(35)}$.

\section{Metodología PRISMA.}

La estructura metodológica sigue las recomendaciones basadas en la Declaración PRISMA, desarrollada en base a QUOROM (Quality of reporting of meta-analysis) y Cochrane que establece directrices sobre la información que debe incluirse en las revisiones sistemáticas.

Esta se compone de una lista de comprobación estructurada de 27 ítems. Prisma sigue la estructura básica de un artículo científico, detallando los contenidos científicos que deberían reportarse en cada sección. También propone el diagrama de flujo para ilustrar el proceso de revisión ${ }^{(175)}$. 


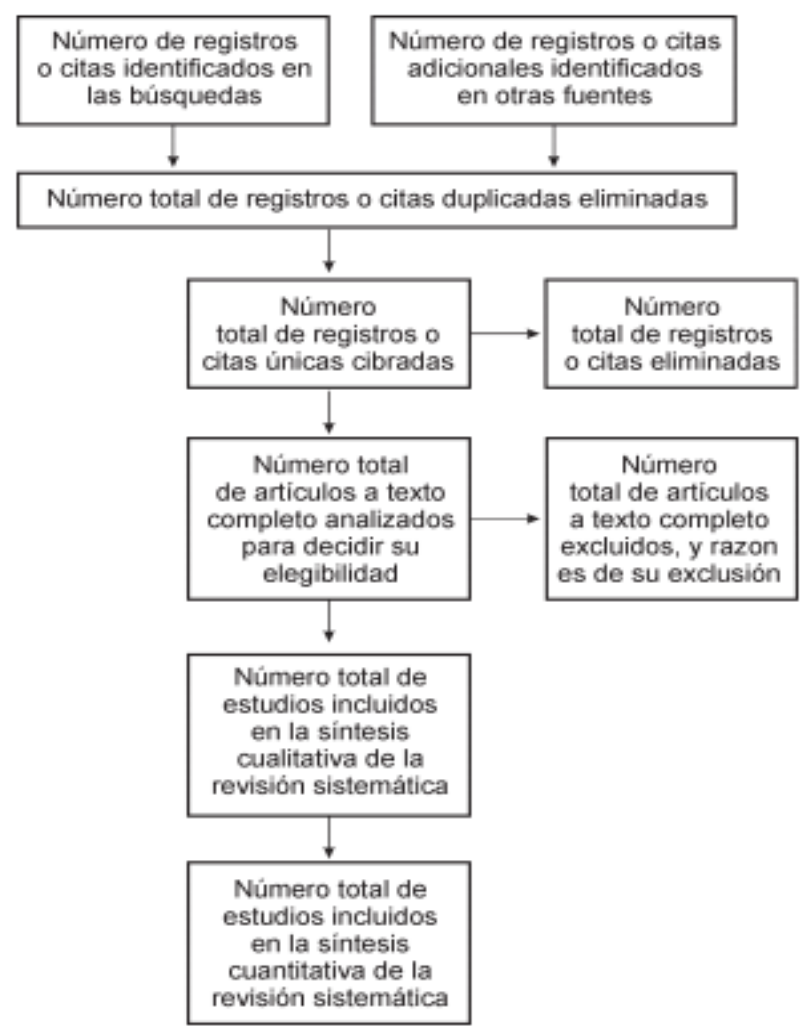

Figura 2. Diagrama de flujo de la información del modelo prisma, a través de las diferentes fases de la revisión sistemática

Fuente: Adaptado de la revista de Medicina Clínica. Declaración PRISMA: una propuesta para mejorar la publicación de revisiones sistemáticas y metaanálisis - $2010^{(176)}$.

En la actualidad, la declaración PRISMA se considera la estructura más adecuada para la realización de una revisión sistemática, es por tal razón que en base a sus recomendaciones se describen líneas abajo los pasos para la elaboración de la revisión:

Paso 1: Formulación de las preguntas de investigación

Paso 2: Búsqueda de la información

Paso 3: Selección de artículos primarios

Paso 4: Valoración de la calidad de los estudios (análisis de riesgo)

Paso 5: Extracción de datos

Paso 6: Síntesis de resultados

Paso 7: Conclusiones y recomendaciones 


\section{Pregunta PICO}

Se refiere a la pregunta con formato estandarizado que se utiliza en el ámbito de la medicina basada en la evidencia. Este formato estandarizado permite que la pregunta sea clara, precisa y enfocada (pregunta PICO: $\mathrm{P}=$ población específica, $\mathrm{I}=$ intervención, $\mathrm{C}=$ comparación, $\mathrm{O}=$ outcome $\mathrm{o}$ desenlace clínico) dando una consideración formal a la revisión sistemática y, además, establecer métodos explícitos y reproducibles que aborden de manera sistemática las sucesivas etapas en el proceso de una revisión: búsqueda e identificación de los estudios, selección de los estudios relevantes, descripción y análisis de su calidad o riesgo de sesgo, extracción de los datos y análisis de los resultados y su interpretación ${ }^{(175)}$. A continuación, se detalla explícitamente la pregunta PICO:

Tabla 10. Pregunta PICO de la investigación.

\begin{tabular}{ll}
\hline & Efecto de las hojas de Moringa oleífera sobre el control de la glucemia en las \\
& ratas diabéticas inducidas: revisión sistemática \\
\hline P & Estudios in vivo en ratas diabéticas inducidas por aloxano o estreptozotocina (stz). \\
I & Consumo de las hojas de Moringa oleifera (extracto acuoso/extracto etanolico/extracto eterico/extracto \\
de acetato de etilo/hoja pulverizada). \\
C & Estudios en ratas diabéticas inducidas por aloxano o estreptozotocina, a las que se administró las \\
hojas de Moringa oleifera para controlar la hiperglicemia con el grupo control.
\end{tabular}

Fuente: Elaboración propia.

\section{Búsqueda de evidencias}

Se realizó la búsqueda de artículos de investigación de alto impacto entre toda la producción científica relacionada, sobre el efecto de las hojas de Moringa oleífera en el control de la glucemia en ratas diabéticas inducidas, a través de los diferentes tipos de bases de datos a las que se tuvo acceso. Se establecieron descriptores MeSH y DeCS en tres idiomas para reducir el sesgo por lenguaje. Además, se realizó una búsqueda inversa a partir de las referencias bibliográficas de los estudios seleccionados.

\section{Bases de datos consultadas}

Se realizaron búsquedas en las bases de datos sin límite de fechas para los artículos publicados hasta agosto del 2018; a continuación, se listará las bases de datos académicas consultadas:

- EBSCO host 


\section{- ProQuest}

- Scopus

- PubMed

- Hindawi

- DOAJ

- AJOL (African Journals online)

- BioMed Central

- Web of Science

- SciELO

- Google Scholar

\section{Palabras clave utilizadas}

Para la realización de la búsqueda se obtuvieron los descriptores MeSH y DeCS, tanto para el uso de los términos en inglés, español y portugués, que se describen a continuación:

- Moringa oleifera

AND "Glucose" "Hypoglycemic agents" "Antihyperglycemic Agents" "Antidiabetic agents" "Diabetes Mellitus" "Diabetes Mellitus type 2" "Glycated Hemoglobin A" "Insulin Sensitivity" "Insulin Resistance" "Blood Glucose" etc.

- Y sus variantes en español y portugués.

Tipo de estudio: Revisión sistemática 


\subsection{Selección de la población y la muestra}

\section{- Población:}

La población se conformó por los artículos primarios extraídos de las diferentes bases de datos científicas de alto impacto que permitan responder la pregunta de investigación del estudio.

A continuación, se presenta el diagrama de flujo

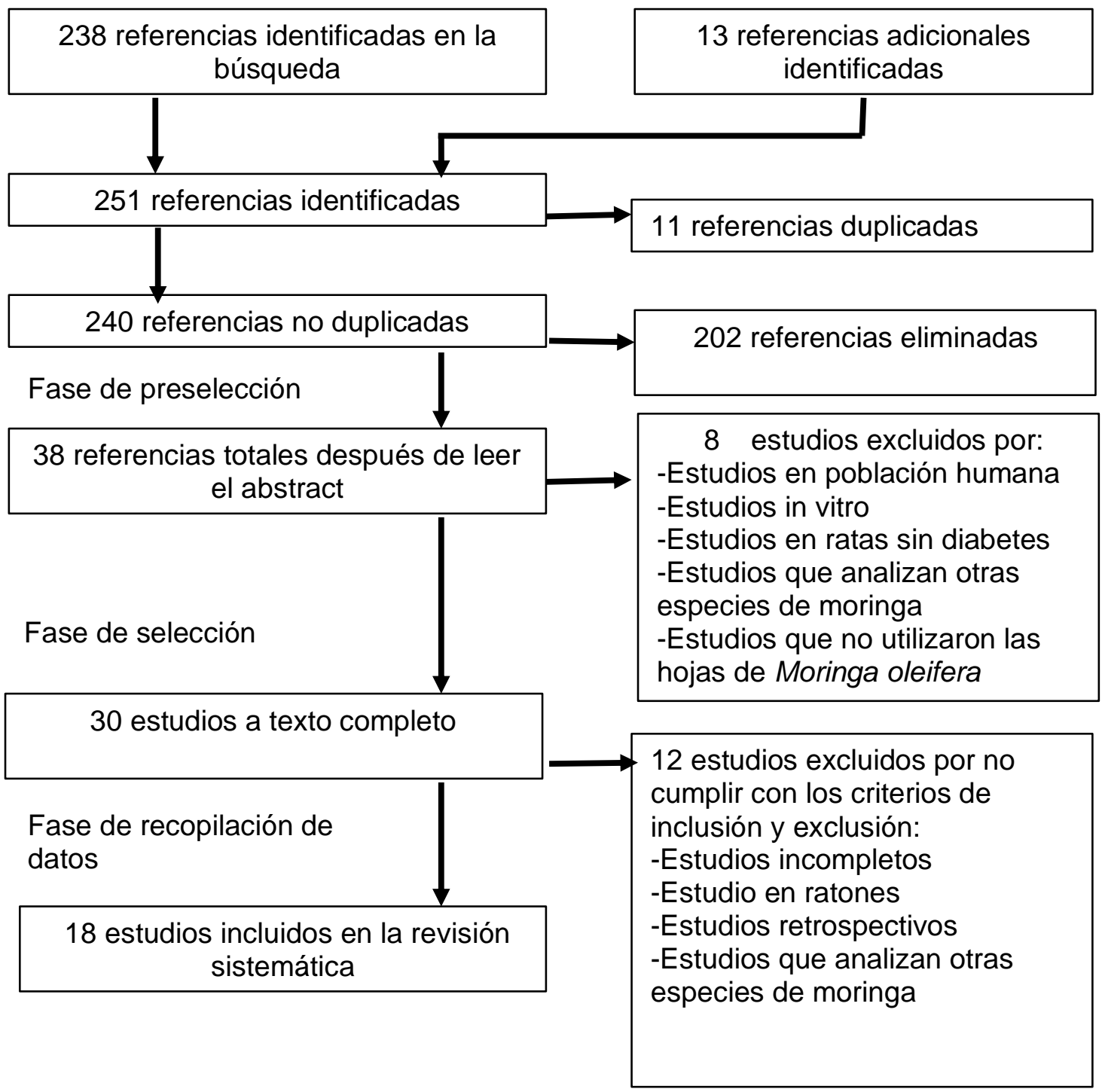




\subsection{Recolección de datos}

Se realizó una búsqueda exhaustiva en diferentes bases de datos de alto impacto y en las referencias bibliográficas de diferentes artículos primarios. Se identificaron 251 artículos que respondieron la pregunta de investigación y en la primera fase se eliminaron 11 artículos duplicados. Luego se procedió a leer los títulos de los artículos y se seleccionaron 38 que cumplieron con los objetivos de la investigación. Posteriormente, se procedió a leer los resúmenes de los 38 artículos restantes y se eliminó los que no respondían la pregunta $\mathrm{PICO}$, quedándonos con una población de 30 artículos que se leyeron a texto completo. La muestra final fue de 18 estudios que cumplieron con los criterios de elegibilidad. Se crearon formatos de resumen para cada artículo y se consideraron diferentes características que puedan ayudar a obtener información de calidad. (VER ANEXO)

\section{Criterios de elegibilidad}

\section{TIPOS DE ESTUDIOS A INCLUIR}

- Criterios de inclusión:

- Estudios in vivo en ratas diabéticas inducidas por aloxano o Estreptozotocina a las que se administró hojas de Moringa oleífera.

-Estudios en ratas inducidas a diabetes se administró hojas de Moringa oleifera y se comparó con el grupo control.

- Estudios que midieron y analizaron la glicemia o insulinemia o PTGO 0 hemoglobina glicosilada (\% HbA1c) o HOMA - IR en el suero de las ratas.

- Estudios que analizaron la respuesta glucémica en las ratas diabéticas ante la administración de las hojas de Moringa oleifera

- Estudio experimental y prospectivo en ratas

- Estudios originales y completos

- Estudios en idioma inglés, portugués y español

- Estudios publicados hasta agosto del 2018

- Criterios de exclusión:

- Artículos donde no mencionan el efecto hipoglucemiante o antidiabético de las hojas de Moringa oleifera

- Estudios donde se administraron a las ratas diabéticas las hojas de Moringa oleifera conjunta con otras plantas 
- Animales a los que se administró las hojas de Moringa oleifera, se comparó con otro grupo de animales tratados por otra planta

- Estudios que utilizaron otras partes de la Moringa oleifera (semillas, frutos, flores, tallo, raíces, etc.) que no eran las hojas, para la administración en ratas diabéticas inducidas

- Estudios duplicados

- Estudios en humanos

- Estudios en animales que no sean las ratas

\subsection{Métodos, técnicas e instrumentos para el análisis de datos}

\section{Métodos e instrumentos:}

- Programa Microsoft Excel: se utilizó el programa para gestionar los términos obtenidos de MeSH y DeCS, que respondieron la pregunta de investigación.

- Mendeley: se utilizó el programa para facilitar la gestión de referencias bibliográficas y evitar la duplicación de estudios.

- Formato para la evaluación de estudios: se utilizó el formato para evaluar y seleccionar los estudios primarios que respondieron la pregunta PICO de la presente revisión.

- Formato para la recolección de datos: se utilizó el formato para la extracción de datos y las características de los estudios incluidos en la revisión.

\section{Riesgo de sesgo en estudios individuales:}

Se encontraron pruebas de calidad dirigidos a ensayos clínicos aleatorizados como Revman, formato JADAD, Escala PEDRO, escala de Guyat y Sacket, etc. Se realizó una búsqueda exhaustiva de pruebas de calidad en estudios experimentales de animales y no se obtuvo ninguna fuente fidedigna que pueda garantizar la calidad de los estudios incluidos en la revisión sistemática, teniendo en cuenta que van dirigidos a estudios realizados en ratas inducidas a diabetes.

\section{Síntesis de resultados:}

Se realizó un formato que permita introducir información consistente que responda la pregunta PICO de cada artículo de investigación. 


\subsection{Aspectos éticos}

La presente investigación evaluó estudios primarios experimentales en animales que siguieron las recomendaciones que determinó la institución local o alguna ley nacional establecida para el cuidado y la utilización de los animales de laboratorio. Ciertamente, al realizar la búsqueda sistemática de los estudios primarios y luego proceder a la evaluación y selección de los estudios; se consideró a aquellos que respondieron la pregunta de investigación y cumplieron con los filtros antes descritos de la revisión sistemática. De tal manera, aquellos estudios que no formaron parte de la investigación no cumplieron el objetivo del estudio y, por lo tanto, se niega tener algún conflicto de interés con algún autor donde su investigación no fue elegida para la presente investigación. 


\section{CAPÍTULO V}

\subsection{Resultados}

\section{Presentación de resultados}

Inicialmente, se identificaron 251 artículos que respondieron la pregunta de investigación. En la primera fase se eliminaron 11 artículos duplicados, luego se procedió a leer los títulos de los artículos y se seleccionaron 38 que cumplieron con los objetivos de la investigación. Posteriormente, se procedió a leer los resúmenes de los 38 artículos restantes y se eliminó los que no respondían la pregunta PICO, quedándonos con una población de 30 artículos que se leyeron a texto completo. La muestra final fue de 18 estudios que cumplieron con los criterios de elegibilidad. Los resultados de las investigaciones incluidas en el estudio se resumieron en tablas $8 \mathrm{~A}, 8 \mathrm{~B}, 8 \mathrm{C}, 8 \mathrm{D}, 8 \mathrm{E}, 8 \mathrm{~F}$.

Los 18 artículos, finalmente, seleccionados para la revisión eran estudios primarios publicados en inglés, español y portugués. El periodo de búsqueda fue desde agosto del 2017 hasta febrero de 2019.

En los estudios incluidos, participaron 749 ratas wistar y Sprague Dawley, inducidas a diabetes por monohidrato de aloxano o estreptozotocina (STZ).

La intervención fue tratar a las ratas diabéticas previamente inducidas con las hojas de Moringa oleífera y comparar con el grupo control diabético sin tratamiento.

En todos los estudios, se redujo significativamente la glucemia en las ratas diabéticas tratadas con las diferentes presentaciones de las hojas de Moringa oleífera, al compararlos con el grupo control. 
Tabla 11 - A: Efecto de las hojas de Moringa oleífera sobre el control de la glucemia en las ratas diabéticas inducidas

\begin{tabular}{|c|c|c|c|c|c|c|c|c|c|c|c|}
\hline Referencia & $\begin{array}{l}\text { Características de } \\
\text { la población }\end{array}$ & $\begin{array}{c}\text { Tamaño de } \\
\text { muestra }\end{array}$ & $\begin{array}{c}\text { Dosis y } \\
\text { duración del } \\
\text { tratamiento }\end{array}$ & Intervención & $\begin{array}{l}\text { Resultados } \\
\text { principales }\end{array}$ & $\begin{array}{l}F B \\
S\end{array}$ & $P P G$ & HbA1c & $\begin{array}{c}\text { HOMA } \\
- \text { - IR }\end{array}$ & In & OGTT \\
\hline $\begin{array}{l}\text { Villarruel- } \\
\text { López A, et } \\
\text { al. (2018) }\end{array}$ & $\begin{array}{l}\text { Ratas Sprague } \\
\text { Dawley } \\
\text { Machos } \\
\text { P: } 180 \text { - } 200 \mathrm{~g} \\
\text { Inducción a la DM: } \\
150 \mathrm{mg} / \mathrm{kg} \text { de } \\
\text { monohidrato de } \\
\text { aloxano }\end{array}$ & $\mathrm{N}=30$ & $\begin{array}{l}50 \mathrm{mg} / \text { día de } \\
\text { polvo de hojas } \\
\text { de } \mathrm{MO} \\
8 \mathrm{Sem}\end{array}$ & $\begin{array}{l}5 \text { grupos }(n=6) \\
\text { G1: Grupo control } \\
\text { G2: Grupo sano + MO } \\
\text { G3: Grupo diabético } \\
\text { G4: Grupo diabético + MO } \\
\text { G5: Grupo diabético + } \\
\text { glibenclamida } 600 \mu / \mathrm{kg} / \\
\text { día }\end{array}$ & $\begin{array}{l}\text { Los niveles de glucosa } \\
\text { en el grupo de } \\
\text { diabéticos tratados con } \\
\text { Moringa oleífera } \\
\text { disminuyeron en } \\
\text { comparación con los } \\
\text { del grupo diabético no } \\
\text { tratado. }\end{array}$ & $\downarrow^{*}$ & $\varnothing$ & $\varnothing$ & $\varnothing$ & $\varnothing$ & $\varnothing$ \\
\hline $\begin{array}{l}\text { Omabe M, et } \\
\text { al. (2014) }\end{array}$ & $\begin{array}{l}\text { Ratas Wistar } \\
\text { albinas } \\
\text { Ambos sexos } \\
\text { P: } 130 \text { - } 200 \mathrm{~g} \\
\text { Inducción a la DM: } \\
84 \mathrm{mg} / \mathrm{kg} \text { de } \\
\text { monohidrato de } \\
\text { aloxano }\end{array}$ & $\begin{array}{c}\mathrm{N}=15 \\
\text { Edad } \\
8-12 \\
\text { semanas }\end{array}$ & $\begin{array}{l}200 \mathrm{mg} / \mathrm{kg} \text { de } \\
\text { extracto } \\
\text { etanólico de } \mathrm{MO} \\
-\mathrm{M} / \mathrm{T} \\
5 \text { días }\end{array}$ & $\begin{array}{l}3 \text { grupos }(\mathrm{n}=5) \\
\text { G1: Grupo control } \\
\text { diabético } \\
\text { G2: Grupo diabético + } \\
\text { Extracto etanólico MO } \\
\text { G3: Grupo diabético + } \\
\text { metformina } 10 \mathrm{mg} / \mathrm{kg}\end{array}$ & $\begin{array}{l}\text { El nivel de glucosa en } \\
\text { sangre de ratas } \\
\text { diabéticas tratadas con } \\
\text { el extracto redujo } \\
\text { significativamente por } 3 \\
\text { veces en comparación } \\
\text { con el nivel de glucosa } \\
\text { en sangre del grupo } \\
\text { diabético no tratado. }\end{array}$ & $\downarrow^{* * *}$ & $\varnothing$ & $\varnothing$ & $\varnothing$ & $\varnothing$ & $\varnothing$ \\
\hline $\begin{array}{l}\text { Irfan, HM, et } \\
\text { al. (2016) }\end{array}$ & $\begin{array}{l}\text { Ratas Sprague } \\
\text { Dawley } \\
\text { Machos } \\
\text { P: } 170 \text { - } 200 \mathrm{~g} \\
\text { Inducción a la DM: } \\
45 \mathrm{mg} / \mathrm{kg} \text { de STZ }\end{array}$ & $\begin{array}{c}\mathrm{N}=36 \\
\text { Edad } \\
5 \text { a } 6 \text { Sem }\end{array}$ & $\begin{array}{l}1000 \mathrm{mg} / \mathrm{kg} \text { de } \\
\text { MMAEO(I) } \\
500 \mathrm{mg} / \mathrm{kg} \text { de } \\
\text { MMAEO(II) } \\
250 \mathrm{mg} / \mathrm{kg} \text { de } \\
\text { MMAEO(III) } \\
125 \mathrm{mg} / \mathrm{kg} \mathrm{de} \\
\text { MMAEO(IV) } \\
14 \text { días }\end{array}$ & $\begin{array}{l}6 \text { grupos ( } \mathrm{n}=6) \\
\text { G1: DM + agua destilada } \\
\text { (10 mg/kg)-CN } \\
\text { G2: DM + metformina } 500 \\
\text { mg / kg - CP } \\
\text { G3: DM + MMAEO(I) } \\
\text { G4: DM + MMAEO(II) } \\
\text { G5: DM + MMAEO(III) } \\
\text { G6: DM + MMAEO(IV) }\end{array}$ & $\begin{array}{l}\text { La reducción máxima } \\
\text { en la concentración de } \\
\text { glucosa fue del } 53,44 \% \\
\text { con una dosis de } 1000 \\
\mathrm{mg} / \mathrm{kg}\end{array}$ & $f^{* * *}$ & $\varnothing$ & $\varnothing$ & $\varnothing$ & $\varnothing$ & $\varnothing$ \\
\hline
\end{tabular}

$\left.{ }^{*}\right) p \leq 0,05\left(^{* *}\right) p \leq 0,01\left(^{* * *}\right) p \leq 0,001$ FBS: Glucosa en ayunas; PPG: Glucosa postprandial; HbA1c: Hemoglobina glicosilada; HOMA - IR: Índice Homa; In: Insulina; OGTT: Prueba de tolerancia a la glucosa oral

MO: Moringa oleífera; MoWE: Extracto acuoso de MO; mome: Extracto metanólico de MO; MMAEO: Extracto etanólico de MO; STZ: Streptozotocina; CN: Control negativo; CP: Control positivo; DM: Diabetes mellitus; NS: No significativo; Ø: No se midió 
Tabla 9- B: Efecto de las hojas de Moringa oleífera sobre el control de la glucemia en las ratas diabéticas inducidas

\begin{tabular}{|c|c|c|c|c|c|c|c|c|c|c|c|}
\hline Referencia & $\begin{array}{l}\text { Características de } \\
\text { la población }\end{array}$ & $\begin{array}{l}\text { Tamaño de } \\
\text { muestra }\end{array}$ & $\begin{array}{c}\text { Dosis y } \\
\text { duración del } \\
\text { tratamiento }\end{array}$ & Intervención & $\begin{array}{l}\text { Resultados } \\
\text { principales }\end{array}$ & $\begin{array}{l}F B \\
S\end{array}$ & $P P G$ & HbA1c & $\begin{array}{c}\text { HOMA } \\
\text { - IR }\end{array}$ & In & OGTT \\
\hline $\begin{array}{l}\text { Irfan, HM, et } \\
\text { al. (2017) }\end{array}$ & $\begin{array}{l}\text { Ratas Sprague } \\
\text { Dawley albinas } \\
\text { Machos } \\
\text { P: } 230 \mathrm{~g} \text { Aprox } \\
\text { Inducción a la DM: } \\
45 \mathrm{mg} / \mathrm{kg} \text { de STZ }\end{array}$ & $\begin{array}{c}\mathrm{N}=84 \\
\text { Edad } \\
8 \text { a } 9 \text { Sem }\end{array}$ & $\begin{array}{l}1000 \mathrm{mg} / \mathrm{kg} \text { de } \\
\text { MMAEO } \\
1000 \mathrm{mg} / \mathrm{kg} \text { de } \\
\text { MoWE } \\
14 \text { días }\end{array}$ & $\begin{array}{l}7 \text { grupos }(\mathrm{n}=6) \\
\text { G1: DM + agua destilada } \\
(10 \mathrm{mg} / \mathrm{kg}) \text {-CN } \\
\text { G2: DM + metformina } 500 \\
\text { mg / } \mathrm{kg} \text { - CP } \\
\text { G3: DM +MMAEO (95\%) } \\
\text { G4: DM +MMAEO (75\%) } \\
\text { G5: DM +MMAEO (50\%) } \\
\text { G6: DM +MMAEO (25\%) } \\
\text { G7: DM + MoWE }\end{array}$ & $\begin{array}{l}\text { La reducción } \\
\text { proporcionada por el } \\
\text { extracto etanólico al } \\
95 \% \text { fue de } 64,07 \% \text { en } \\
\text { comparación con el } \\
\text { grupo control diabético. }\end{array}$ & $\downarrow^{* * *}$ & $\varnothing$ & $\varnothing$ & $\varnothing$ & $\varnothing$ & $\varnothing$ \\
\hline $\begin{array}{l}\text { Bamagous } \\
\text { GA, et al. } \\
(2018)\end{array}$ & $\begin{array}{l}\text { Ratas Sprague } \\
\text { Dawley albinas } \\
\text { P: } 200 \text { - } 250 \mathrm{~g} \\
\text { Inducción a la DM: } \\
55 \mathrm{mg} / \mathrm{kg} \text { de STZ }\end{array}$ & $\begin{array}{c}\mathrm{N}=24 \\
\text { Edad } \\
8-12 \\
\text { semanas }\end{array}$ & $\begin{array}{l}200 \mathrm{mg} / \mathrm{kg} \text { de } \\
\text { fracción del } \\
\text { extracto de } \\
\text { acetato de etilo } \\
\text { de hojas de MO } \\
30 \text { días }\end{array}$ & $\begin{array}{l}4 \text { grupos }(n=6) \\
\text { G1: controles normales } \\
\text { G2: control diabético G3: } \\
\text { Grupo diabético + Extracto } \\
\text { de acetato de etilo de MO } \\
\text { G4: control positivo STZ + } \\
\text { Glibenclamida } 5 \mathrm{mg} / \mathrm{Kg}\end{array}$ & $\begin{array}{l}\text { Los niveles de HbA1c } \\
\text { y glucosa se redujeron } \\
\text { significativamente en } \\
\text { los grupos } 3 \text { y } 4 \text { hacia } \\
\text { los valores normales. }\end{array}$ & $\downarrow^{*}$ & $\varnothing$ & $\perp^{*}$ & $\varnothing$ & $\boldsymbol{\varphi}^{*}$ & $\varnothing$ \\
\hline $\begin{array}{l}\text { Abd Eldaim } \\
\text { MA, et al. } \\
(2018)\end{array}$ & $\begin{array}{l}\text { Ratas Wistar } \\
\text { albinas } \\
\text { Ambos sexos } \\
\text { P: } 110 \text { - } 170 \mathrm{~g} \\
\text { Inducción a la DM: } \\
150 \mathrm{mg} / \mathrm{kg} \text { de } \\
\text { monohidrato de } \\
\text { aloxano }\end{array}$ & $\mathrm{N}=80$ & $\begin{array}{l}250 \mathrm{mg} / \mathrm{kg} \text { de } \\
\text { extracto acuoso } \\
\text { de } \mathrm{MO} \\
18 \text { días }\end{array}$ & $\begin{array}{l}4 \text { grupos }(\mathrm{n}=20) \\
\mathrm{G} 1: \text { Grupo control + } \\
\text { placebo (SS) } \\
\text { G2: Grupo diabético } \\
\text { G3: Grupo sano + } \mathrm{MO} \\
\text { G4: Grupo diabético + MO }\end{array}$ & $\begin{array}{l}\text { El tratamiento de las } \\
\text { ratas diabéticas en el } \\
\text { G4 con extracto de } \\
\text { hojas de MO redujo } \\
\text { significativamente el } \\
\text { nivel de glucosa en } \\
\text { sangre en comparación } \\
\text { con el G2 por cerca de } \\
3.6 \text { pliegues }(p<0,05) \text {. }\end{array}$ & $\downarrow^{*}$ & $\varnothing$ & $\varnothing$ & $\varnothing$ & $\varnothing$ & $\varnothing$ \\
\hline
\end{tabular}

$\left(^{*}\right) p \leq 0,05\left(^{* *}\right) p \leq 0,01\left(^{* *}\right) p \leq 0,001$ FBS: Glucosa en ayunas; PPG: Glucosa postprandial; HbA1c: Hemoglobina glicosilada; HOMA - IR: Índice Homa; In: Insulina; OGTT: Prueba de tolerancia a la glucosa oral

MO: Moringa oleífera; MoWE: Extracto acuoso de MO; mome: Extracto metanólico de MO; MMAEO: Extracto etanólico de MO; STZ: Streptozotocina; CN: Control negativo; CP: Control positivo; DM: Diabetes mellitus; NS: No significativo; Ø: No se midió 
Tabla 9- C: Efecto de las hojas de Moringa oleífera sobre el control de la glucemia en las ratas diabéticas inducidas

\begin{tabular}{|c|c|c|c|c|c|c|c|c|c|c|c|}
\hline Referencia & $\begin{array}{l}\text { Características de } \\
\text { la población }\end{array}$ & $\begin{array}{c}\text { Tamaño de } \\
\text { muestra }\end{array}$ & $\begin{array}{c}\text { Dosis y } \\
\text { duración del } \\
\text { tratamiento }\end{array}$ & Intervención & $\begin{array}{l}\text { Resultados } \\
\text { principales }\end{array}$ & $\begin{array}{l}F B \\
S\end{array}$ & PPG & HbA1c & $\begin{array}{l}\text { HOMA } \\
\text { - IR }\end{array}$ & In & OGTT \\
\hline $\begin{array}{lll}\text { Abd } & \text { El } & \text { Latif } \\
\text { A, et } & \text { al. } \\
(2014) & \end{array}$ & $\begin{array}{l}\text { Ratas Wistar } \\
\text { albinas } \\
\text { P: } 130 \text { - } 170 \mathrm{~g} \\
\text { Inducción a la DM: } \\
100 \mathrm{mg} / \mathrm{kg} \text { de } \\
\text { monohidrato de } \\
\text { aloxano }\end{array}$ & $\mathrm{N}=20$ & $\begin{array}{l}250 \mathrm{mg} / \mathrm{kg} \text { de } \\
\text { extracto acuoso } \\
\text { de } \mathrm{MO} \\
18 \text { días }\end{array}$ & $\begin{array}{l}4 \text { grupos }(n=5) \\
\text { G1: Grupo control + } \\
\text { placebo (SS) } \\
\text { G2: Grupo diabético } \\
\text { G3: Grupo sano + MO } \\
\text { G4: Grupo diabético + MO }\end{array}$ & $\begin{array}{l}\text { La administración oral } \\
\text { del extracto de acuoso } \\
\text { de MO en ratas } \\
\text { diabéticas (grupo 4) } \\
\text { normaliza los niveles } \\
\text { séricos de glucosa } \\
\text { elevados. }\end{array}$ & $\downarrow^{*}$ & $\varnothing$ & $\varnothing$ & $\varnothing$ & $\varnothing$ & $\varnothing$ \\
\hline $\begin{array}{l}\text { Yassa HD, } \\
\text { et al. (2014) }\end{array}$ & $\begin{array}{l}\text { Ratas Sprague } \\
\text { Dawley albinas } \\
\text { Machos } \\
\text { P: } 180 \text { - } 200 \mathrm{~g} \\
\text { Inducción a la DM: } \\
60 \mathrm{mg} / \mathrm{kg} \text { de STZ }\end{array}$ & $\mathrm{N}=50$ & $\begin{array}{l}200 \mathrm{mg} / \mathrm{kg} \mathrm{de} \\
\text { extracto acuoso } \\
\text { de MO } \\
8 \text { Sem }\end{array}$ & $\begin{array}{l}4 \text { grupos }(n=10) \\
\text { G1: control normal } \\
\text { G2: control simulado + } \\
\text { MoWE } \\
\text { G3: DM } \\
\text { G4: DM + MoWE }\end{array}$ & $\begin{array}{l}\text { El grupo que se } \\
\text { administró MO } \\
\text { disminuyó signifi } \\
\text { cativamente FBS (p } \\
<0,05) .\end{array}$ & $\downarrow^{*}$ & $\varnothing$ & $\varnothing$ & $\varnothing$ & $\varnothing$ & $\varnothing$ \\
\hline $\begin{array}{l}\text { Oyedepo } \\
\text { TA, et al. } \\
(2014)\end{array}$ & $\begin{array}{l}\text { Ratas Wistar } \\
\text { albinas } \\
\text { Machos } \\
\text { P: } 160 \text { - 200g } \\
\text { Inducción a la DM: } \\
100 \mathrm{mg} / \mathrm{kg} \text { de } \\
\text { monohidrato de } \\
\text { aloxano }\end{array}$ & $\mathrm{N}=24$ & $\begin{array}{l}400 \mathrm{mg} / \mathrm{kg} \text { de } \\
\text { extracto acuoso } \\
\text { de } \mathrm{MO} \\
28 \text { días }\end{array}$ & $\begin{array}{l}3 \text { grupos }(n=8) \\
\text { Grupo A: control normal } \\
\text { Grupo B: DM + placebo } \\
\text { (SS) } \\
\text { Grupo C: DM + MO }\end{array}$ & $\begin{array}{l}\text { Dosis diaria } \\
\text { administrada de } 400 \\
\text { mg / kg de peso } \\
\text { corporal del extracto } \\
\text { dio lugar a disminución } \\
\text { significativa en la } \\
\text { hiperglucemia } \\
\text { comparándolo con el } \\
\text { control diabético. }\end{array}$ & $\downarrow^{* *}$ & $\varnothing$ & $\varnothing$ & $\varnothing$ & $\varnothing$ & $\varnothing$ \\
\hline
\end{tabular}

$\left.\left({ }^{*}\right) \mathrm{p} \leq 0,05\left(^{* *}\right) \mathrm{p} \leq 0,01{ }^{* * *}\right) \mathrm{p} \leq 0,001$ FBS: Glucosa en ayunas; PPG: Glucosa postprandial; HbA1c: Hemoglobina glicosilada; HOMA - IR: Índice Homa; In: Insulina; OGTT: Prueba de tolerancia a la glucosa oral

MO: Moringa oleífera; MoWE: Extracto acuoso de MO; mome: Extracto metanólico de MO; MMAEO: Extracto etanólico de MO; STZ: Streptozotocina; CN: Control negativo; CP: Control positivo; DM: Diabetes mellitus; NS: No significativo; Ø: No se midió 
Tabla 9 - D: Efecto de las hojas de Moringa oleífera sobre el control de la glucemia en las ratas diabéticas inducidas

\begin{tabular}{|c|c|c|c|c|c|c|c|c|c|c|c|}
\hline Referencia & $\begin{array}{l}\text { Características de } \\
\text { la población }\end{array}$ & $\begin{array}{c}\text { Tamaño de } \\
\text { muestra }\end{array}$ & $\begin{array}{c}\text { Dosis y } \\
\text { duración del } \\
\text { tratamiento }\end{array}$ & Intervención & $\begin{array}{l}\text { Resultados } \\
\text { principales }\end{array}$ & $\begin{array}{l}F B \\
S\end{array}$ & $P P G$ & $H b A 1 c$ & $\begin{array}{c}\text { HOMA } \\
-I R\end{array}$ & In & OGTT \\
\hline $\begin{array}{l}\text { Divi SM, et } \\
\text { al. (2012) }\end{array}$ & $\begin{array}{l}\text { Ratas Wistar } \\
\text { albinas } \\
\text { Machos } \\
\text { P: } 150 \text { - } 160 \mathrm{~g} \\
\text { Inducción a la DM: } \\
55 \mathrm{mg} \text { / kg de STZ }\end{array}$ & $\begin{array}{c}\mathrm{N}=54 \\
\text { Edad } \\
45 \text { Sem }\end{array}$ & $\begin{array}{l}200 \mathrm{mg} / \mathrm{kg} \mathrm{de} \\
\text { extracto acuoso } \\
\text { de MO } \\
60 \text { días }\end{array}$ & $\begin{array}{l}6 \text { grupos }(n=8-11) \\
\text { G1: control normal + agua } \\
\text { destilada } \\
\text { G2: control + MoWE } \\
\text { G3: Fructosa + agua } \\
\text { destilada } \\
\text { G4: Fructosa + MoWE } \\
\text { G5: DM+ agua destilada } \\
\text { G6: DM + MoWE }\end{array}$ & $\begin{array}{l}\text { Los niveles de glucosa } \\
\text { en plasma de } C+ \\
\text { MoWE, F + MoWE y D } \\
+ \text { MoWE durante el } \\
\text { período experimental } \\
\text { indicó claramente que } \\
\text { MoWE mostró un } \\
\text { efecto } \\
\text { antihiperglucémico. }\end{array}$ & $\downarrow^{*}$ & $\varnothing$ & $\varnothing$ & $\boldsymbol{\varphi}^{*}$ & $\hat{\top}^{*}$ & $\downarrow^{*}$ \\
\hline $\begin{array}{l}\text { Jaiswal D, et } \\
\text { al. (2009) }\end{array}$ & $\begin{array}{l}\text { Ratas Wistar } \\
\text { albinas } \\
\text { Machos } \\
\text { P: } 150 \text { - } 200 \mathrm{~g} \\
\text { Inducción a la DM: } \\
55 \mathrm{mg} \text { / kg de STZ }\end{array}$ & $\mathrm{N}=18$ & $\begin{array}{l}200 \mathrm{mg} / \mathrm{kg} \text { de } \\
\text { extracto acuoso } \\
\text { de } \mathrm{MO} \\
21 \text { días }\end{array}$ & $\begin{array}{l}3 \text { grupos }(\mathrm{n}=6) \\
\text { G1: control diabético + } \\
\text { placebo }(\mathrm{SS}) \\
\text { G2: } \mathrm{DM}+\mathrm{MO} \\
\text { G3: DM + Glipizide }(2.5 \\
\mathrm{mg} / \mathrm{kg})\end{array}$ & $\begin{array}{l}\text { La caída observada } \\
\text { después de } 7,14 \text { y } 21 \\
\text { días de tratamiento con } \\
\text { la dosis de } 200 \mathrm{mg} / \mathrm{kg} \\
\text { del extracto fue de } \\
25,9,53,5,69,2 \% \text { en } \\
\text { FBG y } 21,4,37,8, \\
51,2 \% \text { en niveles de } \\
\text { PPG respectivamente. }\end{array}$ & $\downarrow^{* *}$ & $\downarrow^{* *}$ & $\varnothing$ & $\varnothing$ & $\varnothing$ & $\downarrow^{* * *}$ \\
\hline $\begin{array}{l}\text { Khan W, et } \\
\text { al. (2017) }\end{array}$ & $\begin{array}{l}\text { Ratas Wistar } \\
\text { Hembras } \\
\text { P: } 200 \text { - } 250 \mathrm{~g} \\
\text { Inducción a la DM: } \\
45 \mathrm{mg} \text { / kg de STZ }\end{array}$ & $\mathrm{N}=30$ & $\begin{array}{l}100 \mathrm{mg} / \mathrm{kg} \mathrm{de} \\
\text { extracto acuoso } \\
\text { de } \mathrm{MO}\end{array}$ & $\begin{array}{l}5 \text { grupos }(n=6) \\
\text { G1: control normal + } \\
\text { placebo (SS) } \\
\text { G2: control simulado + } \\
\text { MoWE } \\
\text { G3: DM + placebo (SS) } \\
\text { G4:DM + MoWE } \\
\text { G5: DM+ metformina } 42 \\
\text { mg/kg }\end{array}$ & $\begin{array}{l}\text { El grupo diabético } \\
\text { tratado con MO } \\
\text { disminuyó } \\
\text { significativamente la } \\
\text { glucosa en ayunas } \\
(p<0,05) .\end{array}$ & $f^{*}$ & $\varnothing$ & $\varnothing$ & $\varnothing$ & $\varnothing$ & $\downarrow^{* * *}$ \\
\hline
\end{tabular}

$\left.\left.\left({ }^{\star}\right) \mathrm{p} \leq 0,05{ }^{* \star}\right) \mathrm{p} \leq 0,01{ }^{* * *}\right) \mathrm{p} \leq 0,001$ FBS: Glucosa en ayunas; PPG: Glucosa postprandial; HbA1c: Hemoglobina glicosilada; HOMA - IR: Índice Homa; In: Insulina; OGTT: Prueba de tolerancia a la glucosa oral

MO: Moringa oleífera; MoWE: Extracto acuoso de MO; mome: Extracto metanólico de MO; MMAEO: Extracto etanólico de MO; STZ: Streptozotocina; CN:

Control negativo; CP: Control positivo; DM: Diabetes mellitus; NS: No significativo; Ø: No se midió 
Tabla 9 - E: Efecto de las hojas de Moringa oleífera sobre el control de la glucemia en las ratas diabéticas inducidas

\begin{tabular}{|c|c|c|c|c|c|c|c|c|c|c|c|}
\hline Referencia & $\begin{array}{l}\text { Características de } \\
\text { la población }\end{array}$ & $\begin{array}{l}\text { Tamaño de } \\
\text { muestra }\end{array}$ & $\begin{array}{c}\text { Dosis y } \\
\text { duración del } \\
\text { tratamiento }\end{array}$ & Intervención & $\begin{array}{l}\text { Resultados } \\
\text { principales }\end{array}$ & $\begin{array}{l}F B \\
S\end{array}$ & $P P G$ & HbA1c & $\begin{array}{l}\text { HOMA } \\
-I R\end{array}$ & In & OGTT \\
\hline $\begin{array}{l}\text { El-Desouki } \\
\mathrm{NI} \text {, et al. } \\
(2015)\end{array}$ & $\begin{array}{l}\text { Ratas Sprague } \\
\text { Dawley albinas } \\
\text { Machos } \\
\text { P: } 99 \mathrm{~g} \mathrm{Aprox} \\
\text { Inducción a la DM: } \\
150 \mathrm{mg} / \mathrm{kg} \text { de } \\
\text { monohidrato de } \\
\text { aloxano }\end{array}$ & $\begin{array}{c}\mathrm{N}=60 \\
\text { Adultas }\end{array}$ & $\begin{array}{l}200 \mathrm{mg} / \mathrm{kg} \text { de } \\
\mathrm{MoWE}(\mathrm{I}) \\
400 \mathrm{mg} / \mathrm{kg} \text { de } \\
\text { MoWE(II) } \\
30 \text { días }\end{array}$ & $\begin{array}{l}6 \text { grupos }(\mathrm{n}=10) \\
\text { G1: control normal + agua } \\
\text { destilada } 0.1 \mathrm{ml} \\
\text { G2: Control + MoWE(I) } \\
\text { G3: Control + MoWE(II) } \\
\text { G4: DM } \\
\text { G5: DM + MoWE(I) } \\
\text { G6: DM + MoWE(II) }\end{array}$ & $\begin{array}{l}\text { El tratamiento } \\
\text { con MO en ratas } \\
\text { diabéticas con alta } \\
\text { dosis causó } \\
\text { disminución altamente } \\
\text { significativa del valor de } \\
\text { glucosa en sangre (- } \\
76,57 \%) \text { en } \\
\text { comparación al grupo } \\
\text { diabético. }\end{array}$ & $f^{*}$ & $\varnothing$ & $\varnothing$ & $\varnothing$ & $\mathbf{A}^{*}$ & $\varnothing$ \\
\hline $\begin{array}{l}\text { Amin AY, et } \\
\text { al. (2016) }\end{array}$ & $\begin{array}{l}\text { Ratas Wistar Strain } \\
\text { albinas } \\
\text { Machos } \\
\text { P: } 200 \mathrm{~g} \\
\text { Inducción a la } \\
\text { DM:150 mg / kg de } \\
\text { monohidrato de } \\
\text { aloxano }\end{array}$ & $\begin{array}{c}\mathrm{N}=49 \\
\text { Adultas }\end{array}$ & $\begin{array}{l}100 \mathrm{mg} / \mathrm{kg} \text { de } \\
\text { MoWE (I) } \\
200 \mathrm{mg} / \mathrm{kg} \text { de } \\
\text { MoWE (II) } \\
300 \mathrm{mg} / \mathrm{kg} \text { de } \\
\text { MoWE (III) } \\
400 \mathrm{mg} / \mathrm{kg} \text { de } \\
\text { MoWE (IV) } \\
4 \text { Sem }\end{array}$ & $\begin{array}{l}7 \text { grupos }(n=7) \\
\text { G1: control normal } \\
\text { G2: control + MoWE (I) } \\
\text { G3: DM } \\
\text { G4: DM + MoWE (I) } \\
\text { G5: DM + MoWE (II) } \\
\text { G6: DM + MoWE (III) } \\
\text { G7: DM + MoWE (IV) }\end{array}$ & $\begin{array}{l}\text { El tratamiento con MO } \\
\text { dejo una considerable } \\
\text { reducción en los } \\
\text { niveles de glucosa en } \\
\text { ratas diabéticas } \\
\text { inducidas }(p<0,05) \text {. } \\
\text { Una actividad } \\
\text { dependiente de la } \\
\text { dosis. }\end{array}$ & $\downarrow^{*}$ & $\varnothing$ & $\varnothing$ & $\varnothing$ & $\varnothing$ & $\varnothing$ \\
\hline $\begin{array}{l}\text { Omodanisi } \\
\text { El, et al. } \\
\text { (2017) }\end{array}$ & $\begin{array}{l}\text { Ratas Wistar } \\
\text { Machos } \\
\text { P: } 200 \text { - } 250 \mathrm{~g} \\
\text { Inducción a la DM: } \\
55 \mathrm{mg} \text { / kg de STZ }\end{array}$ & $\begin{array}{c}\mathrm{N}=48 \\
\text { Edad } \\
10 \mathrm{a}+ \\
\text { Semanas }\end{array}$ & $\begin{array}{l}250 \mathrm{mg} / \mathrm{kg} \text { de } \\
\text { extracto } \\
\text { metanólico de } \\
\text { MO } \\
6 \text { Sem }\end{array}$ & $\begin{array}{l}4 \text { grupos }(n=12) \\
\text { G1: control normal no } \\
\text { tratado }(N C) \\
\text { G2: } N C+M O \\
\text { G3: Grupo diabético (DM) } \\
\text { G4: DM + MO }\end{array}$ & $\begin{array}{l}\text { El tratamiento de ratas } \\
\text { con MO mostró una } \\
\text { disminución } \\
\text { significativa del nivel de } \\
\text { glucosa en } \\
\text { comparación con el } \\
\text { control diabético. }\end{array}$ & $\downarrow^{*}$ & $\varnothing$ & $\varnothing$ & $\varnothing$ & $\varnothing$ & $\varnothing$ \\
\hline
\end{tabular}

$\left({ }^{*}\right) p \leq 0,05\left(^{* *}\right) p \leq 0,01\left(^{* * *}\right) p \leq 0,001$ FBS: Glucosa en ayunas; PPG: Glucosa postprandial; HbA1c: Hemoglobina glicosilada; HOMA - IR: Índice Homa; In: Insulina; OGTT: Prueba de tolerancia a la glucosa oral

MO: Moringa oleífera; MoWE: Extracto acuoso de MO; mome: Extracto metanólico de MO; MMAEO: Extracto etanólico de MO; STZ: Streptozotocina; CN:

Control negativo; CP: Control positivo; DM: Diabetes mellitus; NS: No significativo; Ø: No se midió 
Tabla 9 - F: Efecto de las hojas de Moringa oleífera sobre el control de la glucemia en las ratas diabéticas inducidas

\begin{tabular}{|c|c|c|c|c|c|c|c|c|c|c|c|}
\hline Referencia & $\begin{array}{l}\text { Características de } \\
\text { la población }\end{array}$ & $\begin{array}{c}\text { Tamaño de } \\
\text { muestra }\end{array}$ & $\begin{array}{c}\text { Dosis y } \\
\text { duración del } \\
\text { tratamiento }\end{array}$ & Intervención & $\begin{array}{l}\text { Resultados } \\
\text { principales }\end{array}$ & $\begin{array}{l}F B \\
S\end{array}$ & $P P G$ & HbA1c & $\begin{array}{c}\text { HOMA } \\
- \text { IR }\end{array}$ & In & OGTT \\
\hline $\begin{array}{l}\text { Olayaki LA, } \\
\text { et al. (2015) }\end{array}$ & $\begin{array}{l}\text { Ratas Wistar } \\
\text { Machos } \\
\text { P: } 150 \text { - } 180 \mathrm{~g} \\
\text { Inducción a la DM: } \\
120 \mathrm{mg} / \mathrm{kg} \text { de } \\
\text { monohidrato de } \\
\text { aloxano }\end{array}$ & $\mathrm{N}=25$ & $\begin{array}{l}300 \mathrm{mg} / \mathrm{kg} \text { de } \\
\mathrm{mome}(\mathrm{I}) \\
600 \mathrm{mg} / \mathrm{kg} \text { de } \\
\mathrm{mome}(\mathrm{II}) \\
6 \mathrm{Sem}\end{array}$ & $\begin{array}{l}5 \text { grupos }(\mathrm{n}=5) \\
\text { G1: control no diabético } \\
\text { G2: DM } \\
\text { G3: DM + mome (I) } \\
\text { G4: DM + mome (II) } \\
\text { G5: DM + metformina } 100 \\
\text { mg / kg }\end{array}$ & $\begin{array}{l}\text { La administración de } \\
\text { mome produjo la } \\
\text { disminución de la } \\
\text { concentración de } \\
\text { glucosa en sangre en } \\
\text { un } 76 \%(p<0,001) \text { y } \\
84 \%(p<0,001) \text { a } 300 \text { y } \\
600 \mathrm{mg} / \mathrm{kg} \text {, } \\
\text { respectivamente. }\end{array}$ & $\downarrow^{* * *}$ & $\varnothing$ & $\varnothing$ & $\varnothing$ & $\boldsymbol{\varphi}^{* *}$ & $\perp^{* *}$ \\
\hline $\begin{array}{l}\text { Adepoju- } \\
\text { Bello AA, et } \\
\text { al. (2017) }\end{array}$ & $\begin{array}{l}\text { Ratas Wistar } \\
\text { Machos } \\
\text { P: aprox } 100 \mathrm{~g} \\
\text { Inducción a la DM: } \\
150 \mathrm{mg} / \mathrm{kg} \text { de } \\
\text { monohidrato de } \\
\text { aloxano }\end{array}$ & $\begin{array}{c}\mathrm{N}=48 \\
\text { Edad } \\
12 \text { semanas }\end{array}$ & $\begin{array}{l}300 \mathrm{mg} / \mathrm{kg} \text { de } \\
\mathrm{MoWE} \\
200 \mathrm{mg} / \mathrm{kg} \text { de } \\
\mathrm{mome} \\
300 \mathrm{mg} / \mathrm{kg} \text { de } \\
\mathrm{mome} \\
200 \mathrm{mg} / \mathrm{kg} \text { de } \\
\mathrm{MMAEO} \\
300 \mathrm{mg} / \mathrm{kg} \text { de } \\
\mathrm{MMAEO} \\
400 \mathrm{mg} / \mathrm{kg} \text { de } \\
\text { MMAEO } \\
24 \text { días }\end{array}$ & $\begin{array}{l}10 \text { grupos }(\mathrm{n}=4 \text { a 5) } \\
\text { G1: CN; G2:DM; G3:DM + } \\
\text { metformina (21,4 mg/kg; } \\
\text { G4:DM + MoWE; } \\
\text { G5: DM + mome; G6: DM } \\
\text { + mome; G7: DM + mome; } \\
\text { G8: DM + MMAEO; G9: } \\
\text { DM + MMAEO; G10: DM + } \\
\text { MMAEO }\end{array}$ & $\begin{array}{l}\text { El disolvente etanólico } \\
\text { de } 50 \%(300 \mathrm{mg} / \mathrm{kg}) \\
\text { (disminución } 83,72 \%) \\
\text { dio mejor efecto } \\
\text { hipoglicemiante que se } \\
\text { compara } \\
\text { favorablemente con } \\
\text { metformina }(84,14 \%) \text {, }\end{array}$ & $\downarrow^{* * *}$ & $\varnothing$ & $\varnothing$ & $\varnothing$ & $\varnothing$ & $\varnothing$ \\
\hline $\begin{array}{l}\text { Idakwoji PA, } \\
\text { et al. (2015) }\end{array}$ & $\begin{array}{l}\text { Ratas Wistar } \\
\text { Ambos sexos } \\
\text { P: } 100-150 \mathrm{~g} \\
\text { Inducción a la DM: } \\
150 \mathrm{mg} / \mathrm{kg} \text { de } \\
\text { monohidrato de } \\
\text { aloxano }\end{array}$ & $\mathrm{N}=54$ & $\begin{array}{l}375 \mathrm{mg} / \mathrm{kg} \text { de } \\
\text { MMAEO(I) } \\
750 \mathrm{mg} / \mathrm{kg} \text { de } \\
\text { MMAEO(II) } \\
1500 \mathrm{mg} / \mathrm{kg} \text { de } \\
\text { MMAEO(III) } \\
28 \text { días }\end{array}$ & $\begin{array}{l}9 \text { grupos }(\mathrm{n}=6) \\
\text { Grupos I: control } \\
\text { normoglucémicos; Grupo I: } \\
\text { DM; Grupo III: DM + } \\
\text { MMAEO(I); Grupo IV: DM } \\
\text { + MMAEO(II) } \\
\text { Grupo V:DM+ MMAEO(III); } \\
\text { Grupo VI: DM + } 150 \text { mg / } \\
\text { kg de metformina } \\
\text { +MMAEO(I); Grupo VII:DM } \\
\text { +150 mg / kg de } \\
\text { metformina + MMAEO(II); } \\
\text { Grupo VIII: DM+ } 150 \text { mg / } \\
\text { kg de metformina + } \\
\text { MMAEO(III); Grupo IX } \\
\text { ratas: DM + } 150 \text { mg / kg de } \\
\text { metformina }\end{array}$ & $\begin{array}{l}\text { MMAEO (1500 mg / kg) } \\
\text { produjo una reducción } \\
\text { significativa } \\
\text { dependiente de la dosis } \\
\text { en el FBS en el día } 7(p \\
<0,05) \text {, días } 14,21 \text { y } 28 \\
(p<0,01), \\
\text { respectivamente. }\end{array}$ & $\downarrow^{* *}$ & $\varnothing$ & $\varnothing$ & $\varnothing$ & $\varnothing$ & $\varnothing$ \\
\hline
\end{tabular}

$\left.\left(^{*}\right) p \leq 0,05\left(^{* *}\right) p \leq 0,01{ }^{* * *}\right) p \leq 0,001$ FBS: Glucosa en ayunas; PPG: Glucosa postprandial; HbA1c: Hemoglobina glicosilada; HOMA - IR: Índice Homa; In: Insulina; OGTT: Prueba de tolerancia a la glucosa oral; MO: Moringa oleífera; MoWE: Extracto acuoso de MO; mome: Extracto metanólico de MO; MMAEO: Extracto etanólico de MO; STZ: Streptozotocina 


\section{Efecto de las hojas de Moringa oleífera sobre el control de la glucemia en las ratas diabéticas inducidas}

Villarruel-López A, et al. (2018) evaluó el efecto del consumo de Moringa oleífera en ratas diabéticas, en 30 ratas Sprague Dawley (180 - 200g), inducidas por monohidrato de aloxano. Administraron a los animales $50 \mathrm{mg} /$ día de polvo de hojas de $\mathrm{MO}$ por un periodo de 8 semanas y se dividieron en 5 grupos; G1: Grupo control, G2: Grupo sano con MO, G3: Grupo diabético, G3: Grupo diabético, G4: Grupo diabético con MO y G5: Grupo diabético con glibenclamida $600 \mu / \mathrm{kg} /$ día. Finalmente, se obtuvo la disminución significativa $(p<0,05)$ de los niveles de glucosa en sangre en el grupo diabético tratado con MO cuando se compara con el grupo diabético no tratado ${ }^{(177)}$.

Omabe M. et al. (2014) realizaron un estudio donde evaluó el potencial antidiabético y la toxicidad del extracto etanólico de MO en ratas diabéticas inducidas por aloxano. Se contó con una población de 15 ratas Wistar albinas (130 - 200g), divididas en 3 grupos; G1: Grupo control diabético, G2: Grupo diabético con Extracto etanólico MO, G3: Grupo diabético con metformina $10 \mathrm{mg} / \mathrm{kg}$. El grupo de prueba se trató con $200 \mathrm{mg} / \mathrm{kg}$ de extracto etanolico de MO (mañana y tarde) durante 5 días. Teniendo como resultado, el nivel de glucosa en sangre de ratas diabéticas tratadas con el extracto redujo significativamente por 3 veces ( $p$ $<0,001$ ) en comparación con el nivel de glucosa en sangre del grupo diabético no tratado $^{(178)}$.

Otro estudio, donde se utilizó el extracto etanólico de $\mathrm{MO}$ en ratas, fue el realizado por Irfan, HM, et al. (2016), donde se evaluó el efecto del extracto etanólico de hojas de MO en el peso y la hiperglucemia en ratas diabéticas inducidas por estreptozotocina (STZ), el estudio fue realizado en ratas Sprague Dawley (170 - 200g),a los cuales se les administró diferentes dosis del extracto a la muestra de 36 ratas divididas en 6 grupos; G1: diabético con placebo, G2: diabético con metformina $500 \mathrm{mg} / \mathrm{kg}$, G3: diabético con $1000 \mathrm{mg} / \mathrm{kg}$ de extracto MO,G4: diabético con $500 \mathrm{mg} / \mathrm{kg}$ de extracto de MO,G5: diabético con $250 \mathrm{mg} / \mathrm{kg}$, G6: diabético con $125 \mathrm{mg} / \mathrm{kg}$. El periodo de estudio fue por 14 días; se evaluó el efecto agudo $(0,3,5$, y $7 \mathrm{~h})$ y crónico en la glucosa $(0,7$ y 14$)$. Al final del estudio se observó en el grupo tratado con $1000 \mathrm{mg} / \mathrm{kg}$ dosis mostró una reducción del 16\%, mientras que la metformina se mantuvo en el 54,95\% después de $7 \mathrm{~h}$. En relación al tratamiento sub crónico el extracto etanólico de $\mathrm{MO}$ redujo significativamente $(p<0,001)$ la concentración de glucosa en sangre en ayunas en los días 7 y 14. La reducción máxima en la concentración 
de glucosa fue del 53,44\% con una dosis de $1000 \mathrm{mg} / \mathrm{kg}$, la caída de la glucosa no se observó en el caso de un tratamiento con 125 mg / kg incluso el día $14{ }^{(179)}$.

Igualmente, Irfan, HM, et al. (2017), realizaron una investigación, donde utilizaron el extracto etanólico de $\mathrm{MO}$; asimismo, en el estudio, utilizaron cinco extractos de etanol acuoso $(95,75,50,25$, v/v y $100 \%$ de agua) que se aplicaron por vía oral a 42 ratas Sprague Dawley albinas (230gr aprox) inducidas con estreptozotocina (STZ) por 14 días. Se dividió la muestra en 7 grupos: G1: diabético con placebo, G2: diabético con metformina $500 \mathrm{mg} /$ kg, G3: diabético con $1000 \mathrm{mg} / \mathrm{kg}$ de extracto (95\%), G4: diabético con $1000 \mathrm{mg} / \mathrm{kg}$ de extracto (75\%), G5: diabético con $1000 \mathrm{mg} / \mathrm{kg}$ de extracto (50\%), G6: diabético con 1000 $\mathrm{mg} / \mathrm{kg}$ de extracto (25\%),G7: diabético con $1000 \mathrm{mg} / \mathrm{kg}$ de extracto (100\%). Se evaluó el efecto agudo y sub crónico de la hiperglucemia similar al estudio anterior y se pudo observar que 7 horas después de la administración, los extractos de etanol 95 y $75 \%$ (v / v) bajaron el nivel de glucemia basal por 30,28 y 18,05\%, respectivamente. Los extractos de etanol 50 y $25 \%$ ( $/ \mathrm{v}$ ) no reducen notablemente el nivel de glucosa basal, mientras que el extracto acuoso bajó el nivel de la glucemia de manera significativa a solamente $1 \mathrm{~h}$ después de la administración $(p<0,05)$. La evaluación del tratamiento sub crónico se obtuvo la reducción significativa $(p<0,001)$ de los niveles de glucosa en ayunas con el tratamiento del extracto de etanol $(95,75,50$, y $25 \%[\mathrm{v} / \mathrm{v}])$, el extracto acuoso y metformina en los días 7 y 14 del estudio. De todos los extractos, el extracto de etanol (95\%) fue el más activo en la reducción de glucosa en comparación con el control ${ }^{(137)}$.

Bamagous GA, et al. (2018), analizaron la actividad antidiabética de la fracción del extracto de acetato de etilo de Moringa oleífera en ratas diabéticas albinas inducidas con estreptozotocina (STZ) por 30 días. Las ratas eran de la especie Sprague Dawley (200 a $250 \mathrm{~g}$ ), participaron 24 ratas en el estudio y la muestra se dividió en 4 grupos: G1: controles normales, G2: control diabético, G3: Grupo diabético con $200 \mathrm{mg} / \mathrm{kg}$ de fracción del extracto de acetato de etilo de hojas de MO, G4: control positivo STZ con Glibenclamida $5 \mathrm{mg} / \mathrm{Kg}$. Se midieron los niveles de hemoglobina glicosilada, glucosa en ayunas e insulina en sangre. Al final del estudio, los niveles de hemoglobina glicosilada se elevaron significativamente en el grupo 2 en comparación con el grupo $1(p<0,05)$. En contraste, los niveles de hemoglobina glicosilada y glucosa en sangre se redujeron significativamente ( $p$ $<0,05)$ hacia los niveles normales en el grupo 3 y grupo 4 en los animales. Sorprendentemente los niveles de insulina en suero aumentaron en el grupo 3 y 4 comparado con el grupo 2 en ratas $(p<0,05)^{(180)}$. 
En otro estudio, realizado por Abd Eldaim MA, et al. (2018), evaluaron el efecto del extracto acuoso de las hojas de Moringa oleífera sobre los niveles de glucosa en ayunas en ratas diabéticas inducidas por monohidrato de aloxano. La población constó de 80 ratas Wistar albinas divididas en 4 grupos: G1: Grupo control con placebo (SS), G2: Grupo diabético sin tratamiento, G3: Grupo sano con $250 \mathrm{mg} / \mathrm{kg}$ de extracto acuoso de MO, G4: Grupo diabético con $250 \mathrm{mg} / \mathrm{kg}$ de extracto acuoso de MO. Se le administró 1 vez al día el extracto de $\mathrm{MO}$ y la duración del tratamiento fue 18 días. Al terminar el tratamiento, el grupo 3 no presentó cambios significativos en los niveles de glucosa cuando se comparó con el grupo $1(p<0,05)$, en contraste se pudo observar con el tratamiento del extracto acuoso de MO en las ratas diabéticas del cuarto grupo redujo significativamente el nivel de glucosa en sangre en comparación con el segundo grupo por cerca de 3,6 pliegues $(p<0,05)^{(181)}$.

Un estudio similar, al descrito anteriormente, fue realizado por Abd El Latif A, et al. (2014), investigaron como el extracto acuoso de las hojas de Moringa oleífera aminoran la hiperglicemia en ratas diabéticas inducidas por aloxano. Al igual que el estudio anterior la muestra de 20 ratas Wistar albinas se dividió en 4 grupos: G1: Grupo control con placebo (SS), G2: Grupo diabético se dejaron sin tratamiento, G3: Grupo sano con 250 mg/ kg de extracto acuoso de MO, G4: Grupo diabético con $250 \mathrm{mg} / \mathrm{kg}$ de extracto acuoso de MO, se administró por vía oral durante 18 días. Luego del periodo de estudio, la administración oral del extracto acuoso de MO en ratas diabéticas (grupo 4) normalizaron los niveles séricos de glucosa elevados $(p<0,05)^{(38)}$.

Yassa HD, et al. (2014) realizaron un estudio con el objetivo de evaluar el posible efecto antidiabético del extracto acuoso de hojas de Moringa oleífera en ratas diabéticas inducidas por estreptozotocina (STZ), se realizó el estudio en ratas Sprague Dawley albinas (180 200g). La muestra estuvo conformada por 50 ratas divididas 4 grupos: el Grupo 1 recibió dieta estándar solamente, Grupo 2: recibió extracto acuoso de MO (200 mg / kg) durante 8 semanas y sirvió como control simulado, Grupo 3: diabético inducido por STZ, el Grupo 4: diabético inducido por STZ se le administró mediante intubación gástrica el extracto acuoso de $\mathrm{MO}(200 \mathrm{mg} / \mathrm{kg})$. El extracto se administra una vez al día en un momento fijo para todo el período de ocho semanas del experimento. Al terminar el estudio, se obtuvo una disminución significativa en los niveles de glucosa plasmática en ayunas en el grupo diabético tratado con el extracto acuosos de $\mathrm{MO}(\mathrm{p}<0,05)$, mientras que el grupo diabético inducido por STZ sin tratamiento mostró un aumento significativo ocho semanas después de la inyección de STZ $(p<0,05)^{(28)}$. 
Oyedepo TA, et al. (2014), evaluaron el efecto del extracto acuoso de las hojas de Moringa oleífera sobre el nivel de glucosa en plasma en ratas Wistar albinas (160 - 200g) inducidas por monohidrato de aloxano. La muestra estuvo formada por 24 ratas albinas a quienes se les indujo diabetes por una sola inyección intraperitoneal de $100 \mathrm{mg} / \mathrm{kg}$ de aloxano monohidrato obtenido de Sigma Chemical Co. (St. Louis, MO, EE.UU.), después de $72 \mathrm{~h}$ de la inducción; las ratas, con la glucosa en plasma nivel $\geq 200 \mathrm{mg} / \mathrm{dl}$, se separaron y se utilizan como grupo diabético en este estudio. Las ratas se distribuyeron aleatoriamente en tres grupos de ocho ratas cada uno: Grupo A: normal y recibieron agua destilada (control normal), Grupo B: diabética y recibió agua destilada (Diabetic Control), Grupo C: diabéticos tratados con $400 \mathrm{mg} / \mathrm{kg}$ de extracto acuoso MO (Diabetic con Extracto). Las ratas se trataron durante 28 días. Al final del período experimental, la dosis diaria de $400 \mathrm{mg} / \mathrm{kg}$ de peso corporal del extracto acuoso de $\mathrm{MO}$ administrada al grupo $\mathrm{C}$, dio lugar a la disminución significativa $(p<0,01)$ en la hiperglucemia comparándolo con el grupo control diabético ${ }^{(182)}$.

Divi SM, et al. (2012), evaluaron el potencial antidiabético y antihiperlipidémico del extracto acuoso de Moringa oleífera en modelos de ratas Wistar albinas resistentes a la insulina (IR) y tipo 1 inducidas por estreptozotocina (STZ). Aproximadamente veintidós ratas se hicieron diabéticas mediante una inyección intraperitoneal de estreptozotocina (STZ) recién preparada en tampón de citrato 0,05 M PH 4.5, a una dosis de $55 \mathrm{mg} / \mathrm{kg}$ de peso corporal. La muestra estuvo conformada por 54 ratas divididas en seis grupos: Grupo 1: control con agua destilada, Grupo 2: control con extracto acuoso de MO (200mg/kg), Grupo 3: se administró una dieta alta en Fructosa más agua destilada, Grupo 4: Fructosa con extracto de hojas de $\mathrm{MO}(200 \mathrm{mg} / \mathrm{kg})$, Grupo 5: diabético con agua destilada y el Grupo 6: diabético con extracto de hojas de MO $(200 \mathrm{mg} / \mathrm{kg})$. El extracto se administró a una dosis de $200 \mathrm{mg}$ / kg de peso corporal por intubación oral durante un período de 60 días. Al final del período experimental la administración de $\mathrm{MO}$ evidencio un efecto antihiperglucemico en el grupo $\mathrm{F}+\mathrm{MO}$ y solo un aumento del $23.22 \%$ en $\mathrm{D}+\mathrm{MO}$ en comparación con el grupo control. En el estudio, los niveles de insulina fueron significativamente mayores $(109,6 \%)$ en el grupo diabético con MO que grupo diabético sin tratamiento. Sin embargo, la recuperación fue parcial como los niveles de insulina en $F+M O$ y $D+M O$ no llegaron alcanzar los niveles del grupo control. Según la prueba Índice HOMA se obtuvo una mejora de la sensibilidad a la insulina tanto en los grupos $\mathrm{F}+\mathrm{MO}$ y $\mathrm{D}+\mathrm{MO}$ como fue evidente a partir de $91,3 \%$ y el $355 \%$ de recuperación de HOMA en $F+M O$ y los grupos D + MO respectivamente $(p<0,05)$. Al finalizar, el estudio se procedió a realizar la prueba de tolerancia oral a la glucosa y se obtuvo como resultado el mayor valor de la glucosa a los 
60 minutos después de la administración de la solución que fue significativamente mayor en los grupos $\mathrm{F}$ y $\mathrm{D}$ en comparación con $\mathrm{C}$. Los grupos $\mathrm{F}+\mathrm{MO}$ y $\mathrm{D}+\mathrm{MO}$ mostraron una mejor tolerancia a la glucosa $(p<0,05)$ frente a los grupos $F$ y $D^{(183)}$.

Un estudio realizado por Jaiswal D., et al. (2009), analizaron el efecto del extracto acuoso de las hojas de Moringa oleífera como terapia en ratas Wistar albinas hiperglucémicas inducidas por estreptozotocina (STZ), la muestra de 18 ratas Wistar fue dividida en tres grupos de seis ratas cada uno, el tratamiento con $200 \mathrm{mg} / \mathrm{kg}$ de extracto acuoso de hojas de Moringa oleífera duro 21 días. El grupo 1 sirvió como control diabético recibido del vehículo (agua destilada), mientras que los grupos 2 y 3 se trataron con una dosis única de $200 \mathrm{mg} / \mathrm{kg}$ de extracto de MO y $2.5 \mathrm{mg} / \mathrm{kg}$ de Glipizide respectivamente. Después de los 21 días que duró el tratamiento, se observó la caída de la glucosa después de 7,14 y 21 días de tratamiento con la dosis de $200 \mathrm{mg} / \mathrm{kg}$ del extracto de MO fue de 25,9, 53,5, 69,2\% en FBG y $21,4,37,8,51,2 \%$ en niveles de PPG respectivamente $(p<0,01)^{(8)}$.

Khan W, et al. (2017) estudiaron el potencial hipoglucemiante del extracto acuoso de las hojas de Moringa oleífera en ratas Wistar inducidas por estreptozotocina (STZ). Se evaluó el efecto agudo y crónico después de la administración del extracto en ratas normales y diabéticas. La duración del tratamiento fue tres semanas y la muestra estuvo conformada por 30 ratas divididas en cinco grupos de seis ratas cada uno: Grupo 1 recibió solución salina normal, Grupo 2: recibió extracto acuoso de $\mathrm{MO}(100 \mathrm{mg} / \mathrm{kg})$ durante 3 semanas y sirvió como control simulado, Grupo 3: diabético sin tratamiento, Grupo 4: diabético y recibió extracto acuoso de $\mathrm{MO}(100 \mathrm{mg} / \mathrm{kg}$ ), Grupo 5 recibió metformina (42 mg / kg) y sirvió como control positivo. El efecto agudo del consumo del extracto acuoso de $\mathrm{MO}$ en la glucosa en ayunas de ratas inducidas por STZ y normales mostró una caída máxima de $53,2 \%$ en la glucosa en ayunas después de $4 \mathrm{~h}$ de la administración oral, mientras que la caída de 40,1,45,6, y 41,7\% se observó después de 3, 6, y 8 h, respectivamente en el día 1 y el día 2. En las ratas diabéticas, el tratamiento con $\mathrm{MO}$ y metformina tuvieron una actividad hipoglucemiante dependiente de tiempo. El efecto crónico del consumo de extracto acuoso de MO disminuyó significativamente la glucosa en ayunas en el grupo inducido por STZ $(p<0,05)^{(184)}$. 
El-Desouki NI, et al. (2015) estudiaron el efecto del extracto acuoso de las hojas de Moringa oleífera sobre los niveles de glucosa en sangre e insulina en ratas Sprague Dawley albinas inducidas por monohidrato de aloxano a la diabetes. Se midieron los niveles de glucosa en sangre, y el nivel de glucosa $>250 \mathrm{mg} / \mathrm{dl}$ fue lo aceptado para ser diabético. En este estudio se utilizó dos tipos de dosis; dosis baja, la cual estuvo representada por $200 \mathrm{mg} / \mathrm{kg}$ y dosis alta de $400 \mathrm{mg} / \mathrm{kg}$ del extracto acuoso de MO. Las 60 ratas diabéticas se dividieron en seis grupos de diez cada uno: Grupo 1: control más agua destilada, Grupo 2: control con dosis baja de $\mathrm{MO}(200 \mathrm{mg} / \mathrm{kg})$ durante 30 días, Grupo 3: control con dosis alta de $\mathrm{MO}(400 \mathrm{mg} / \mathrm{kg})$ durante 30 días, Grupo 4: ratas diabéticas sin tratamiento, Grupo 5: diabético con dosis baja de MO $(200 \mathrm{mg} / \mathrm{kg})$ durante 30 días, Grupo 6: diabético con dosis alta de MO $(200 \mathrm{mg} / \mathrm{kg})$ durante 30 días. Después de los primeros 7 días de tratamiento con alta dosis de extracto acuoso de MO en ratas diabéticas, causó una disminución significativa del valor de glucosa en sangre $(377,5 \pm 53,5 \mathrm{mg} / \mathrm{I})$ con diferencia $(-23,98 \%)$ que el tratamiento con dosis baja de moringa (437,3 $\pm 29,72 \mathrm{mg} / \mathrm{I})$ con diferencia $(-11,9 \%)$ en comparación con el valor correspondiente de las ratas diabéticas al $(p=0,05)$. Al final del experimento, el tratamiento con altas dosis del extracto de $\mathrm{MO}$ en ratas diabéticas causo una disminución significativa del valor de glucosa en sangre (118 $\pm 1,00 \mathrm{mg} / \mathrm{l}) \mathrm{con}$ diferencia $(-76,57 \%)$ que el tratamiento con dosis baja de moringa $(124,8 \pm 2,48 \mathrm{mg} / \mathrm{I}) \mathrm{con}$ diferencia $(-75,22 \%)$ en comparación con el valor correspondiente de las ratas diabéticas al $(p=0.05)$. Se pudo observar al término del tratamiento a ratas diabética con alta dosis del extracto de $\mathrm{MO}$ el aumento significativo del valor de insulina $(13,74 \pm .38 \mathrm{mg} / \mathrm{I}) \mathrm{con}$ diferencia $(42,67 \%)$ que el tratamiento con dosis baja de moringa $(12,20 \pm 0,69 \mathrm{mg} / \mathrm{l})$ causó una ligero aumento en el valor de insulina con diferencia $(30,34 \%)$ en comparación con el valor correspondiente de las ratas diabéticas $(p<0,05)^{(185)}$

Un estudio similar, realizado por Amin AY, et al. (2016), utilizaron varias dosis del extracto acuoso de Moringa oleífera para evaluar sus propiedades terapéuticas en ratas Wistar albinas diabéticas inducidas por monohidrato de aloxano. Las 60 ratas diabéticas se dividieron en siete grupos de siete cada uno: El grupo 1: control recibió solamente una dieta basal, Grupo 2: control recibió el extracto acuoso de MO (100mg/kg), Grupo 3: ratas diabéticas sin tratamiento, Grupo 4: ratas diabéticas recibió extracto acuoso de MO (100mg/kg), Grupo 5:diabético recibió extracto acuoso de MO (200mg/kg), Grupo 6: diabético recibió extracto acuoso de MO $(300 \mathrm{mg} / \mathrm{kg})$, Grupo 7: diabético recibió extracto acuoso de $\mathrm{MO}(400 \mathrm{mg} / \mathrm{kg})$. Se administró, el extracto de MO, 3 veces a la semana durante 4 semanas utilizando un Sonda-aguja por el método sonda gástrica. Al finalizar, la intervención se obtuvo una reducción considerable $(p<0,05)$ en los niveles de glucosa en las ratas diabéticas inducidas por aloxano cuando fueron tratados con el extracto acuoso 
de MO. Además, se produjo la disminución de glucosa en sangre en ratas diabéticas inducidas por aloxano después de 6 horas de la administración con el extracto acuoso de MO a diferentes dosis $(100,200,300 \mathrm{mg} / \mathrm{kg}$ ) dio lugar a 40,69\%, 33,29\% y $44,06 \%$ disminución correspondiente ${ }^{(186)}$.

Omodanisi El, et al. (2017) evaluaron la actividad antihiperglucémica del extracto metanólico de las hojas de Moringa oleífera en ratas wistar macho nefrotóxicas inducidas a diabetes por estreptozotocina (STZ). La muestra estuvo conformada por 48 ratas albinas que se dividieron aleatoriamente en cuatro grupos doce cada uno: G1: control normal no tratado, G2: control normal recibió extracto metanólico de MO (250 mg / kg), G3: Grupo diabético sin tratamiento, G4: grupo diabético recibió extracto metanólico de MO $(250 \mathrm{mg} /$ $\mathrm{kg}$ ) y se administró a través de una sonda oral durante 6 semanas. Al término del estudio, se observó el aumento del nivel de glucosa en sangre en el grupo de diabéticos en comparación con el control normal. Por otro lado, los niveles de glucosa disminuyeron significativamente $(p<0,05)$ en el grupo de ratas diabéticas tratadas con el extracto metanólico de $\mathrm{MO}$ en comparación con los controles diabéticos ${ }^{(152)}$.

En otro estudio realizado por Olayaki LA, et al. (2015), se estudió los posibles efectos de los extractos metanólicos de Moringa oleífera en la tolerancia a la glucosa, la secreción de la insulina y la captación de glucosa en ratas diabéticas inducidas por monohidrato de aloxano. El estudio fue realizado en ratas Wistar macho (160 - 200g). La muestra estuvo conformada por 25 animales divididos en cinco grupos: G1: control no diabético, G2: diabético sin tratamiento, G3: diabético recibió dosis graduadas de extracto metanólico de MO (300 mg / kg), G4: diabético recibió extracto metanólico de MO (600mg / kg), G5: grupo diabético recibió metformina (100 $\mathrm{mg} / \mathrm{kg}$ ) por sonda oral. El tiempo de estudio fue 6 semanas; en el último día del experimento, se administró por vía intraperitoneal $25 \%$ de glucosa $(2 \mathrm{gr} / \mathrm{kg}$ ) para realizar la prueba de tolerancia oral a la glucosa. Al finalizar el estudio, el tratamiento con metformina mejoró significativamente la tolerancia a la glucosa en ratas diabéticas $(p<0,01)$, similar a los resultados mostrados con el tratamiento de 300 - $600 \mathrm{mg} / \mathrm{kg}$ de extracto metanólico de $\mathrm{MO}$, mejorando la tolerancia a la glucosa en un $56 \%$ y $57 \%$, respectivamente $(p<0,01)^{(39)}$.

Adepoju-Bello AA, et al. (2017) realizaron una investigación con el objetivo de evaluar la actividad antihiperglucemica de los extractos de las hojas de Moringa oleífera en ratas Wistar diabéticas inducidas por monohidrato de aloxano a la diabetes. Las 48 ratas diabéticas se dividieron en 10 grupos de 4 a 5 ratas por grupo: Grupo 1: Control negativo que recibió alimentación y agua solamente, Grupo 2: diabéticos no tratados, Grupo 3: diabéticos tratados con metformina $21,4 \mathrm{mg} / \mathrm{kg}$, Grupo 4 : diabéticos tratados con $300 \mathrm{mg}$ 
/kg de extracto acuoso de MO, Grupo 5: diabéticos tratados con $200 \mathrm{mg} / \mathrm{kg}$ de extracto metanólico de MO (50\% mome), Grupo 6: diabéticos tratados con 300 mg/kg de extracto metanólico de MO (50\% mome), Grupo 7: diabético tratados con 300 mg/kg de extracto metanólico de MO (100\% mome), Grupo 8: diabético tratados con 200 mg/ kg de extracto etanólico de MO (50\% MMAEO), Grupo 9: diabético tratados con $300 \mathrm{mg} / \mathrm{kg}$ de extracto etanólico de MO (MMAEO 50\%), Grupo 10: diabético tratados con $400 \mathrm{mg} / \mathrm{kg}$ de extracto etanólico de MO (100\% MMAEO). Los extractos se administraron por vía oral sobre la base de los pesos corporales, una vez al día durante 24 días. Se obtuvo al terminar el estudio la reducción significativa $(p<0,001)$ en los niveles de glucosa en sangre en las ratas diabéticas tratadas con el extracto acuoso de MO, pero a $300 \mathrm{mg} / \mathrm{kg}$. Sin embargo, se observó una mayor reducción de la glucosa con el disolvente etanólico e hidro-etanólica en sistemas de 50\% (disminución 83,72\%) y 100\% (disminución 82,42\%) (300 mg/ kg) ( p < 0,001). El extracto etanólico resultó tener un mejor efecto hipoglucemiante que se comparó favorablemente con la metformina $(84,14 \%)^{(187)}$.

Otro estudio realizado por Idakwoji PA, et al. (2015), se investigaron el efecto del extracto etanólico de Moringa oleífera sobre los niveles séricos de glucosa en ratas Wistar diabéticas inducidas por monohidrato de aloxano; además, este estudio evaluó el efecto de la coadministración de MO con metformina. El estudio estuvo conformado por 54 animales divididos en 9 grupos de 6 ratas cada uno: Grupos 1: control normoglucémicos, Grupo 2: control diabéticos Grupos 3: diabéticos recibieron extracto etanólico de MO (375 $\mathrm{mg} / \mathrm{kg}$ ), Grupo 4: diabéticos recibieron extracto etanólico de MO (750 mg/kg), Grupo 5: diabéticos recibieron extracto etanólico de MO (1500 mg/kg), Grupo 6: diabéticos recibieron $150 \mathrm{mg} / \mathrm{kg}$ de metformina con $375 \mathrm{mg} / \mathrm{kg}$ de extracto etanólico de MO, Grupo 7: diabéticos recibieron $150 \mathrm{mg} / \mathrm{kg}$ de metformina con $750 \mathrm{mg} / \mathrm{kg}$ de extracto etanólico de MO, Grupo 8: diabéticos recibieron $150 \mathrm{mg} / \mathrm{kg}$ de metformina con $1500 \mathrm{mg} / \mathrm{kg}$ de extracto etanólico de MO, Grupo 9: ratas diabéticas que recibieron solo $150 \mathrm{mg} / \mathrm{kg}$ de metformina durante 28 días. Al finalizar el tratamiento, el extracto etanólico de $\mathrm{MO}$ a dosis de $750 \mathrm{mg} / \mathrm{kg}$ produjo una reducción altamente significativa $(p<0,01)$ en los niveles de glucosa en ayunas durante los días 21 y 28 del tratamiento, mientras el extracto etanólico a dosis de $1500 \mathrm{mg} / \mathrm{kg}$ produjo una reducción significativa dependiente de la dosis sobre los niveles de glucosa en ayuna en el día 7 ( $p<0,05)$, días 14, 21 y 28 ( $p<0,01)$ respectivamente. Además, la coadministración del extracto etanólico de $\mathrm{MO}(375 \mathrm{mg} / \mathrm{kg}$ ) con metformina y la administración del extracto etanólico de MO $(750 \mathrm{mg} / \mathrm{kg}$ ) con metformina redujo significativamente los niveles de glucosa en ayunas para el día $7(p<0,05)$, días 14 y 21 ( $p$ $<0,01)$ y el día 28 ( $p<0,001)$, respectivamente, cuando se compara con el control diabético(188). 


\subsection{Discusión}

A partir de la búsqueda exhaustiva y la metodología rigurosa utilizada se identificaron estudios experimentales que establecieron la relación del tratamiento con las hojas de Moringa oleífera sobre la reducción en los niveles de glucemia en ratas diabéticas inducidas.

En un estudio realizado por Villarruel-López A. et al. (2018), donde se evaluó el efecto del polvo de las hojas de Moringa oleífera, se administraron $50 \mathrm{mg}$ diarios del polvo a las ratas diabéticas inducidas por aloxano durante 8 semanas, obteniéndose una reducción significativa $(P<0,05)$ en los niveles de glucosa en ayunas en el grupo diabético con tratamiento ${ }^{(177)}$. Similares hallazgos, se encontraron en un estudio realizado a 15 personas con obesidad y diabetes mellitus que recibieron $50 \mathrm{~g}$ de polvo de hojas secas de Moringa oleífera durante 60 días. Al finalizar, el tratamiento se evaluó la glucosa basal y postprandial en la población de estudio y, se observó que el porcentaje en los niveles de glucosa disminuyó 8,9\% (134,33 - 122,33 mg por $100 \mathrm{ml}$ de suero) siendo significativo ( $<<0,05)$. Los resultados obtenidos son favorables, aunque el tamaño de muestra no es significativa para poder generalizar el real beneficio del consumo de las hojas de MO para el tratamiento de la enfermedad crónica ${ }^{(11)}$. Un segundo estudio realizado a 32 pacientes diabéticos tipo 2 sin tratamiento (edad promedio: 55 a), recibieron $8 \mathrm{~g}$ por día de cápsulas de hojas de MO durante 4 semanas; al finalizar el estudio no se encontraron diferencias significativas en FBS y $\mathrm{HbA1c}$ entre los grupos, el diseño del estudio fue aleatorizado y controlado, presento una mejor calidad metodológica frente al estudio antes mencionado realizado en humanos (189). Un tercer estudio evaluó el efecto del consumo de cápsulas de hojas de Moringa oleífera en pacientes diabéticos sobre los niveles de HbA1c, la muestra estuvo conformada por 56 adultos (80\% mujeres) con edad promedio de 61,21 \pm 8,01 años, cada persona recibió 1 cápsula de $500 \mathrm{mg}$ tres veces al día durante 12 semanas y se observó que la media de pre-HgbA1c fue 6,96\% (IC 95\% 6,64-7,09) y se redujo a 6,06\% (IC 95\% 5,88$6,24)$ post HgbA1c. La reducción media del $0,6 \%$ fue significativo $(p<0,0001)^{(12)}$, similares a los resultados presentados en la revisión, aunque se necesita realizar más estudios en población humana para poder confirmar la eficacia del tratamiento con Moringa oleífera sobre el control de la glucemia en personas con diabetes mellitus.

Por otro lado, se encontraron resultados similares y favorecedores a la hipótesis del presente estudio, como se describe en una investigación realizada en ratones diabéticos que recibieron $150 \mathrm{mg} / \mathrm{kg}$ de extracto etanólico de MO durante 5 semanas (190), observándose al finalizar el tratamiento una reducción significativa en los niveles de 
glucosa en plasma (de 483 a $132 \mathrm{mg} / \mathrm{dl}$ ), y un aumento en los niveles de insulina de 946 92 a $1678-268 \mathrm{pg} / \mathrm{ml}$. Similares resultados se obtuvieron en el estudio realizado por Bamagous GA, et al. (2018), quienes evaluaron el efecto antidiabético de la fracción de acetato de etilo de las hojas de MO en ratas diabéticas inducidas por STZ y hallaron una reducción significativa en los niveles de glucosa en ayunas $(p<0,05)$ y un aumento significativo de insulina plasmática $(p<0,05)(180)$. Si comparamos este resultado con el estudio anterior realizado en ratones, podemos observar que la Moringa oleífera tiene un efecto favorable en el control de la glucemia en animales diabéticos inducidos.

En relación a la dosis administrada de los extractos de hojas de Moringa oleífera, en los estudios analizados, se encontraron investigaciones como la realizada por Khan W, et al. (2017), donde se evaluó el potencial hipoglucemiante del extracto acuoso de las hojas de MO en ratas Wistar inducidas por STZ, la dosis administrada fue $100 \mathrm{mg} / \mathrm{kg}$ del extracto de referencia, durante un periodo de 3 semanas y, finalmente, se obtuvo una disminución significativa en los niveles de glucosa en ayunas $(p<0,05)$ y hemoglobina glicosilada ( $p$ $<0,001$ ), al término del estudio, en el grupo diabético tratado con el extracto acuoso de $\mathrm{MO}^{(191)}$. Un segundo estudio utilizó la misma dosis de $\mathrm{MO}(100 \mathrm{mg} / \mathrm{kg})$ para la investigación en ratas Wistar diabéticas inducidas por monohidrato de aloxano durante 4 semanas. Se concluyó que el extracto de MO dio lugar a una reducción de 40,69\% en la concentración de glucosa en sangre después de 6 horas de la administración del extracto y al final del tratamiento $(p<0,05)^{(186)}$. De los estudios incluidos en la revisión se encontró una investigación que analizó el efecto del consumo de MO con grandes dosis del extracto, realizada por Idakwoji PA, et al. (2015), donde se administraron diferentes dosis del extracto etanlóico de las hojas de MO, siendo la mayor dosis administrada; $1500 \mathrm{mg} / \mathrm{kg}$ en ratas diabéticas inducidas por monohidrato de aloxano durante 28 días. Al final del estudio, se observó una reducción significativa dependiente de la dosis en el FBS en el día 7 ( $p$ $<0,05)$, días 14,21 y 28 ( $p<0,01)$ respectivamente ${ }^{(188)}$. Se analizaron estudios donde usaron desde pequeñas hasta grandes dosis del extracto de las hojas de MO para evaluar el efecto antihiperglucémico en ratas diabéticas inducidas, encontrando en la mayoría de los estudios incluidos en la revisión, la disminución significativa en los niveles de glucosa en sangre, esto demuestra que las hojas de MO tienen propiedades hipoglicemiantes. Además, se realizaron pruebas de toxicidad con la dosis ensayada de moringa oleífera y no mostraron ningún efecto adverso en los animales experimentales.

Por otro lado, la dosis más utilizada en la mayoría de los estudios ( $\mathrm{n}: 8 ; 45 \%$ ) fue $200 \mathrm{mg} / \mathrm{kg}$ de extracto de las hojas de MO en ratas diabéticas inducidas por aloxano o STZ, en todos los estudios donde se administraron la dosis antes mencionada desde el estudio más corto 
(5 días) hasta el de mayor duración (60 días). Se observó, al finalizar la investigación, la reducción significativa $(p<0,05)$ en los niveles de glucosa en ayunas, glucosa postprandial, hemoglobina glicosilada, mejora en la tolerancia a la glucosa y un aumento significativo en los niveles de insulina $(p<0,05)^{(28)(180)(186)(185)(8)(178)(187)(183) . ~ S e ~ o b s e r v a r o n ~ a l g u n o s ~ e s t u d i o s ~}$ que evaluaron el efecto crónico y agudo en respuesta al tratamiento con Moringa oleífera y se obtuvo también un descenso en los niveles de glucosa en sangre y mejora en la sensibilidad a la insulina en los animales diabéticos ${ }^{(179)(137)}$.

El estudio que obtuvo la mayor reducción glucémica fue el realizado por Olayaki L, et al. (2015), que evaluó el efecto hipoglucemiante de la MO y la mejora en la tolerancia a la glucosa en ratas Wistar, donde se administraron a un grupo de estudio dosis de $600 \mathrm{mg} / \mathrm{kg}$ de extracto metanólico de hojas de MO durante 6 semanas y se observó una disminución del $84 \%$ en los niveles de glucosa en ayunas $(p<0,001)$ y una reducción del $57 \%$ en OGTT mejorando significativamente la tolerancia a la glucosa ( $p<0,01)$; este estudio exhibió un

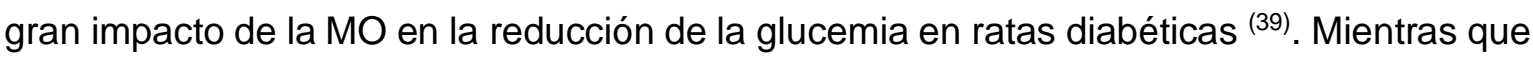
el estudio con la menor reducción en los niveles de glucosa fue el realizado por Omodanisi El, et al. (2017), que evaluó la actividad antihiperglucemica del extracto metanólico de las hojas de MO en ratas Wistar diabéticas inducidas por STZ. A los animales inducidos se les administró una dosis de $250 \mathrm{mg} / \mathrm{kg}$ del extracto metanólico de MO durante 6 semanas y al finalizar el tratamiento solo se obtuvo una reducción del 6,7\% en los niveles de glucosa en ayunas en comparación al grupo diabético sin tratamiento ${ }^{(152)}$. Este estudio fue el único que presentó la menor reducción de la glicemia en ratas diabéticas inducidas, por el contrario. En la mayoría de estudios analizados ( $n$ : 17), se mostró una reducción significativa en los niveles de glucemia del $33 \%$ hasta $84 \%$ en los animales diabéticos tratados con $\mathrm{MO}$.

El solvente de extracción que se utilizó en la mayoría de los estudios fue el agua al 100\% (n: 11) para obtener el extracto acuoso de las hojas de MO. También se utilizaron diferentes sistemas disolventes en otros estudios incluidos en la investigación como el metanol al $100 \%$, etanol al $100 \%$ etanol al $90 \%$, agua-metanol ${ }^{(50 / 50)}$, agua etanol ${ }^{(50 / 50)}$, acetato de etilo, etc. Hubo estudios que analizaron el impacto hipoglucemiante de una variedad de extractos de $\mathrm{MO}$ (dosis y sistemas disolvente) en ratas diabéticas inducidas, como el realizado por Adepoju-Bello AA, et al. (2017), donde menciona que el objetivo era evaluar el mejor sistema disolvente para las hojas de $\mathrm{MO}$ en la reducción de los niveles de glucemia en ratas diabéticas. Para fines del estudio, se utilizaron disolventes como el agua, etanol y metanol en diferentes porcentajes, el tiempo del estudio fueron 12 semanas. Al finalizar el estudio, se observó que el grupo de ratas diabéticas que recibieron $200 \mathrm{mg} / \mathrm{kg}$ al $50 \%$ de 
extracto metanólico mostraron la menor reducción $(66,34 \%)$ en la concentración de glucosa. Mientras que el grupo que recibió $300 \mathrm{mg} / \mathrm{kg}$ al $50 \%$ de extracto etanólico obtuvo una mayor reducción $(83,2 \%)$ en los niveles de glucosa, efectos que se compara favorablemente con metformina $(84,14 \%){ }^{(187)}$. Por lo tanto, se puede inferir de la investigación que el extracto hidro - metanólico (50: 50) no sería un disolvente de extracción eficaz, mientras que el extracto hidro - etanólico (50: 50) de MO exhibiría mejor efecto hipoglucemiante casi comparables con la metformina. Un segundo estudio realizado por Irfan Hafiz Muhammad et al. (2016) evaluó el efecto antidiabético de la actividad del extracto acuoso y etanólico (25,50,75 y 95\%) en ratas albinas diabéticas inducidas por STZ durante 14 días. Al término del estudio, se observó una mayor reducción de la glucemia en las ratas diabéticas que fueron administradas con el extracto etanólico (1000 mg/kg) al 95\% $(p<0,001)$; según el autor, pudiera ser atribuible al ácido criptoclorogenico, quercetina 3- $\beta$ D-glucósido, y kaempferol-3-O-glucósido presentes en el extracto etanolico de la $\mathrm{MO}^{(137)}$. En ambos estudios el disolvente que mostró tener una mejor actividad hipoglucemiante fue el etanol al $50 \%$ y $95 \%$ para las hojas de $\mathrm{MO}$, sin embargo, se necesita realizar más investigaciones donde se compare la actividad hipoglucemiante de los diferentes extractos de MO para poder confirmar el sistema disolvente más eficaz en el tratamiento de ratas diabéticas inducidas.

En relación al tiempo del tratamiento con las hojas de $\mathrm{MO}$, los estudios presentados tuvieron tiempos de tratamiento variables que fueron desde 5 días hasta 60 días. En todos los estudios, se observó una reducción significativa en los niveles de glucosa en sangre; sin embargo, en la mayoría se estableció una relación de la actividad hipoglucemiante significativa dependiente con el tiempo de tratamiento. Se refleja claramente lo encontrado con el estudio realizado por Irfan HM, et al. (2016), donde se exhibió una reducción del $16 \%$ en los niveles de glucosa en ayunas después de 7 horas tras la administración con $1000 \mathrm{mg} / \mathrm{kg}$ de extracto etanólico de hojas de MO, mientras que después de 21 días de tratamiento se observó la reducción del $53,44 \%$, siendo la caída máxima en la concentración de glucosa y estableciendo relación del efecto hipoglucemiante dependiente del tiempo del tratamiento ${ }^{(179)}$.

Las investigaciones incluidas en la revisión fueron realizadas en ratas de diferentes especies; las más utilizadas para el propósito del estudio fueron Wistar y Sprague Dawley, la mayoría fueron ratas albinas que pesaron entre $99 \mathrm{~g}$ - 250g aprox; también, se observó una mayor preferencia por realizar el estudio en ratas macho. La inducción a la diabetes fue mediante la inyección con monohidrato de aloxano o STZ en los grupos experimentales, se confirmó mediante la medición de los niveles de glucosa en plasma en ayunas (FPG). 
Una vez confirmado la diabetes mellitus en el animal se esperó 72 horas para iniciar el tratamiento con el extracto de hojas de MO (177)(188)(182)(192)(39)(28)(179)(183)(137).

Según la evidencia acumulada en los estudios presentados en la revisión, se relacionaron diversos factores que convergen a favor del control glucémico en ratas diabéticas inducidas después de administrarse las hojas de Moringa oleífera. Resultó evidente la inhibición de las enzimas a-glucosidasa y la a-amilasa disminuyendo la absorción de los carbohidratos y reduciendo los niveles de glucosa tras la ingesta. También, se observó un aumento significativo en la expresión del ARNm del GS (Glucógeno sintasa) hepática una enzima glucogénica clave en la formación de glucógeno a partir de glucosa ${ }^{(38)}$. En el mismo estudio realizado por Abd Eldaim MA, et al. (2018), se observó que después de la administración del extracto acuoso de $\mathrm{MO}$ se redujo significativamente $(\mathrm{p}<0,05)$ la expresión del ARNm de la PC (Piruvato carboxilasa) hepática elevada en comparación con las ratas diabéticas sin tratamiento, PC es una enzima implicada en la gluconeogénesis que cataliza la conversión de piruvato en oxalacetato. La gluconeogénesis excesiva también es un factor contribuidor a la hiperglucemia en la diabetes tipo 2 debido a sensibilidad alterada de la gluconeogénesis a la regulación descendente en respuesta a la insulina ${ }^{(38)}$. En el estudio presentado por Olayaki L, et al. (2015), demostraron que la administración oral del extracto metanólico de hojas de MO redujo significativamente la concentración de glucosa en sangre en ratas diabéticas inducida por aloxano mediante la estimulación hepática y la síntesis de glucógeno muscular, el aumento de la captación de glucosa en el hígado y tejidos musculares (39), reafirmando los hallazgos encontrados en la investigación de Mabrouk y col.

Asimismo, se evaluó el poder antioxidante de la MO en varios estudios incluidos en la investigación, y se obtuvo un incremento significativo en las concentraciones de las enzimas antioxidantes: SOD (superóxido dismutasa),GSH (Glutatión reducido),CAT (catalasa) en las ratas diabéticas que recibieron $\mathrm{MO}$ en comparación a las ratas diabéticas sin tratamiento ${ }^{(180)(38)}$. También, se observó una caída significativa en los niveles de MDA(Malondialdehído) en las ratas diabéticas tratadas con MO, reduciendo la peroxidación lipídica producto del estrés oxidativo generado por la inducción en ratas con STZ o monohidrato de aloxano (38)(180)(152)(38)(28). Según la evidencia encontrada, la MO tiene la capacidad de regenerar los hepatocitos y las células pancreáticas mediante la mejora de las defensas antioxidantes celulares contra el estrés oxidativo aumentado, producto de la lesión tisular después de la inducción en ratas. También, se realizaron tamizajes fitoquímicos de las hojas de MO; sin embargo, los estudios incluidos en la presente investigación analizaron diferentes extractos de hojas de MO (etanólico, metanólico y 
acuoso); el extracto metanólico de MO reveló la presencia de saponina, flavonoides, esteroides, fenol, glucósidos, y taninos ${ }^{(39)}$. En el extracto etanólico, también, se identificaron estos compuestos bioactivos como la presencia de fenoles, taninos, flavonoides, alcaloides, saponinas, terpenoides y glucósidos ${ }^{(179)(137)}$. El extracto acuoso carecía de alcaloides y terpenoides ${ }^{(137)}$. Las hojas de MO parecen tener una óptima calidad y cantidad de fenoles totales y flavonoides; estos compuestos combaten los síntomas de la diabetes y regeneran las células $\beta$ del páncreas por sus efectos antioxidantes. 


\subsection{Conclusiones}

1. Mediante la revisión sistemática, se identificaron 18 estudios realizados en ratas diabéticas que cumplieron con los criterios de inclusión y exclusión, encontrándose que la administración (100 - $1500 \mathrm{mg} / \mathrm{kg}$ ) subcrónica (5 - 60 días) con las hojas de MO reduce en forma significativa los niveles de glucemia en ratas diabéticas inducidas con los siguientes $p$ valores, $<0,05,<0,01<0,001$, restaurando el daño producido por monohidrato de aloxano o STZ. Asimismo, aumenta la secreción y mejora la sensibilidad a la insulina, también mejora la tolerancia y disminuye la absorción intestinal de la glucosa, permitiendo tener un mejor control en los niveles de glucemia en ratas diabéticas. Estos resultados indican que las hojas de $\mathrm{MO}$ poseen efectos hipoglicemiantes con potencial antidiabético en el tratamiento y el manejo de la diabetes.

2. Los posibles mecanismos de acción encontrados en los extractos de las hojas de MO sobre las ratas diabéticas inducidas, según los hallazgos experimentales, indicaron claramente: mejora en la captación de la glucosa por el músculo esquelético y el tejido hepático; así pues, se aumentó de forma significativa la expresión del ARNm del GS hepático. Además, se restauró la expresión del ARNm de PC elevado a sus niveles normales; también resultó evidente la inhibición de las enzimas $\alpha$-glucosidasa y la $\alpha$ amilasa disminuyendo la absorción de los carbohidratos. Sumado a lo descrito, anteriormente, se observó la reducción significativa en los niveles de MDA. Todo lo señalado, contribuye a mantener la homeostasis de la glucosa alterada por la lesión inducida.

3.En cuanto a la dosis efectiva, podemos concluir que todos los estudios incluidos en la revisión sistemática mostraron reducción significativa en los niveles de glucemia, desde dosis administradas de $100 \mathrm{mg} / \mathrm{kg}$ hasta $1500 \mathrm{mg} / \mathrm{kg}$ de extracto de hojas de $\mathrm{MO}$, en ratas diabéticas inducidas. 


\subsection{Recomendaciones}

Se anima a realizar nuevos estudios clínicos en pacientes diabéticos para evaluar el efecto de las hojas de MO sobre el control de la glucemia. No obstante, también se sugiere la realización de ensayos clínicos controlados aleatorizados (ECCA), con el objeto de que se pueda establecer el uso de las hojas de $\mathrm{MO}$ en el tratamiento coadyuvante de la diabetes mellitus.

También, se recomienda realizar investigaciones bioquímicas adicionales para dilucidar los mecanismos de acción precisos y sitios de acción de los componentes bioactivos aislados de las hojas de MO.

Según los hallazgos experimentales de estudios científicos incluidos en la presente revisión, indican claramente una oportunidad para recomendar el uso de las hojas de MO como alimento funcional, aditivo alimentario; además, puede ser útil en el desarrollo de fitofármacos antidiabéticos y hasta poder evaluar su utilización en el descubrimiento de nuevos fármacos.

Además, se sugiere a los profesionales de salud que intervienen en el manejo integral de la diabetes mellitus, que investiguen sobre el efecto de las hojas de MO para el tratamiento de la diabetes, debido a que puede ser útil en el manejo terapéutico de la enfermedad, mejorando el pronóstico de la enfermedad y, además, poder prevenir las complicaciones macro y microvasculares.

También, la presente investigación evidencia que el tratamiento con hojas de MO presenta un efecto positivo en la reducción de los niveles de glucemia en ratas diabéticas inducidas con aloxano o eztreptozotocina; siendo la MO una planta de origen tropical aún desconocida por muchas personas, se sugiere al estado futuras inversiones en la investigación de esta planta, de manera tal, que puedan ser utilizadas como tratamiento coadyuvante de la diabetes mellitus y así se pueda mejorar la gestión de la enfermedad disminuyendo los altos costos que demanda las complicaciones para el estado.

Por último, según la calidad nutricional de las hojas de MO donde se exhibe su alto poder antioxidante, se anima a realizar emprendimientos a base de esta planta, generando nuevas fuentes de trabajo, además del bajo costo de producción que puedan promover estilos de alimentación saludable y sostenible en la población. 


\section{REFERENCIAS}

1. Wang F, Zhong H-H, Chen W-K, Liu Q-P, Li C-Y, Zheng Y-F, et al. Potential hypoglycaemic activity phenolic glycosides from Moringa oleifera seeds. Nat Prod Res. 2016;6419:1-6.

2. Dixit S, Tripathi A, Kumar P, Culture T. Medicinal Properties of Moringa oleifera : A Review International Journal of Education and Science Research Review. IJESRR. 2016;3(2):173-85.

3. Anwar F, Latif S, Ashraf M. Moringa oleifera: A Food Plant with Multiple Medicinal Uses. Phytother Res. 2006;21:17-25.

4. Gupta R, Mathur M, Bajaj VK, Katariya P, Yadav S, Kamal R, et al. Evaluation of antidiabetic and antioxidant activity of Moringa oleifera in experimental diabetes. J Diabetes. 2012;4(2):164-71.

5. Bonal R, Rivera RM, Bolivar ME. Moringa oleifera: una opción saludable para el bienestar. MediSan. 2012;16(10):1-13.

6. Bennett RN, Mellon FA, Foidl N, Pratt JH, Dupont MS, Perkins L, et al. Profiling glucosinolates and phenolics in vegetative and reproductive tissues of the multi-purpose trees Moringa oleifera L. (Horseradish tree) and Moringa stenopetala L. J Agric Food Chem. 2003;51(12):3546-53.

7. Fahey J. Moringa oleifera: A Review of the Medical Evidence for Its Nutritional, Therapeutic, and Prophylactic Properties. TFLJ. 2005;1(5):157-64.

8. Jaiswal D, Kumar Rai P, Kumar A, Mehta S, Watal G. Effect of Moringa oleifera Lam. leaves aqueous extract therapy on hyperglycemic rats. J Ethnopharmacol. 2009;123(3):392-6.

9. Mbikay M. Therapeutic potential of Moringa oleifera leaves in chronic hyperglycemia and dyslipidemia: A review. Front Pharmacol. 2012;3(24):1-12.

10. Anthanont $P$, Lumlerdkij $N$, Akarasereenont $P$, Vannasaeng $S$, Sriwijitkamol A. Moringa oleifera leaf increases insulin secretion after single dose administration: A preliminary study in healthy subjects. J Med Assoc Thail. 2016;99(3):308-13.

11. Prasanna KK. Effect of Moringa oleifera on blood glucose, LDL levels in Type II diabetic obese people. Innov J Med Heal Sci. 2013;3(1):23-5.

12. Mozo RN, Caole-Ang I. The effects of malunggay (Moringa oleifera) leaves capsule supplements on high specificity C-reactive protein and hemoglobin A1c levels of diabetic patients in ospital ng Maynila medical center: A prospective cohort study. Phillippine J Intern 
Med. 2015;53(4):1-10.

13. Mathers CD, Loncar D. Projections of global mortality and burden of disease from 2002 to 2030. PLoS Med. 2006;3(11):2011-30.

14. Organizacion Mundial de la Salud. Informe Mundial Sobre la diabetes. Ginebra; 2016.

15. Vargas-Uricoechea $\mathrm{H}$, Casas-Figueroa LÁ. Epidemiología de la diabetes mellitus en Sudamérica: la experiencia de Colombia. Clínica e Investig en Arterioscler. 2016 Sep $1 ; 28(5): 245-56$.

16. Calle NH, Moreno GA. Peru, enfermedades no transmisibles y transmisibles, 2015. INEI. Lima: Instituto Nacional de Estadística e Informática; 2016. 137 p.

17. Ahmad L a., Crandall JP. Type 2 Diabetes Prevention: A Review. Clin Diabetes. 2010;28(2):53-9.

18. Gupta V, Kalra S. Choosing a Gliptin. Indian J Endocrinol Metab. 2011;15(4):298.

19. Steven E. Nissen, M.D., and Kathy Wolski MPH. Effect of Rosiglitazone on the Risk of Myocardial Infarction and Death from Cardiovascular Causes. N Engl J Med. 2010;354(24):2457-71.

20. Tang Y, Choi E-J, Han WC, Oh M, Kim J, Hwang J-Y, et al. Moringa oleifera from Cambodia Ameliorates Oxidative Stress, Hyperglycemia, and Kidney Dysfunction in Type 2 Diabetic Mice. J Med Food. 2017;20(5):502-10.

21. Evans JL. Antioxidants: do they have a role in the treatment of insulin resistance? Indian J Med Res. 2007;125(3):355-72.

22. Suanarunsawat T, Devakul Na Ayutthaya W, Songsak T, Thirawarapan S, Poungshompoo S. Lipid-lowering and antioxidative activities of aqueous extracts of Ocimum sanctum L. leaves in rats fed with a high-cholesterol diet. Oxid Med Cell Longev. 2011;2011:9.

23. Rochette L, Zeller M, Cottin Y, Vergely C. Diabetes, oxidative stress and therapeutic strategies. Biochim Biophys Acta - Gen Subj. 2014;1840(9):2709-29.

24. King GL, Loeken MR. Hyperglycemia-induced oxidative stress in diabetic complications. Histochem Cell Biol. 2004;122(4):333-8.

25. Ibarra R, Luisa M, González B, Margarita C, Meda G, Claudia B. Diabetes, estrés oxidativo y antioxidantes. Investig en Salud. 2006;8(1):7-15.

26. Al-malki AL, Rabey HA El. The Antidiabetic Effect of Low Doses of Moringa oleifera Lam . 
Seeds on Streptozotocin Induced Diabetes and Diabetic Nephropathy in Male Rats. Biomed Res Int. 2015;2015:13.

27. Farooq F, Rai M, Tiwari A, Khan AA, Farooq S. Medicinal properties of Moringa oleifera: An overview of promising healer. J Med Plants Res. 2012;6(27):4368-74.

28. Yassa HD, Tohamy AF. Extract of Moringa oleifera leaves ameliorates streptozotocin-induced Diabetes mellitus in adult rats. Acta Histochem. 2014;116(5):844-54.

29. Khalafalla M, Abdellatef E. Active principle from Moringa oleifera Lam leaves effective against two leukemias and a hepatocarcinoma. Afr J Biotechnol. 2010;9(49):8467-71.

30. Luqman S, Srivastava S, Kumar R, Maurya AK, Chanda D. Experimental assessment of Moringa oleifera leaf and fruit for its antistress, antioxidant, and scavenging potential using in vitro and in vivo assays. Evidence-based Complement Altern Med. 2012;2012:12.

31. Pal SK, Mukherjee PK, Saha K, Pal M, Saha BP. Antimicrobial Action of the Leaf Extract of Moringa. Anc Sci Life. 1995;14(3):197-9.

32. Thurber MD, Fahey JW. Adoption of Moringa oleifera to Combat Under-Nutrition Viewed Through the Lens of the "Diffusion of Innovations" Theory. Ecol Food Nutr. 2009;48(3):212-25.

33. Organización Mundial de la Salud. Informe Mundial de la diabetes. Resumen de orientación. Ginebra; 2016.

34. Martin C, Martin G, Garcia A, Fernandez T, Hernandez E, Puls J. Pastos y Forrajes. Pastos y Forrajes. 2013;36(2):150-8.

35. Argimon JM, Jimenez J. Metodos de la investigacion clinica y epidemiologica. 4th ed. Vol. 136, Journal of Experimental Psychology: General. España; 2007. 23-42 p.

36. Martín C, Martín G, García A, Fernández T, Hernández E. Potentiales applicaciones de Moringa oleifera . Una revisión crítica. Pastos y Forrajes. 2013;36(2):137-49.

37. Bohórquez S. Efecto de la Espirulina en el manejo de las alteraciones metabólicas relacionadas a la obesidad. Revisión Sistemática. Universidad San Ignacio de Loyola; 2017.

38. Abd El Latif A, El Bialy BES, Mahboub HD, Abd Eldaim MA. Moringa oleifera leaf extract ameliorates alloxan-induced diabetes in rats by regeneration of $\beta$ cells and reduction of pyruvate carboxylase expression. Biochem Cell Biol. 2014;92(5):413-9.

39. Olayaki LA, Irekpita JE, Yakubu MT, Ojo OO. Methanolic extract of Moringa oleifera leaves improves glucose tolerance, glycogen synthesis and lipid metabolism in alloxan-induced diabetic rats. J Basic Clin Physiol Pharmacol. 2015;26(6):585-93. 
40. Paula PC, Sousa DOB, Oliveira JTA, Carvalho AFU, Alves BGT, Pereira ML, et al. A protein isolate from Moringa oleifera leaves has hypoglycemic and antioxidant effects in alloxaninduced diabetic Mice. Molecules. 2017;22(2):15.

41. Jaiswal D, Rai PK, Mehta S, Chatterji S, Shukla S, Rai DK, et al. Role of Moringa oleifera in regulation of diabetes-induced oxidative stress. Asian Pac J Trop Med. 2013;6(6):426-32.

42. Roses M, Rosas G. Guías ALAD de diagnóstico, control y tratamiento de la Diabetes Mellitus Tipo 2. Pan American Health organization. 2009. 80 p.

43. Domínguez C, Pinal-Fernandez M, lago. Guía de práctica clínica de diabetes mellitus tipo 2. Arch Med. 2014;10(2):1-18.

44. García Bello L, Torales Salinas J, Giménez MB, Flores LE, Gómez de Ruiz N, Centurión OA. The risk of those who care for risk: FIDRISK in healthcare personnel. Rev Virtual la Soc Paraguaya Med Interna. 2016 Sep;3(2):71-6.

45. Agius L. New hepatic targets for glycaemic control in diabetes. Best Pract Res Clin Endocrinol Metab. 2007;21(4):587-605.

46. Frenk Baron P, Márquez E. Diabetes Mellitus Tipo 2 En Niños Y Adolescentes. Med Interna México Vol. 2010;26(1):12.

47. Resumen de las Guías ADA 2016. 2016.

48. Velásquez Figueroa C. Identificación de marcadores moleculares para el diagnóstico temprano de la Diabetes Mellitus Tipo II, en una población de Lima. Universidad Nacional Mayor de San Marcos; 2014.

49. Organización Mundial de la Salud. Prevención de las enfermedades crónicas : una inversión vital. 2005;34.

50. León Gamboa Z. Efecto hipoglicemiante del extracto hidroalcohólico de los tubérculos de Colocasia esculenta Schott "pituca" en ratas Holtzman. Ayacucho - 2017. Universidad Nacional San Cristóbal de Huamanga; 2017.

51. Yataco NJT. Actividad hipoglucemiante del extracto hidroalcohólico de las hojas de Smallanthus sonchifolius ( yacón ) en ratas con diabetes tipo 1 y 2 . Universidad Nacional Mayor de San Marcos; 2007.

52. Defronzo RA. Pathogenesis of type 2 diabetes mellitus. 2004;88:787-835.

53. Standards of Medical Care in Diabetes-2018. Diabetes Care. 2018;41(9):2045-7. 
54. Buell C, Kermah D, Davidson MB. Utility of A1C for diabetes screening in the 19992004 NHANES population. Diabetes Care. 2007;30(9):2233-5.

55. Rosas-Saucedo J, Caballero AE, Brito-Córdova G, García-Bruce H, Costa-Gil J, Lyra R, et al. Consenso de Prediabetes. Documento de posición de la Asociación Latinoamericana de Diabetes (ALAD). Vol. 7, Alad. 2017.

56. Artiaga JF. Tesis Doctoral Diabetes y trabajo. Análisis de la influencia del control de la enfermedad y de las condiciones de trabajo en el absentismo laboral de las personas diabéticas. Universidad Autonoma de Barcelona. 2012.

57. Nicolau Ramis JA. Prevalencia de trastornos psicopatológicos en la obesidad y la diabetes mellitus tipo 2: influencia sobre el control metabólico, complicaciones de la diabetes tipo 2 y respuesta al tratamiento de la obesidad [Internet]. Universitat Autònoma de Barcelona; 2018. Available from: http://www.tdx.cat/handle/10803/463028

58. Muñoz de Escalona-Rojas JE, Quereda-Castañeda A, García-García O. Actualización de la retinopatía diabética para médicos de atención primaria: Hacia una mejora de la medicina telemática. Semergen. 2016;42(3):172-6.

59. De La Haza Calvo M del C. Contribución al estudio de los factores relacionados con la microangiopatía diabética. Universidad Complutense. 2013.

60. Villa Rincón J. Relación entre Diabetes Mellitus y enfermedad renal en una población general de Extremadura. Universidad de Extremadura; 2017.

61. Turner R, Matthews D, Neil A, Mcelroy H. Tight blood pressure control and risk of macrovascular and microvascular complications in type 2 diabetes: UKPDS 38. Br Med Journaledical. 1998;317:703-13.

62. Dunselman PHJM, Ph D, Janus CL, Bendermacher PEF. Multifactorial Intervention and cardiovascular disease in patients with type 2 diabetes mellitus. New Engl J. 2005;1095-104.

63. Najafian B, Alpers CE, Fogo AB. Pathology of Human Diabetic Nephropathy. Contrib Nephrol Basel, Karger. 2011;170:36-47.

64. Mora Fernández C, Macía Heras M, Martínez Castelao A, Navarro González F. Fisiopatología de la nefropatía diabética. Nefro Plus. 2008;1(1):28-38.

65. Marrón B, Egido AOJ. Factores patogénicos en la nefropatía diabética. ¿De dónde venimos y hacia dónde vamos? Nefrologia. $2001 ; 21(3): 18-23$.

66. Hernández Toledo J. Las bacterias GRAM negativas y su influencia en la cicatrización de 
úlceras de pie diabético. Universidad Complutense De Madrid; 2014.

67. Olmos PR, Niklitschek S, Olmos RI, Faúndez JI, Quezada TA, Bozinovic MA, et al. Bases fisiopatológicas para una clasificación de la neuropatía diabética. Rev Med chile. 2012;140:1593-605.

68. Houssay BA, Penhos JC. Pancreatic diabetes and hypophysectomy in the snake Xenodon merremii. Acta Endocrinol (Copenh). 1960;35:313-23.

69. Ramos H, Méndez J. Diabetes Mellitus Experimental. Cienc Vet. 1994;6(12):348-71.

70. Islam S, Wilson R. Experimentally Induced Rodent Models of Type 2 Diabetes. Arch Med Res. 2012;933:161-74.

71. Goldner MG, Gomori G. Further Studies on the Mechanism of Alloxan Diabetes, Pancreatectomy and Alloxan. Proc Soc Exp Biol Med. 1947;65(1):18-21.

72. Islam MS, Loots DT. Experimental rodent models of type 2 diabetes: A review. Methods Find Exp Clin Pharmacol. 2009;31(4):249.

73. Yamamoto H, Uchigata $\mathrm{Y}$, Okamoto H. Streptozotocin and alloxan induce DNA strand breaks and poly(ADP-ribose) synthetase in pancreatic islets. Nature. 1981;294(5838):284-6.

74. Lenzen S. The mechanisms of alloxan- and streptozotocin-induced diabetes. Diabetologia. 2008;51(2):216-26.

75. Srinivasan K, Viswanad B, Asrat L, Kaul CL, Ramarao P. Combination of high-fat diet-fed and low-dose streptozotocin-treated rat: A model for type 2 diabetes and pharmacological screening. Pharmacol Res. 2005;52(4):313-20.

76. Mata M. Metformin and type-2 diabetes mellitus. Aten Primaria. 2008;40(3):147-53.

77. Gomez F, Escalada F, Menéndez E, Mata M, Ferrer J, Ezkurra P, et al. Recomendaciones de la Sociedad Española de Diabetes (SED) para el tratamiento farmacológico de la hiperglucemia en la diabetes tipo 2: Actualización 2018. EDN. 2018;843:1-14.

78. Franco JM. Guía para la prescripción y visado de antidiabéticos. Valencia; 2019.

79. Pallardo Sánchez LF. Sulfonilureas en el tratamiento del paciente con diabetes mellitus tipo 2. Endocrinol Nutr. 2008;55(Supl. 2):17-25.

80. KM N. Indian Materia Medica. 3th ed. India: Apau Central Library; 1976. 548-550 p.

81. Balbir S. Mathur. Moringa. Trees for Life International. 2009. 36 p. 
82. Foidl N, Makkar HP., Becker K. The potential of Moringa oleifera for agricultural and industrial uses. Dar Es Salaam; 2001.

83. Gopalakrishnan L, Doriya K, Kumar DS. Moringa oleifera: A review on nutritive importance and its medicinal application. Food Sci Hum Wellness. 2016;5(2):49-56.

84. Maida Aslam, Farooq Anwar, Raizya Nadeem, Umer Rashid, T.G. Kazi MN. Mineral Composition of Moringa Oleifera Leaves and Pods From Different Regions of Punjab Pakistan.Pdf. Vol. 4, Asian Journal of Plant Sciences. 2005. p. 417-21.

85. Kasolo J, Bimenya G, Ojok L, Ochieng J, JW O-O. Phytochemicals and uses of Moringa oleifera leaves in Ugandan rural communities. J Med Plants Res. 2012;4(9):753-7.

86. Dillard CJ, Bruce German J. Phytochemicals: Nutraceuticals and human health. J Sci Food Agric. 2000;80(12):1744-56.

87. Makkar HPS, Becker K. Nutrional value and antinutritional components of whole and ethanol extracted Moringa oleifera leaves. Anim Feed Sci Technol. 1996;63(1-4):211-28.

88. Witt K. The Nutrient Content of Moringa oleifera Leaves. Echo Res Notes. 2013;1(1):1-6.

89. Lua A, Kourc W. Evaluation of hypoglycemic properties and fertility effect of Piper sarmatosum. Int J Phytomedicine. 2014;6:448-54.

90. Faizal A, Razis A, Ibrahim MD, Kntayya SB, Dqg D, Lqfoxglqj Q, et al. Health Benefits of Moringa oleifera. 2014;2:8571-6.

91. Francis JA, Jayaprakasam B, Olson LK, Nair MG. Insulin Secretagogues from Moringa oleifera with Cyclooxygenase Enzyme and Lipid Peroxidation Inhibitory Activities. Helv Chim Acta. 2004;87(2):317-26.

92. Tende JA, Ezekiel I, Dikko AAU, Goji ADT. Effect of Ethanolic Leaves Extract of Moringa oleifera on Blood Glucose Levels of Streptozocin-Induced Diabetics and Normoglycemic Wistar Rats. Br J Pharmacol Toxicol. $2011 ; 2(1): 1-4$.

93. Torres-Castillo JA, Sinagawa-Garcia SR, Martinez-Avila GCG, Lopez-Flores AB, SanchezGonzalez El, Aguirre-Arzola VE, et al. Moringa oleifera: phytochemical detection, antioxidants, enzymes and antifugal properties. Phyton-International J Exp Bot. 2013;82:193-202.

94. Okiki PA, Osibote IA, Balogun O, Oyinloye BE, Idris O, Olufunke A, et al. Evaluation of Proximate, Minerals, Vitamins and Phytochemical Composition of Moringa oleifera Lam . Cultivated in Ado Ekiti, Nigeria. Adv Biol Res (Rennes). 2015;9(6):436-43.

95. Rubio Sánchez S. Flavonoides con Actividad Antitumoral: Identificación Y Estudio Del 
Mecanismo De Acción. Tesis Doctoral. Departamento de Patología Animal, Ciencia y Tecnologia de los Alimentos y Departamento de Ciencias Clínicas. Universidad de Las Palmas de Gran Canaria; 2009.

96. Kasolo JN, Bimenya GS, Ojok L, Ochieng J, Ogwal-Okeng JW. Phytochemicals and uses of Moringa oleifera leaves in Ugandan rural communities. J Med Plants Res. 2010;4(9):753-7.

97. Rani NZA, Husain K, Kumolosasi E. Moringa genus: A review of phytochemistry and pharmacology. Front Pharmacol. 2018;9(108):1-26.

98. Leone A, Spada A, Battezzati A, Schiraldi A, Aristil J, Bertoli S. Cultivation, genetic, ethnopharmacology, phytochemistry and pharmacology of Moringa oleifera leaves: An overview. Int J Mol Sci. 2015;16(6):12791-835.

99. Makkar HPS, Francis G, Becker K. Bioactivity of phytochemicals in some lesser-known plants and their effects and potential applications in livestock and aquaculture production systems. Animal. 2007;1(9):1371-91.

100. Vergara-Jimenez M, Almatrafi M, Fernandez M. Bioactive Components in Moringa Oleifera Leaves Protect against Chronic Disease. Antioxidants. 2017;6(4):91.

101. Di Camillo Orfali G, Duarte AC, Bonadio V, Martinez NP, De Araújo MEMB, Priviero FBM, et al. Review of anticancer mechanisms of isoquercitin. World J Clin Oncol. 2016;7(2):189-99.

102. Vongsak B, Sithisarn P, Gritsanapan W. Simultaneous HPLC quantitative analysis of active compounds in leaves of moringa oleifera lam. J Chromatogr Sci. 2014;52(7):641-5.

103. Riaz A, Rasul A, Hussain G, Zahoor MK, Jabeen F, Subhani Z, et al. Astragalin: A Bioactive Phytochemical with Potential Therapeutic Activities. Adv Pharmacol Sci. 2018;2018.

104. Leone A, Fiorillo G, Criscuoli F, Ravasenghi S, Santagostini L, Fico G, et al. Nutritional characterization and phenolic profiling of moringa oleifera leaves grown in chad, sahrawi refugee camps, and Haiti. Int J Mol Sci. 2015;16(8):18923-37.

105. Kowalski J, Samojedny A, Paul M, Pietsz G, Wilczok T. Effect of apigenin, kaempferol and resveratrol on the expression of interleukin-1 $\beta$ and tumor necrosis factor- $\alpha$ genes in $\mathbf{J 7 4} .2$ macrophages. Pharmacol Reports. 2005;57(3):390-4.

106. Manguro LOA, Lemmen P. Phenolics of Moringa oleifera leaves. NAT PROD RES. 2007;21(1):56-68.

107. Ren B, Qin W, Wu F, Wang S, Pan C, Wang L, et al. Apigenin and naringenin regulate glucose and lipid metabolism, and ameliorate vascular dysfunction in type 2 diabetic rats. EJP. 
2016;773:13-23.

108. Malik S, Suchal K, Khan SI, Bhatia J, Kishore K, Dinda AK, et al. Apigenin ameliorates streptozotocin-induced diabetic nephropathy in rats via MAPK-NF-KB-TNF- $\alpha$ and TGF- $\beta 1$ MAPK-fibronectin pathways. Vol. 313, Am J Physiol Renal Physiol. 2017. 414-422 p.

109. Qian LB, Wang HP, Chen Y, Chen FX, Ma YY, Bruce IC, et al. Luteolin reduces high glucosemediated impairment of endothelium-dependent relaxation in rat aorta by reducing oxidative stress. PHARMACOL RES. 2010;61(4):281-7.

110. Qian W, Liu M, Fu Y, Zhang J, Liu W, Li J, et al. Antimicrobial mechanism of luteolin against Staphylococcus aureus and Listeria monocytogenes and its antibiofilm properties. Microb Pathog. 2020;142(December 2019):104056.

111. Irrera N, Pizzino G, D'Anna R, Vaccaro M, Arcoraci V, Squadrito F, et al. Dietary management of skin health: The role of genistein. Nutrients. 2017;9(6):1-10.

112. Sun M, Ye Y, Xiao L, Rahman K, Xia W, Zhang H. Daidzein: A Review Pharmacological effects. 2016;13:117-32.

113. Abdulkhaleq LA, Assi MA, Noor MHM, Abdullah R, Saad MZ, Taufiq-Yap YH. Therapeutic uses of epicatechin in diabetes and cancer. Vet World. 2017;10(8):869-72.

114. Wang J, Fang X, Ge L, Cao F, Zhao L, Wang Z, et al. Antitumor, antioxidant and antiinflammatory activities of kaempferol and its corresponding glycosides and the enzymatic preparation of kaempferol. PLoS One. 2018;13(5):1-12.

115. Cruz-Vega D, Verde-Star MJ, Salinas-Gonzalez NR, Rosales-Hernandez B, Estrada-Garcia I, Mendez-Aragon $P$, et al. Review of pharmacological effects of Glycyrrhiza radix and its bioactive compounds. Zhongguo Zhong Yao Za Zhi. 2009;22(April 2008):557-9.

116. Tumer TB, Rojas-Silva P, Poulev A, Raskin I, Waterman C. Direct and indirect antioxidant activity of polyphenol- and isothiocyanate-enriched fractions from moringa oleifera. JAFC. 2015;63(5):1505-13.

117. Palliyaguru DL, Yuan JM, Kensler TW, Fahey JW. Isothiocyanates: Translating the Power of Plants to People. Mol Nutr Food Res. 2018;62(18):1-23.

118. Waterman C, Rojas-silva P, Tumer TB, Kuhn P, Richard J, Wicks S, et al. Isothiocyanate-rich Moringa oleifera extract reduces weight gain, insulin resistance and hepatic gluconeogenesis in mice. Mol Nutr Food Res. 2014;1:1-29.

119. Mehta J, Shukla A, Bukhariya V, Charde R. The Magic Remedy of Moringa Oliferia: an 
Overview. IJBAR. $2011 ; 2(6)$.

120. Arora R, Malhotra P, Sharma A, Haniadka R, Yashawanth HS, Baliga MS. Medicinal Efficacy of Indian Herbal Remedies for the Treatment of Arthritis. 1st ed. Bioactive Food as Interventions for Arthritis and Related Inflammatory Diseases. India: Elsevier Inc.; 2013. 601-617 p.

121. Patel SS, Goyal RK. Cardioprotective effects of gallic acid in diabetes-induced myocardial dysfunction in rats. Phcog Res. 2011;3(4):239-45.

122. Kahkeshani N, Farzaei F, Fotouhi M, Alavi SS, Bahramsoltani R, Naseri R, et al. Pharmacological effects of gallic acid in health and disease: A mechanistic review. IJBMS. 2019;22(3):225-37.

123. Verma AR, Vijayakumar M, Mathela CS, Rao C V. In vitro and in vivo antioxidant properties of different fractions of Moringa oleifera leaves. FCT. 2009;47(9):2196-201.

124. Zhao Q, Dai C, Fan S, Lv J, Nie L. Synergistic efficacy of salicylic acid with a penetration enhancer on human skin monitored by OCT and diffuse reflectance spectroscopy. Sci Rep. 2016;6(September):1-11.

125. Marczyk B, Mucha P, Budzisz E, Rotsztejn H. Comparative study of the effect of $50 \%$ pyruvic and $30 \%$ salicylic peels on the skin lipid film in patients with acne vulgaris. J Cosmet Dermatol. 2014;13(1):15-21.

126. Joshi R, Gangabhagirathi R, Venu S, Adhikari S, Mukherjee T. Antioxidant activity and free radical scavenging reactions of gentisic acid: In-vitro and pulse radiolysis studies. Free Radic Res. 2012;46(1):11-20.

127. Muthukumaran J, Srinivasan S, Venkatesan RS, Ramachandran V, Muruganathan U. Syringic acid, a novel natural phenolic acid, normalizes hyperglycemia with special reference to glycoprotein components in experimental diabetic rats. JAD. 2013;2(4):304-9.

128. Polce SA, Burke C, França LM, Kramer B, Paes AM de A, Carrillo-Sepulveda MA. Ellagic acid alleviates hepatic oxidative stress and insulin resistance in diabetic female rats. Nutrients. 2018;10(5):1-15.

129. Rozentsvit A, Vinokur K, Samuel S, Li Y, Gerdes AM, Carrillo-Sepulveda MA. Ellagic Acid Reduces High Glucose-Induced Vascular Oxidative Stress Through ERK1/2/NOX4 Signaling Pathway. Cell Physiol Biochem. 2017;44(3):1174-87.

130. Chowdhury S, Ghosh S, Das AK, Sil PC. Ferulic acid protects hyperglycemia-induced kidney damage by regulating oxidative insult, inflammation and autophagy. Front Pharmacol. 
2019;10(FEB):1-24.

131. Pittala V, Salerno L, Romeo G, Acquaviva R. Therapeutic Potential of Caffeic Acid Phenethyl Ester (CAPE) in Diabetes. Curr Med Chem. 2018;25(37):4827-36.

132. Un JJ, Lee MK, Yong BP, Jeon SM, Choi MS. Antihyperglycemic and antioxidant properties of caffeic acid in db/db mice. J Pharmacol Exp Ther. 2006;318(2):476-83.

133. Carrión AV, Cándida J, García Gómez R. Preparación de extractos vegetales: determinación de eficiencia de metódica. Universidad de Cuenca; 2010.

134. Pragasam SJ, Venkatesan V, Rasool M. Immunomodulatory and anti-inflammatory effect of $p$ coumaric acid, a common dietary polyphenol on experimental inflammation in rats. Inflammation. 2013;36(1):169-76.

135. Ong KW, Hsu A, Tan BKH. Anti-diabetic and anti-lipidemic effects of chlorogenic acid are mediated by ampk activation. Biochem Pharmacol. 2013;85(9):1341-51.

136. Santana-Gálvez J, Cisneros-Zevallos L, Jacobo-Velázquez DA. Chlorogenic Acid: Recent advances on its dual role as a food additive and a nutraceutical against metabolic syndrome. Molecules. 2017;22(3):1-21.

137. Irfan HM, Asmawi MZ, Khan NAK, Sadikun A, Mordi MN. Anti-diabetic activity-guided screening of aqueous-ethanol Moringa oleifera extracts and fractions: Identification of marker compounds. Trop J Pharm Res. 2017;16(3):543-52.

138. Sahakitpichan P, Mahidol C, Disadee W, Ruchirawat S, Kanchanapoom T. Unusual glycosides of pyrrole alkaloid and 4'-hydroxyphenylethanamide from leaves of Moringa oleifera. Phytochemistry. 2011;72(8):791-5.

139. Panda S, Kar A, Sharma P, Sharma A. Cardioprotective potential of N, a-I-rhamnopyranosyl vincosamide, an indole alkaloid, isolated from the leaves of Moringa oleifera in isoproterenol induced cardiotoxic rats: In vivo and in vitro studies. Bioorganic Med Chem Lett. 2013;23(4):959-62.

140. Pandey A, Pandey R, Poonam T, Gupta P. Moringa Oleifera Lam. (Sahijan) - A Plant with a Plethora of Diverse Therapeutic Benefits: An Updated Retrospection. MAP. 2012;1(5):1-8.

141. Guevara AP, Vargas C, Sakurai H, Fujiwara Y, Hashimoto K, Maoka T, et al. An antitumor promoter from Moringa oleifera Lam. MRGTEM. 1999;440(2):181-8.

142. Jung IL. Soluble extract from Moringa oleifera leaves with a new anticancer activity. PLoS One. 2014;9(4):1-10. 
143. Murakami A, Kitazono Y, Jiwajinda S, Koshimizu K, Ohigashi H. Niaziminin, a thiocarbamate from the leaves of Moringa oleifera, holds a strict structural requirement for inhibition of tumorpromoter-induced epstein- barr virus activation. Planta Med. 1998;64(4):319-23.

144. Gupta R, Sharma AK, Dobhal MP, Sharma MC, Gupta RS. Antidiabetic and antioxidant potential of $\beta$-sitosterol in streptozotocin-induced experimental hyperglycemia. J Diabetes. $2011 ; 3(1): 29-37$.

145. Ponnulakshmi R, Shyamaladevi B, Vijayalakshmi P, Selvaraj J. In silico and in vivo analysis to identify the antidiabetic activity of beta sitosterol in adipose tissue of high fat diet and sucrose induced type-2 diabetic experimental rats. Toxicol Mech Methods. 2019;29(4):276-90.

146. American Diabetes Association. Implications of the diabetes control and complications trial. Vol. 26, Diabetes care. 2003.

147. Kou X, Li B, Olayanju JB, Drake JM, Chen N. Nutraceutical or pharmacological potential of Moringa oleifera Lam. Nutrients. 2018;10(3):1-12.

148. Ghazali HM, Mohammed AS. Moringa (Moringa oleifera) Seed Oil: Composition, Nutritional Aspects, and Health Attributes. Nuts Seeds Heal Dis Prev. 2011;93:787-93.

149. Ullah MF, Bhat SH, Abuduhier FM. Antidiabetic Potential of Hydro-Alcoholic Extract of Moringa Peregrina Leaves: Implication as Functional Food for Prophylactic Intervention in Prediabetic Stage. J Food Biochem. 2015;39:360-7.

150. Kar A, Choudhary BK, Bandyopadhyay NG. Comparative evaluation of hypoglycaemic activity of some Indian medicinal plants in alloxan diabetic rats. J Ethnopharmacol. 2003;84(1):105-8.

151. Di Fabio G, Romanucci V, De Marco A, Zarrelli A. Triterpenoids from Gymnema sylvestre and Their Pharmacological Activities. Molecules. 2014;19(8):10956-81.

152. Omodanisi El, Aboua YG, Oguntibeju OO, Lamuela-Raventós RM. Assessment of the antihyperglycaemic, anti-inflammatory and antioxidant activities of the methanol extract of moringa oleifera in diabetes-induced nephrotoxic male wistar rats. Molecules. 2017;22(4):1-17.

153. Edoga CO, Njoku OO, Amadi EN, Okeke JJ. Blood Sugar Lowering Effect of Moringa Oleifera Lam in Albino Rats. Int J Sci Technol. 2013;3(1):88-90.

154. Manohar VS, Jayasree T, Kishore KK, Rupa LM, Dixit R. Evaluation of hypoglycemic and antihyperglycemic effect of freshly prepared aqueous extract of Moringa oleifera leaves in normal and diabetic rabbits. J chem pharm. 2012;4(1):249-53.

155. Serra Sansone M. Actualización en medicamentos antidiabéticos y riesgo cardiovascular. Rev 
Urug Cardiol. 2016;31(8):522-46.

156. Escorza M, Calderón J. La Capacidad Antioxidante Total. Bases Y Aplicaciones. Rev Educ Bioquímica. 2009;28(3):89-101.

157. Cubillos V, López C, Alberdi A. Estudio histopatológico e inmunohistoquímico de páncreas en perros diabéticos inducidos con aloxano. Arch Med Vet. 2008;40:169-77.

158. Arison RN, Ciaccio El, Glitzer MS, Cassaro JA, Pruss MP. Light and electron microscopy of lesions in rats rendered diabetic with streptozotocin. Diabetes. 1967;16(1):51-6.

159. Damasceno DC, Netto AO, lessi IL, Gallego FQ, Corvino SB, Dallaqua B, et al. Streptozotocininduced diabetes models: Pathophysiological mechanisms and fetal outcomes. Biomed Res Int. 2014;2014:11.

160. Gonzales A. Obtención de aceites esenciales y extractos etanolicos de plantas del Amazonas. Universidad Nacional de Colombia; 2004.

161. Nakai H, Okuyama M, Kim YM, Saburi W, Wongchawalit J, Mori H, et al. Molecular analysis of a- glucosidase belonging to GH-family 31. Biol - Sect Cell Mol Biol. 2005;60(16):131-5.

162. Janeček Š, Svensson B, MacGregor EA. $\alpha$-Amylase: An enzyme specificity found in various families of glycoside hydrolases. Vol. 71, Cellular and Molecular Life Sciences. 2014. p. 114970.

163. De La Cruz Palomino F. Digestión. In: Fisiología y fisiopatología de la nutrición : I Curso de Especialización en Nutrición. Coruña; 2005. p. 25-36.

164. Del Rio D, Stewart AJ, Pellegrini N. A review of recent studies on malondialdehyde as toxic molecule and biological marker of oxidative stress. Nutr Metab Cardiovasc Dis. 2005;15(4):316-28.

165. Zhu Y, Aredo B, Chen B, Zhao CX, He Y, Rafael L. Mice With a Combined Deficiency of Superoxide Dismutase 1 (Sod1), DJ-1 (Park7), and Parkin (Prkn) Develop Spontaneous Retinal Degeneration With Aging. Invest Ophthalmol. 2019;60(12):3740-51.

166. Fernández-Novell JM, Díaz-Lobo M. Immunochemical Study of the Effect of F2Glc on Glycogen Synthase Translocation and Glycogen Synthesis in Isolated Rat Hepatocytes. Appl Biochem Biotechnol. 2018;184(3):909-18.

167. Kaushal J, Mehandia S, Singh G, Raina A, Arya SK. Catalase enzyme: Application in bioremediation and food industry. Biocatal Agric Biotechnol. 2018;16:192-9.

168. Espinoza SE, Guo H, Fedarko N, DeZern A, Fried LP, Xue QL, et al. Glutathione Peroxidase 
Enzyme Activity in Aging. Journals Gerontol - Ser A Biol Sci Med Sci. 2008;63(5):505-9.

169. Chepote MA. SIEMBRA DEL CULTIVO DE MORINGA (Moringa oleífera) EN LA PAMPA DE VILLACURÍ, DEPARTAMENTO DE ICA. Universidad Nacional Agraria La Molina; 2018.

170. Glicemia - EcuRed [Internet]. [cited 2019 Feb 8]. Available from: https://www.ecured.cu/Glicemia

171. Glucemia en ayunas - DiaBalance [Internet]. [cited 2019 May 29]. Available from: https://medlineplus.gov/spanish/ency/article/003482.htm

172. Pereira O, Palay M, Rodriguez A, RF N, Chia M. Glycosilated hemoglobin in patients with diabetes mellitus. MEDISAN. 2015;19(4):555-60.

173. Haffner SM, Kennedy E, Gonzalez C, Stern MP, Miettinen H. A prospective analysis of the HOMA model. The Mexico City Diabetes Study. Diabetes Care. 1996;19(10):1138-41.

174. Prueba de tolerancia a la glucosa - Mayo Clinic [Internet]. [cited 2019 May 30]. Available from: https://www.mayoclinic.org/es-es/tests-procedures/glucose-tolerance-test/about/pac-20394296

175. Munive Rojas S, Gutiérrez Garibay M. ¿Cómo realizar una revisión sistemática y un metaanálisis? Rev Cardiol del Cuerpo Médico del Inst Nac Cardiovasc. 2015;(2):32-7.

176. Urrútia G, Bonfill X. Declaración PRISMA: una propuesta para mejorar la publicación de revisiones sistemáticas y metaanálisis. Med Clin (Barc). 2010;135(11):507-11.

177. Villarruel-López A, López-de la Mora DA, Vázquez-Paulino OD, Puebla-Mora AG, Torres-Vitela MR, Guerrero-Quiroz LA, et al. Effect of Moringa oleifera consumption on diabetic rats. BMC Complement Altern Med. 2018;18(1):1-10.

178. Omabe M, Nwudele C, Omabe KN, Okorocha AE. Anion gap toxicity in alloxan induced type 2 diabetic rats treated with antidiabetic noncytotoxic bioactive compounds of ethanolic extract of moringa oleifera. J Toxicol. 2014;2014:7.

179. Irfan HM, Asmawi MZ, Khan NAK, Sadikun A. Effect of ethanolic extract of moringa oleifera lam. Leaves on body weight and hyperglycemia of diabetic rats. Pakistan J Nutr. 2016;15(2):112-7.

180. Bamagous G, Rengarajan T, Al Ghamdi S, Shammah A, Arulselvan P, Mahfoz A, et al. Antidiabetic and antioxidant activity of ethyl acetate extract fraction of Moringa oleifera leaves in streptozotocin-induced diabetes rats via inhibition of inflammatory mediators. Asian Pac J Trop Biomed. 2018;8(6):320.

181. Abd Eldaim M, Abd Elrasoul A, Abd Elaziz S. An aqueous extract from Moringa oleifera leaves 
ameliorates hepatotoxicity in alloxan-induced diabetic rats. AJRCMB Artic. 2018;1-32.

182. Oyedepo TA, Babarinde S. O, Ajayeova TA. Evaluation of Anti-hyperlipidemic Effect of Aqueous Leaves Extract of Moringa oleifera in Alloxan Induced Diabetic Rats. Int J Biochem Res Rev. 2014;3(3):162-70.

183. Divi SM, Bellamkonda R, Dasireddy SK. Evaluation of antidiabetic and antihyperlipedemic potential of aqueous extract of moringa oleifera in fructose fed insulin resistant and STZ induced diabetic wistar rats: A comparative study. Asian J Pharm Clin Res. 2012;5(1):67-72.

184. Khan W, Parveen R, Chester K, Parveen S, Ahmad S. Emotional intelligence in asperger syndrome: Implications of dissonance between intellect and affect. Educ Train Autism Dev Disabil. 2010;45(4):566-82.

185. El-Desouki NI, Basyony MA, Abdelmonaim Hegazi MM, El-Aama MSI. Moringa oleifera leaf extract ameliorates glucose, insulin and pancreatic beta cells disorder in alloxan-induced diabetic rats. Res J Pharm Biol Chem Sci. 2015;6(3):642-54.

186. Amin AY, El Tobgy KMK, Salam A, Hemat S. Phytochemical detection and therapeutical properties of Moringa oleifera leaves. Int J ChemTech Res. 2016;9(9):156-68.

187. Adepoju-Bello A, Jolayemi O, Ehianeta T, Ayoola G. Preliminary phytochemical screening, antioxidant and antihyperglycaemic activity of Moringa oleifera leaf extracts. Pak J Pharm Sci. 2017;30(6):2217-22.

188. Idakwoji PA, Salawu OA, Maiha BB, Obidike I, Tijani AY. Co-administeration of Ethanolic Leaf Extract of Moringa oleifera and Metformin Improves Glucose, Lipid and Protein Profiles of Diabetic Wistar rats. Biokemistri. 2015;27(3):129-38.

189. Rutchaporn T, Natchaagorn L, Sathit V, Pravit A, Sriwijitkamol A. Effect of Moringa oleifera Leaf Capsules on Glycemic Control in Therapy-Naive Type 2 Diabetes Patients: A Randomized Placebo Controlled Study. eCAM. 2017;2017:6.

190. Tang Y, Park P-J, Moon S-H, Kim Y-S, Han WC, Kim J, et al. Moringa oleifera from Cambodia Ameliorates Oxidative Stress, Hyperglycemia, and Kidney Dysfunction in Type 2 Diabetic Mice. J Med Food. 2017;20(5):502-10.

191. R EO, S BC, C El. Phytochemical Analysis and Antidiabetic Effect of Aqueous and Ethanolic Extracts of Moringa Oleifera Leaves in Alloxan-Induced Diabetic Wistar Albino Rats Using Insulin as Reference Drug. Int J Diabetes Res. 2016;5(3):48-53.

192. Azad S Bin, Ansari P, Azam S, Hossain SM, Shahid MI-B, Hasan M, et al. Anti-hyperglycaemic 
activity of Moringa oleifera is partly mediated by carbohydrase inhibition and glucose-fibre binding. Biosci Rep. 2017;37(3):11. 


\section{ANEXOS}

ANEXO 1. MATRIZ DE CONSISTENCIA

TìTULO: "EFECTO DE LAS HOJAS DE MORINGA OLEÍFERA SOBRE EL CONTROL DE LA GLUCEMIA EN LAS RATAS DIABÉTICAS INDUCIDAS: REVISIÓN SISTEMÁTICA"

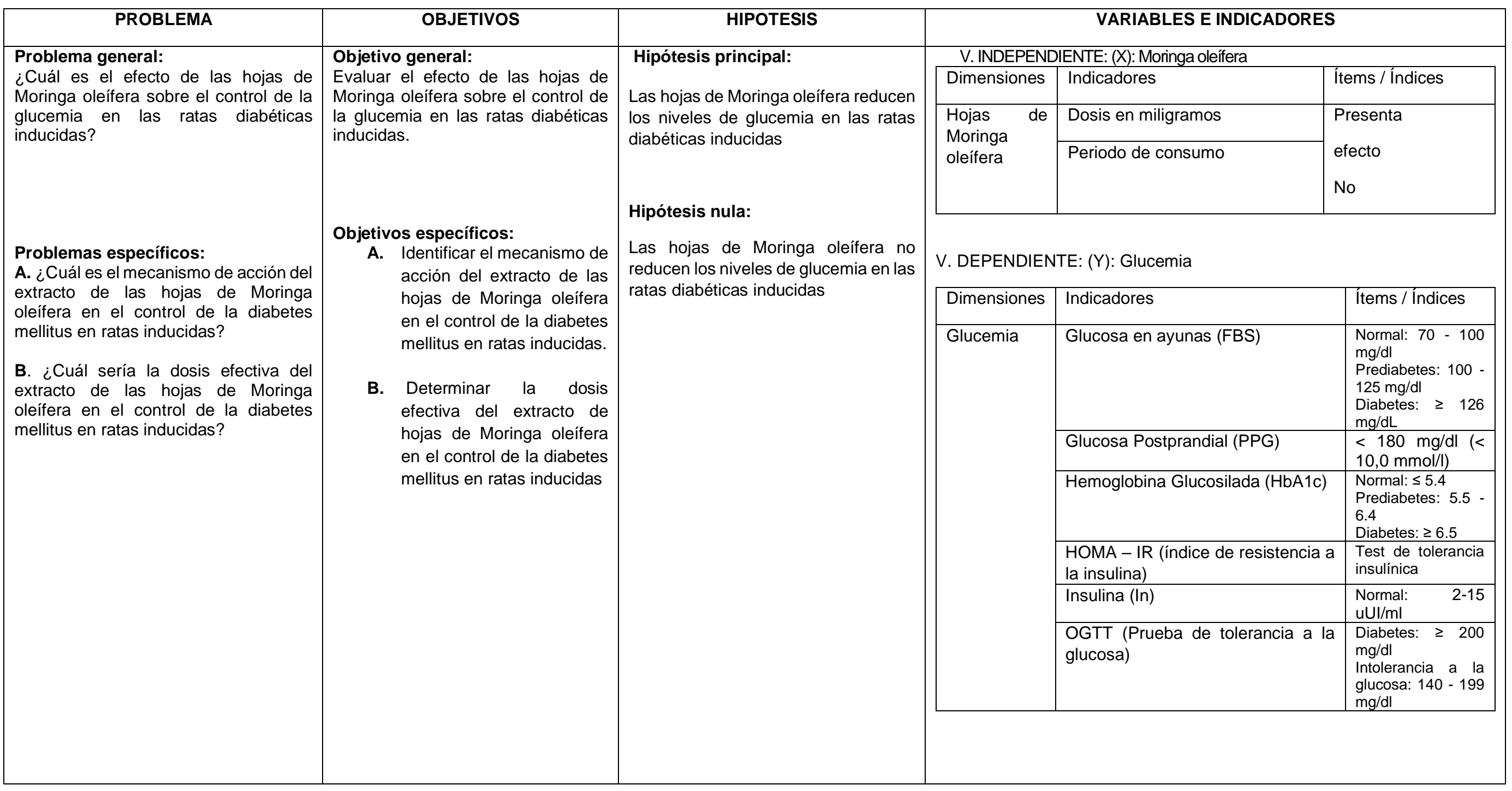




\section{ANEXO 2. FORMATO DE SELECCIÓN DE ESTUDIO - PICO}

\section{Referencia del estudio:}

\section{Nivel de selección (marcar donde aplique):}

Título

Resumen Texto completo

\section{Criterios de selección:}

\section{Población:}

¿Se estudia en ratas diabéticas inducidas por aloxano o Estreptozotocina? SI/NO

Intervención:

¿Se administró al menos a uno de los grupos el tratamiento con hojas Moringa oleifera? $\mathrm{SI} / \mathrm{NO}$ ¿Se midieron y analizaron la glucemia o insulinemia o PTGO o hemoglobina glicosilada (\% HbA1c) o HOMA - IR, en el suero de las ratas? SI/NO

¿Se analizó la respuesta glucémica en las ratas diabéticas ante la administración de las hojas de Moringa oleifera? SI/NO

\section{Control:}

¿Se compara al grupo experimental (grupo diabético con tratamiento de hojas de Moringa oleífera) con el grupo control (positivo y negativo)? SI/NO

\section{Medidas de resultado:}

¿Se incluyen algunos de los siguientes eventos que presentaron un desenlace clínico relacionado al descenso en los niveles de glucosa o hemoglobina glicosilada (\% HbA1c) o aumento de la tolerancia a la glucosa o mejora a la sensibilidad insulínica en ratas diabéticas inducidas y tratadas con las hojas de Moringa oleifera?

$\mathrm{SI} / \mathrm{NO}$

\section{Diseño:}

¿Es un diseño experimental, prospectivo y comparativo en ratas?

ACCIÓN (incluir el artículo donde TODAS las respuestas a las diferentes interrogantes haya sido SI

Incluido

Excluido

Dudoso 
ANEXO 3. FICHA DE RECOLECCIÓN DE DATOS

Title

Reference

Methods

Participants

Interventions

Outcomes

Notes 